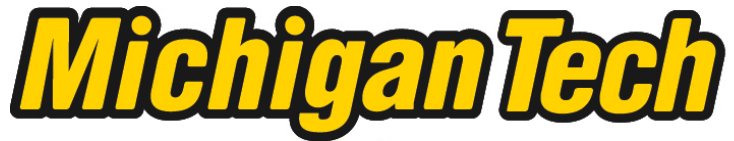 \\ Michigan Technological University Create the Future Digital Commons @ Michigan Tech
}

2012

\section{INTEGRATED ASSESSMENT OF ANTHROPOGENIC, CLIMATE, AND POLICY INDUCED CHANGES OF PHOSPHORUS EXPORT IN THE UNITED STATES LAURENTIAN GREAT LAKES WATERSHEDS}

Meredith Ballard LaBeau

Michigan Technological University

Follow this and additional works at: https://digitalcommons.mtu.edu/etds

Part of the Biochemistry Commons, Environmental Engineering Commons, and the Water Resource Management Commons

Copyright 2012 Meredith Ballard LaBeau

\section{Recommended Citation}

Ballard LaBeau, Meredith, "INTEGRATED ASSESSMENT OF ANTHROPOGENIC, CLIMATE, AND POLICY INDUCED CHANGES OF PHOSPHORUS EXPORT IN THE UNITED STATES LAURENTIAN GREAT LAKES WATERSHEDS", Dissertation, Michigan Technological University, 2012.

https://doi.org/10.37099/mtu.dc.etds/706

Follow this and additional works at: https://digitalcommons.mtu.edu/etds

Part of the Biochemistry Commons, Environmental Engineering Commons, and the Water Resource Management Commons 
INTEGRATED ASSESSMENT OF ANTHROPOGENIC, CLIMATE, AND POLICY INDUCED CHANGES OF PHOSPHORUS EXPORT IN THE UNITED STATES

LAURENTIAN GREAT LAKES WATERSHEDS

By

Meredith Ballard LaBeau

\begin{abstract}
A DISSERTATION
Submitted in partial fulfillment of the requirements for the degree of DOCTOR OF PHILOSOPHY

In Environmental Engineering
\end{abstract}

MICHIGAN TECHNOLOGICAL UNIVERSITY

2012

(C) 2012 Meredith Ballard LaBeau 
This dissertation, "Integrated Assessment of Anthropogenic, Climate, and Policy Induced Changes of Phosphorus Export in the United States Laurentian Great Lakes Watersheds," is hereby approved in partial fulfillment of the requirements for the Degree of DOCTOR OF PHILOSOPHY IN ENVIRONMENTAL ENGINEERING

Department of Civil and Environmental Engineering

Signatures:

Dissertation Advisor

Alex S. Mayer

Department Chair

David W. Hand

Date 


\section{Table of Contents}

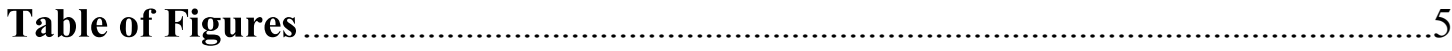

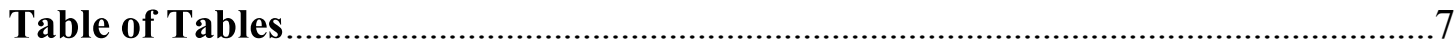

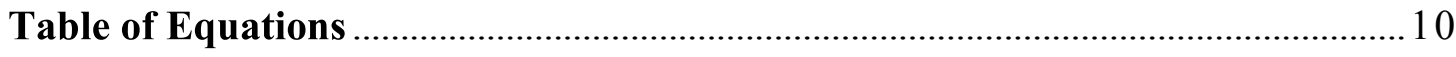

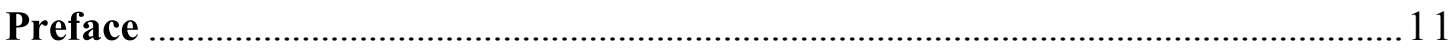

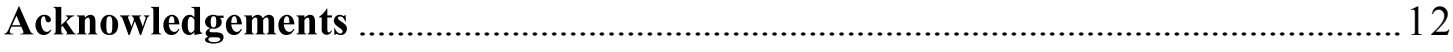

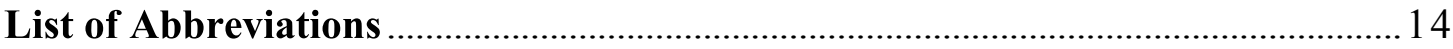

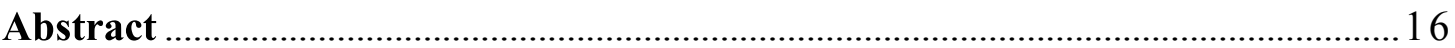

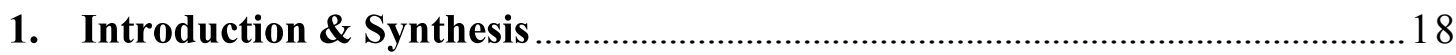

1.1. Laurentian Great Lakes .................................................................................... 18

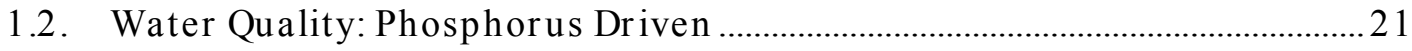

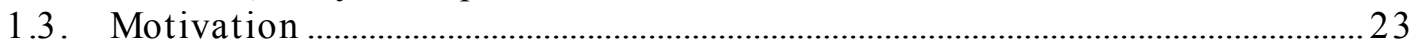

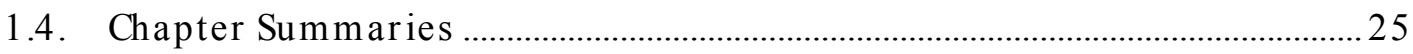

Chapter Two ………………………………………………………………………………………25

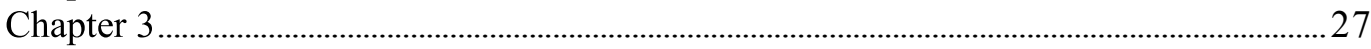

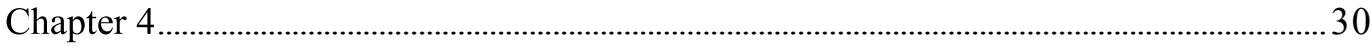

2. Future Urban and Biofuel Crop Expansions Will Increase Riverine Export of Phosphorus to the Laurentian Great Lakes: Coupled Model Simulation for the

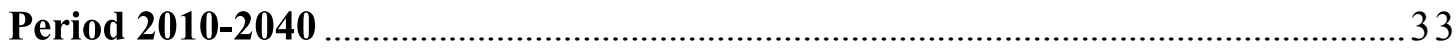

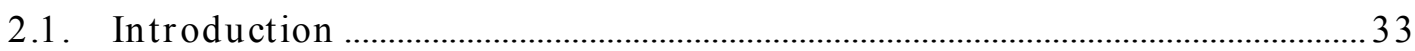

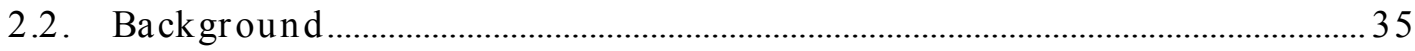

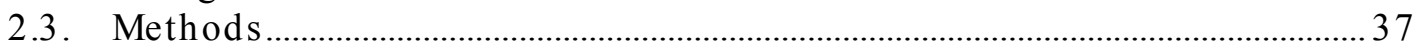

2.4. Results and Discussion ........................................................................................... 41

Projected Changes in Land Use, Population, and P Sources......................................................4 41

Phosphorous Delivery to the Great Lakes.................................................................................44

Changes in Phosphorus Yields by HUC8 Watershed................................................................47

Importance of Phosphorus Loading Predictions for Watershed Planning ............................50

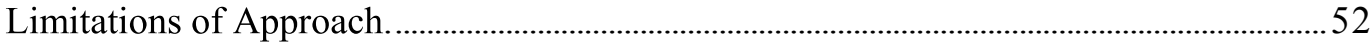

2.5. Acknowledgements.............................................................................................53

3. Climate Induced Changes on Phosphorus Export into the Great Lakes: Development of Linkages between Extreme Weather Events and Tributary

Phosphorus Loading ……………………………………….................................. 54

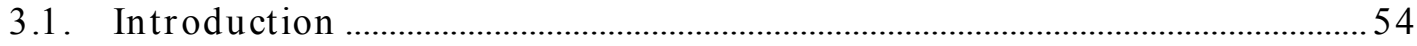

3.2. Methodology ……………………………………………………………….....

General Approach …………………………………………………………………………………….....5

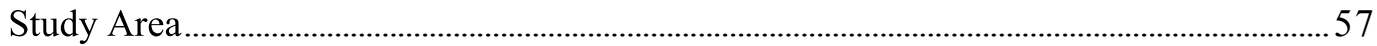

Climate Change Projections and Future Flow Calculations .........................................................60

Load-Discharge Regression Model Development..........................................................................64

Future Flow-Load Calculations ...........................................................................................................68 


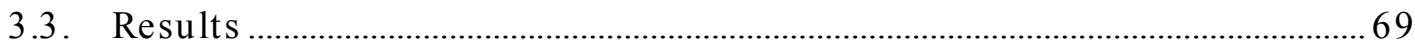

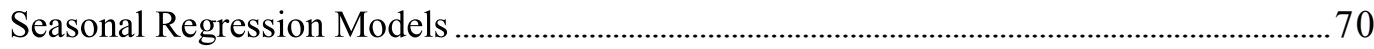

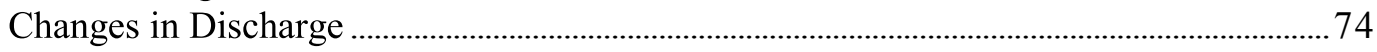

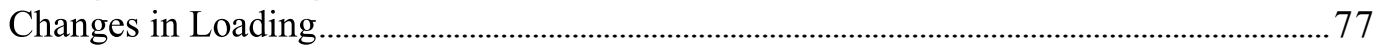

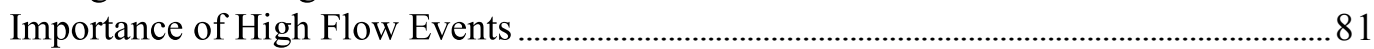

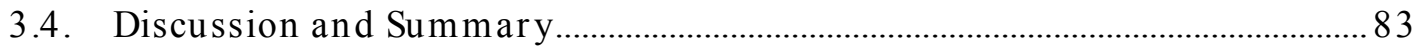

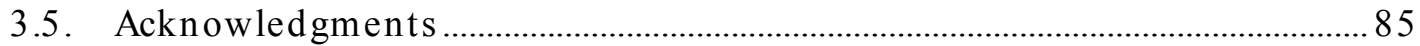

4. Phosphorus Monitoring in the U. S. Portion of the Laurentian Great Lake

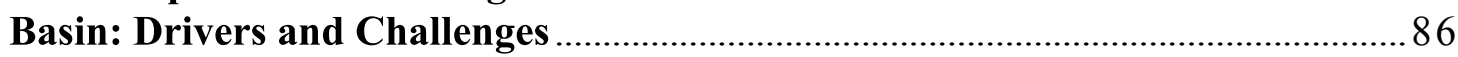

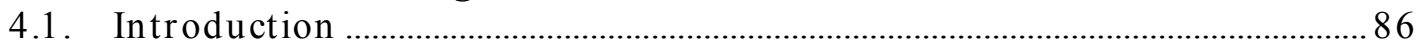

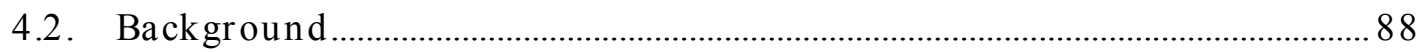

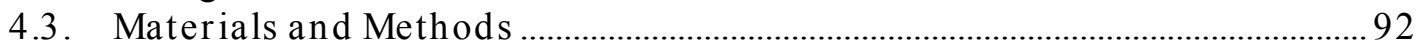

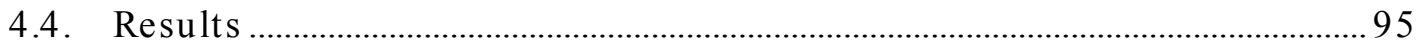

Rationales for Establishing Water Quality Monitoring Programs.............................................95

Concerns and Challenges..........................................................................................................98

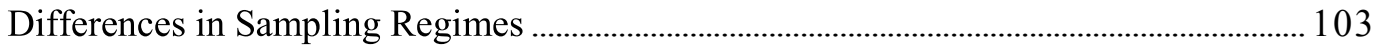

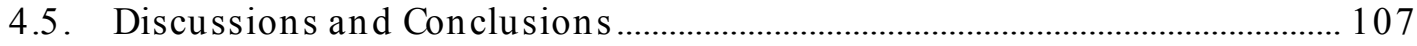

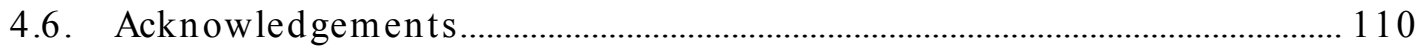

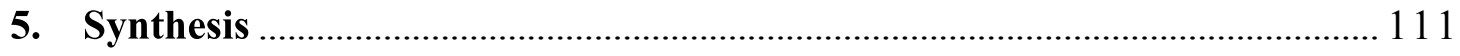

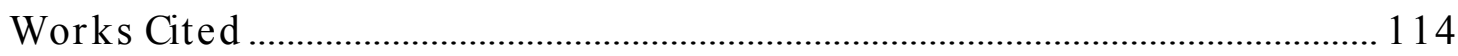

6. Appendix A: Supporting Information for ES\&T Manuscript....................... 130

7. Appendix B: Open-Ended Multipart Interview Questions............................ 149 


\section{Table of Figures}

Figure 1-1: Great Lakes Basin (Basin, political boundaries and shoreline from (Figure created by author using data from (7))) …………………………………........ 18

Figure 1-2: Annual Precipitation Average for United States Great Lakes Basin 19712000 (Figure created by author using data from (8))

Figure 1-3: 2006 Land Use Classifications for United States Great Lakes Basin (Data obtained from NLCD; (Figure created by author using data from (17))) .............21

Figure 2-1: 2040 Land Use and Cover Across the Major River Basin 3 including the Great Lakes Basin (US Great Lakes Basin and Lake Drainage, (Figure created by author using data from (7))).

Figure 2-2: (a) Total Annual Delivered TP Load to Each Great Lake for 2010 and increases from 2010 to 2040 for (b) the urban expansion scenario (c) the biofuel future scenario, subdivided by source (Sources of boundaries, 41).

Figure 2-3:Total Delivered TP Yield in $2010\left(\mathrm{~kg} / \mathrm{km}^{2}\right)$ (a) and \% change in 2040 urban expansion scenario (b) and 2040 biofuels future scenario (c). Note that color scheme in (a) is adjusted to normalize for each Great Lake basin. (Figure created by author using data from (41)) .................................................................. 48

Figure 3-1: Location of the 14 selected Great Lakes Watersheds. The legend for the ID is found in Table 3-1. (Figure created by author using data from (7)). .58

Figure 3-2: Predicted changes in precipitation by watershed averaged over 53 CMIP projections and prediction interval compared to the 1961-1999 period.

Figure 3-3: Predicted changes in temperature by watershed averaged over 53 CMIP projections and prediction interval compared to the 1961-1999 period.

Figure 3-4: Normalized Change in Temperature versus Change in Precipitation Plot of 53 CMIP3 Climate Scenarios across 14 watersheds in both the near and far future projections. 64

Figure 3-5: Observed load versus modeled load for a) St. Louis River b) Cuyahoga River and c) Maumee River.

Figure 3-6: Normalized median discharges averaged over the 9 climate projections for the near and far future prediction intervals for the 14 selected watersheds. Discharges are normalized against median flows for the simulated historical period.

Figure 3-7: Normalized average $90^{\text {th }}$ percentile discharges over the 9 climate projections for the near and far future prediction intervals for the 14 selected 
watersheds. Discharges are normalized against $90^{\text {th }}$ percentile flows for the simulated historical period.

Figure 4-1: The Great Lakes States and Long-Term Water Quality Monitoring Sites used in SPARROW with the Great Lakes Basin outlined in grey (Figure created by author using data from (7)(62)).

Figure 6-1: Point source input rates for TP in $\mathrm{kg} / \mathrm{km}^{2} / \mathrm{yr}$ for 2010 (A) and 2040 (B). Great Lakes outline from GLIN and US states outline from USGS. (Figure created by author using data from (2)).

Figure 6-2: Manure Confined (A and B), Manure Unconfined (C and D), and Farm Fertilizer (E and F) input rates from TP in $\mathrm{kg} / \mathrm{km}^{2} / \mathrm{yr}$ for 2010 and 2040. (Figure created by author using data from (2)).

Figure 6-3: Incremental $\mathrm{P}$ yields in $\mathrm{kg} / \mathrm{km}^{2}$ for MRB3 Basin (A) and the $\%$ changes from 2010 to 2040 for the UE scenario (B) and BF scenario (C). (Figure created by author using data from (2))

Figure 6-4: HUC8s of Lake Erie TP Yield in $\mathrm{kg} / \mathrm{km}^{2}$ for 2010 (A) and the changes to 2040 for UE (B) and BF (C). (Figure created by author using data from (2))....139

Figure 6-5: Average Soil Permeability for catchments in the Great Lakes basin. (Figure created by author using data from (2)).

Figure 6-6: Percentage of area drained by tiles for catchments in the Great Lakes (Figure created by author using data from (2)).

Figure 6-7: Delivery fraction of catchments in the Great Lakes (Figure created by author using data from (2)).

Figure 6-8: Fertilizer and Manure Inputs (kg) to catchments in the Great Lakes in 2010 model (Figure created by author using data from (2)). 


\section{Table of Tables}

Table 2-1: Base Year and Changes in Population and Land Use to 2040 across the US

Portion of the Great Lakes Basin.

Table 2-2: Estimated Annual Delivered Loads of Total Phosphorous into each Great Lake from 2010 to 2040 for US Drainage Areas .................................................4

Table 3-1: General characteristics of the 14 selected Great Lakes watersheds (Agr.: Agricultural Land, For: Forested Land, Urb: Urban Land, $\mathrm{km}^{2}$ : square kilometers,

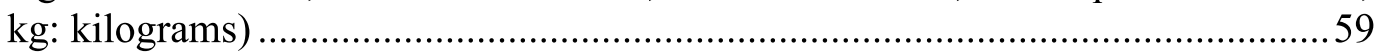

Table 3-2: Period of Record and Sample size for the selected 14 watersheds .............60

Table 3-3: Comparison of Water Quality Site Upstream Drainage Area and LBRM

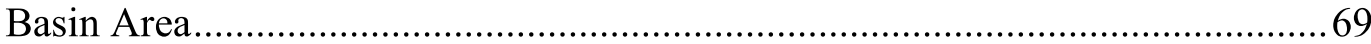

Table 3-4: Watershed Statistics of Developed Seasonal Models from Chi-Squared Test

Table 3-5: Nash-Sutcliffe Efficiency of the 14 Seasonal, Annual \& Literature Models

for each watershed .......................................................................................... 72

Table 3-6: Changes in total load for far future simulation periods for the nine climate projections, normalized by the historical total loads. (Red indicating largest increases and blue illustrating largest decreases, with the temperatureprecipitation changes listed above each projection)

Table 3-7: Changes in high flow load (loads occurring during the highest $10 \%$ of flows) for far future simulation periods for the nine climate projections, normalized by the historical storm total loads. (Red indicating largest increases and blue illustrating largest decreases, with the temperature-precipitation changes listed above each projection)

Table 3-8: Median loads (L50) for far future simulation periods for 14 selected sites and each of the nine projections normalized against the historical median loads. (Red indicating largest increases and blue illustrating largest decreases, with the temperature-precipitation changes listed above each projection)

Table 3-9: Changes in percentage of high flow load to total load for far future simulation periods for the nine climate projections, normalized by the historical total loads. (Red indicating largest increases and blue illustrating largest decreases, with the temperature-precipitation changes listed above each projection)

Table 4-1: 1976 and Target Phosphorus Loads for the Great Lakes (133)..................90

Table 4-2: Interviewed Organizations 
Table 4-3: Monitoring Program Costs in Great Lakes. 102

Table 4-4: Interview Responses of Sampling Design and Frequency 105

Table 6-1: Total Annual 2010 Load and Yields for each Great Lake and percent of P source

Table 6-2: Total Annual 2040 UE Load and Yields for each Great Lake and percent of $\mathrm{P}$ source ("con" is confined and "uncon" is unconfined) 144

Table 6-3: Total Annual 2040 BF Load and Yields for each Great Lake and percent of $\mathrm{P}$ source ("con" is confined and "uncon" is unconfined) 145

Table 6-4: Total TP loads for 2020 and 2030 for each Great Lake 145

Table 6-5: Total annual 2010 TP loads and yields with percent contribution by source for Major River Basin 3's HUC8. (kg, kilogram; km², square kilometer) (HUCs are based on 4)

Table 6-6: Total annual 2020 UE TP loads and yields with percent contribution by source for Major River Basin 3's HUC8. (kg, kilogram; km², square kilometer) (HUCs are based on 4)

Table 6-7: Total annual 2020 BF TP loads and yields with percent contribution by source for Major River Basin 3's HUC8. (kg, kilogram; $\mathrm{km}^{2}$, square kilometer) (HUCs are based on 4)

Table 6-8: Total annual 2030 UE TP loads and yields with percent contribution by source for Major River Basin 3's HUC8. (kg, kilogram; km², square kilometer) (HUCs are based on 4)

Table 6-9: Total annual 2030 BF TP loads and yields with percent contribution by source for Major River Basin 3's HUC8. (kg, kilogram; km², square kilometer) (HUCs are based on 4)

Table 6-10: Total annual 2040 UE TP loads and yields with percent contribution by source for Major River Basin 3's HUC8. (kg, kilogram; km², square kilometer) (HUCs are based on 4)

Table 6-11: Total annual 2040 BF TP loads and yields with percent contribution by source for Major River Basin 3's HUC8. (kg, kilogram; km², square kilometer) (HUCs are based on 4)

Table 6-12: Total 2010 annual phosphorus loads and yields for all tributaries into the U.S. Great Lakes greater than 150 square kilometers. The ranks are based on their relative loads and yields, with a value of 1 indicating it has the largest load or relatively largest yield. ( $\mathrm{kg}$, kilogram; $\mathrm{km}^{2}$, square kilometer) 
Table 6-13: Total 2020 UE annual phosphorus loads and yields for all tributaries into the U.S. Great Lakes greater than 150 square kilometers. The ranks are based on their relative loads and yields, with a value of 1 indicating it has the largest load or relatively largest yield. (kg, kilogram; $\mathrm{km}^{2}$, square kilometer)

Table 6-14: Total $2020 \mathrm{BF}$ annual phosphorus loads and yields for all tributaries into the U.S. Great Lakes greater than 150 square kilometers. The ranks are based on their relative loads and yields, with a value of 1 indicating it has the largest load or relatively largest yield. (kg, kilogram; $\mathrm{km}^{2}$, square kilometer) 147

Table 6-15: Total 2030 UE annual phosphorus loads and yields for all tributaries into the U.S. Great Lakes greater than 150 square kilometers. The ranks are based on their relative loads and yields, with a value of 1 indicating it has the largest load or relatively largest yield. ( $\mathrm{kg}$, kilogram; $\mathrm{km}^{2}$, square kilometer) 147

Table 6-16: Total $2030 \mathrm{BF}$ annual phosphorus loads and yields for all tributaries into the U.S. Great Lakes greater than 150 square kilometers. The ranks are based on their relative loads and yields, with a value of 1 indicating it has the largest load or relatively largest yield. (kg, kilogram; $\mathrm{km}^{2}$, square kilometer)

Table 6-17: Total 2040 UE annual phosphorus loads and yields for all tributaries into the U.S. Great Lakes greater than 150 square kilometers. The ranks are based on their relative loads and yields, with a value of 1 indicating it has the largest load or relatively largest yield. ( $\mathrm{kg}$, kilogram; $\mathrm{km}^{2}$, square kilometer).

Table 6-18: Total $2040 \mathrm{BF}$ annual phosphorus loads and yields for all tributaries into the U.S. Great Lakes greater than 150 square kilometers. The ranks are based on their relative loads and yields, with a value of 1 indicating it has the largest load or relatively largest yield. (kg, kilogram; $\mathrm{km}^{2}$, square kilometer) 147 


\section{Table of Equations}

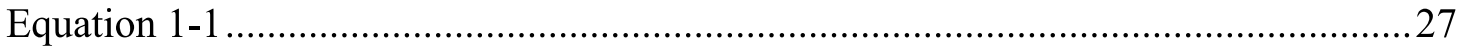

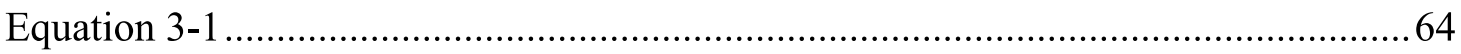

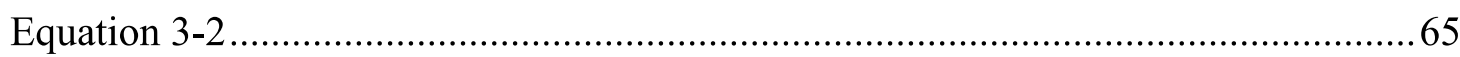

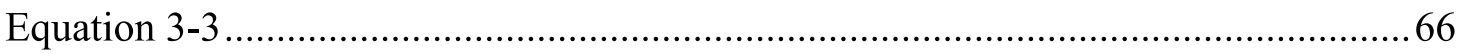

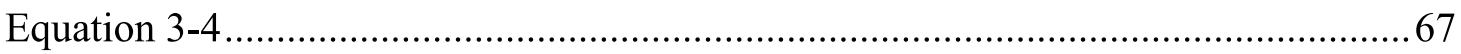




\section{Preface}

This work was supported by a grant from the National Science Foundation's Materials Use: Science, Engineering and Society program through Michigan Technological University Center for Water and Society's project number CBET0725636 and entitled: Modeling and Analyzing the Use, Efficiency, Value and Governance of Water as a Material in the Great Lakes Region Through an Integrated Approach. Chapter two, three, and four of this dissertation are either submitted or to be submitted as journal publications. The climate change scenarios research in chapter three was conducted in collaboration with Rabi Gywali, a doctoral student at Michigan Technological University, who developed the flows for our selected climate scenarios. Meredith Ballard LaBeau then utilized these flows to perform the rest of the research contained in that chapter. In addition, the interviews in chapter four were conducted with the assistance of master's student Alicia Sherrin. All the journal articles and text were completely written by Meredith Ballard LaBeau with the assistance of the coauthors through a lengthy editorial process. 


\section{Acknowledgements}

I wish to express my gratitude to my advisor, Dr. Alex Mayer for his continual guidance and supervision both academically and personally through this dissertation. I would like to thank him for the support, criticism, and patience through my doctoral studies. The willingness to share his expertise and teach me was wonderful, without that help, I would have never made it to the completion.

I would also like to extend my gratitude to my committee members, Dr. Dale Robertson, Dr. Hugh Gorman, and Dr. Veronica Griffis for assisting me in each step of this process, including mentoring me on development of research and journal articles.

I am also very grateful for the supporting authors on the journal articles associated with this dissertation including Dr. Bryan Pijanowski, Dave Dempsey, and Dr. Watkins for their insight and assistance on creating valuable manuscripts. In addition, I would like to thank the National Science Foundation for granting me research scholarships to conduct this work through the Material Use: Science, Engineering and Society program's grant (CBET-0725636) and for a three-year SSTEM scholarship (Grant No. 0806569).

I am extremely thankful to my family, especially my husband Mike LaBeau for his continual encouragement and support even during the rough times and my parents Robert and Cindy Ballard. I am also grateful for my community of friends who supported me and shared laughter during the hard time including Zeyad, Agustin, Matt, Melissa, and many more. Without your support, this dissertation would not have been possible.

Finally, I would like to thank those along my journey to push me into a career focused around environmentalism, especially Dr. T. Allan Comp with the OSM/VISTA Appalachian Coal Country Watershed Team for directing my passions. I would like to close with my inspiration as a young child that was a precursor to my future: 
"You're glumping the pond where the Humming-Fish hummed!

No more can they hum, for their gills are all gummed.

So I'm sending them off. Oh their future is dreary.

They'll walk on their fins and get woefully weary

In search of some water that isn't so smeary.

I hear things are just as bad up in Lake Erie.” (1) 


\section{List of Abbreviations}

P: Phosphorus

SPARROW: Spatially referenced regressions on watershed attributes model

LTM: Land Transformation Model

(US) EPA: (United States) Environmental Protection Agency

PCBs: Polychlorinated biphenyls

GLWQA: Great Lakes Water Quality Agreement

IJC: International Joint Commission

AOC: Areas of Concern

GLRI: Great Lakes Restoration Initiative

BF: Biofuels Future

UE: Urban Expansion

HUC8: Hydrologic unit code 8 (watersheds)

PCS: Permit Compliance System

MRB3: Major River Basin 3

USDA: United States Department of Agriculture

USGS: United States Geological Survey

NOAA: National Oceanic Atmospheric Administration

IISG: Illinois-Indiana Sea Grant

HCC: Heidelberg College Center for National Water Quality Program

WDNR: Wisconsin Department of Natural Resources

MIDEQ: Michigan Department of Environmental Quality

OHEPA: Ohio Environmental Protection Agency 
INDEM: Indiana Department of Environmental Management

WIUSGS: Wisconsin United States Geological Survey

NYDEC: New York Department of Environmental Conservation

NWIS: National Water Inventory System

STORET: Storage and Retrieval System

WQX: Water Quality Exchange

MNPCA: Minnesota Pollution Control Agency 


\section{Abstract}

Anthropogenic activities have increased phosphorus (P) loading in tributaries to the Laurentian Great Lakes resulting in eutrophication in small bays to most notably, Lake Erie. Changes to surface water quality from P loading have resulted in billions of dollars in damage and threaten the health of the world's largest freshwater resource. To understand the factors affecting P delivery with projected increasing urban lands and biofuels expansion, two spatially explicit models were coupled. The coupled models predict that the majority of the basin will experience a significant increase in urban area $\mathrm{P}$ sources while the agriculture intensity and forest sources of $\mathrm{P}$ will decrease. Changes in P loading across the basin will be highly variable spatially.

Additionally, the impacts of climate change on high precipitation events across the Great Lakes were examined. Using historical regression relationships on phosphorus concentrations, key Great Lakes tributaries were found to have future changes including decreasing total loads and increases to high-flow loading events. The urbanized Cuyahoga watersheds exhibits the most vulnerability to these climateinduced changes with increases in total loading and storm loading, while the forested $\mathrm{Au}$ Sable watershed exhibits greater resilience.

Finally, the monitoring network currently in place for sampling the amount of phosphorus entering the U.S. Great Lakes was examined with a focus on the challenges to monitoring. Based on these interviews, the research identified three issues that policy makers interested in maintaining an effective phosphorus monitoring network in the Great Lakes should consider: first, that the policy objectives driving different monitoring programs vary, which results in different patterns of sampling design and frequency; second, that these differences complicate efforts to encourage collaboration; and third, that methods of funding sampling programs vary from agency to agency, further complicating efforts to generate sufficient long-term data to improve our understanding of phosphorus into the Great Lakes. 
The dissertation combines these three areas of research to present the potential future impacts of $\mathrm{P}$ loading in the Great Lakes as anthropogenic activities, climate and monitoring changes. These manuscripts report new experimental data for future sources, loading and climate impacts on phosphorus. 


\section{Introduction \& Synthesis}

\subsection{Laurentian Great Lakes}

The Great Lakes, vast inland freshwater seas containing $18 \%$ of the available global fresh surface water and $300,000 \mathrm{~km}^{2}$ of land surrounding the lakes, are critically important for water consumption, fisheries, power, transportation, and water consumption (2)(Figure 1-1). The Great Lakes Basin is home to 30 million people, roughly $10 \%$ of the U.S. population and $30 \%$ of the Canadian population, and these lakes provide $47 \%$ of the Great Lakes U.S. population with drinking water and more than $70 \%$ of the Ontario population derive their drinking water from the Great Lakes (3). Additionally, approximately 8 million people use Great Lakes beaches each year (4) and the watersheds support a $\$ 4$ billion per year fishery and recreation industry (5)(6).

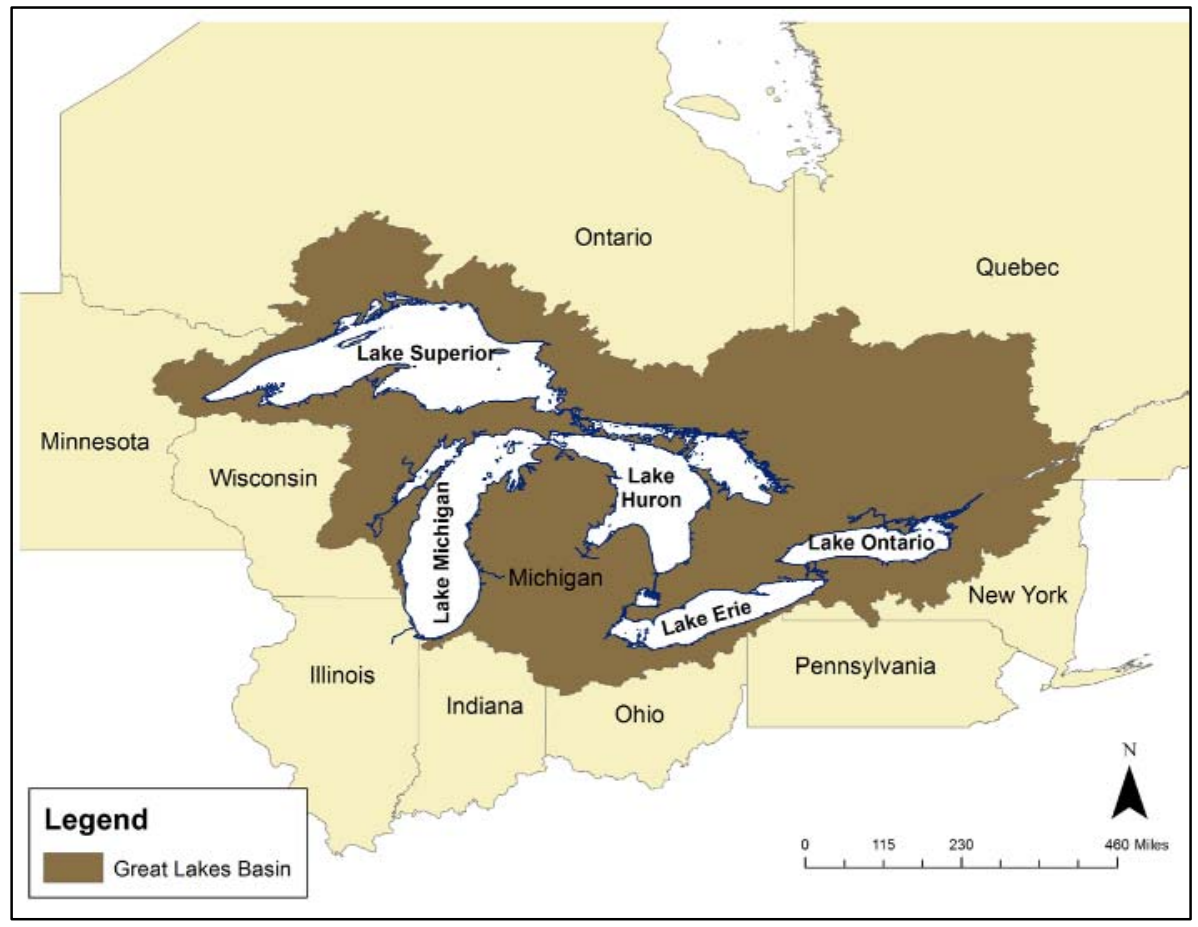

Figure 1-1: Great Lakes Basin (Basin, political boundaries and shoreline from (Figure created by author using data from (7))) 
The climate, soils and topography vary greatly across the Great Lakes Basin. In the northern region the climate is much cooler with acidic soils and granite bedrock. This region consists of coniferous and northern hardwood forests. Conversely, the southern region soils are a mixture of clays, silts, sands, gravels and boulders deposited from the glacial age. In the southern region, the watershed is dominated by agriculture due to its abundance of fertile soils (6).

Annual precipitation in the United States portion of the Great Lakes Basin averages from 1971-2000 ranges from 30 in/year in the northwestern region to 42 in/year in the southern and southeastern regions (Figure 1-2).

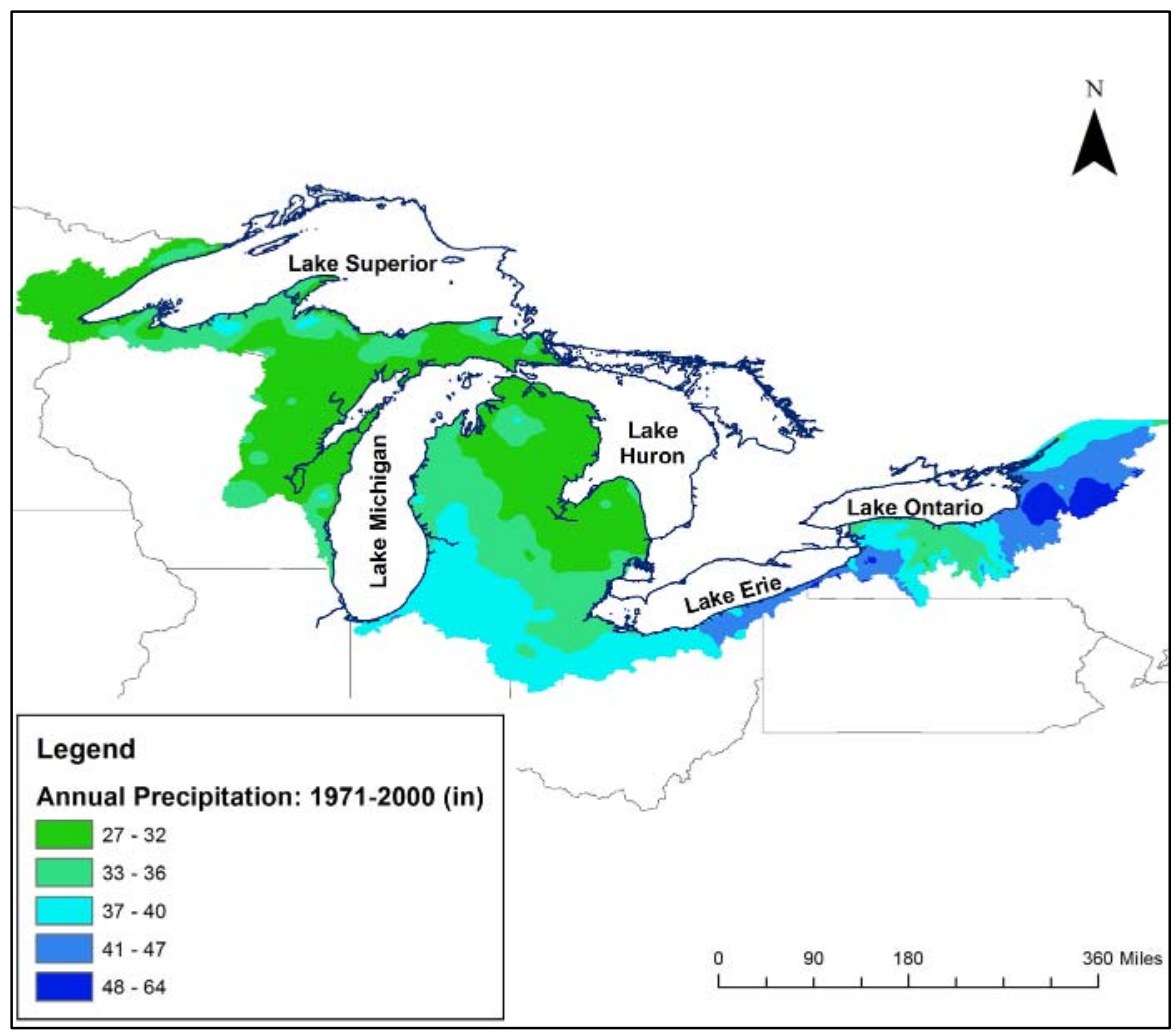

Figure 1-2: Annual Precipitation Average for United States Great Lakes Basin 1971-2000 (Figure created by author using data from (8))

The temperature also varies across the basin with the northwestern regions having an average annual daily maximum to minimum temperature ranges from 44.3 to $20.8^{\circ} \mathrm{F}$ from data compiled annually from 1971-2000 (8). In the southern region, 
the average annual daily maximum and minimum temperature ranges from 61.3 to $42.7^{\circ} \mathrm{F}$. The temperature and precipitation can influence the transport of pollutants and nutrients from the land surface to the receiving tributaries through weather patterns such as incidence of storms (9).

The Great Lakes Basin exhibits large variation in the intensity of agriculture, urban development, and amount of atmospheric deposition (10), with 7\% of U.S. farm production occurring in the Great Lakes Basin (11). In addition, this area holds high ecological significance with 100 species and 31 communities that are critically imperiled, threatened or rare based on the global basis (12). The Great Lakes Basin is particularly vulnerable to climate and land use changes through increases in nutrient transport because of the intensity of developed land with little nutrient retention and the amount of vulnerable areas in the region that are already exhibit nutrient problems.

In 2004 , roughly $93 \%$ of the assessed streams along the Great Lakes basin were reported EPA as impaired. The leading cause of most impairment in this region stem from nutrients to PCBs, toxic organics, pesticides, dioxins, and sediments. Legacy or historical contaminated sediment was the leading cause of much of the shoreline impairment, followed by municipal discharges and sewage (2). This work focuses on nutrient impairment. For over two decades, nutrients, especially phosphorus (the focus of this dissertation) exported from agricultural, urbanized, and forested lands have directly affected the water quality in the Great Lakes (13). The Great Lakes water receive phosphorus from many tributaries draining areas that range from intensively fertilized agriculture, to large urban centers, to pristine forests, with input being extremely variable $(14)(15)(16)$.

Land use across the region ranges from forested areas undisturbed by human activity in the northern-central regions to highly urbanized and agriculture areas in the south-central to southern region (Figure 1-3). There are also six large urban areas in the basin: Chicago, Illinois; Detroit, Michigan; Cleveland, Ohio; Toledo, Ohio; Buffalo, New York; and Toronto, Ontario with other large urban areas in the central 
region of the basin. These urban and agriculture land uses have a great effect on water quality and quantity within this vast basin (9).

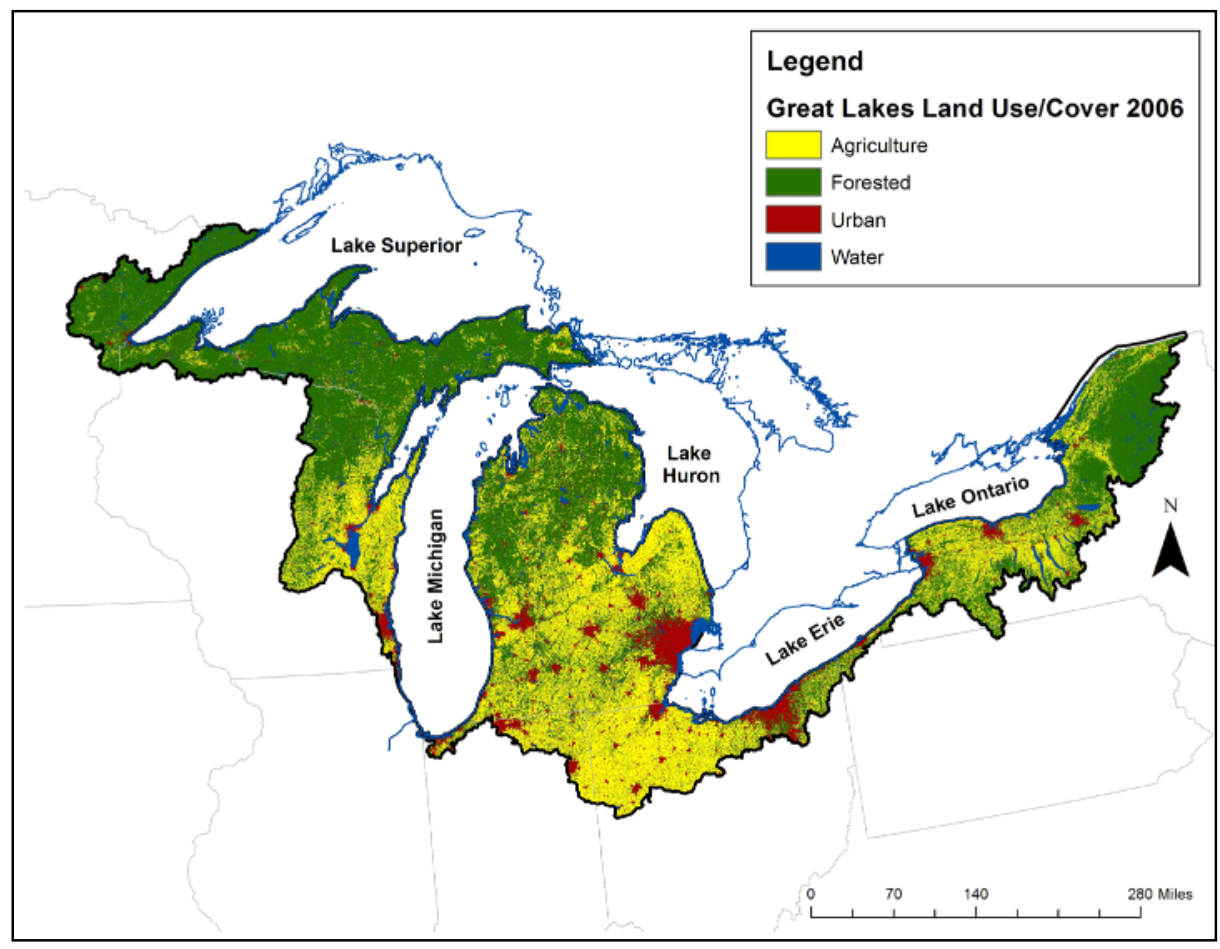

Figure 1-3: 2006 Land Use Classifications for United States Great Lakes Basin (Data obtained from NLCD; (Figure created by author using data from (17)))

\subsection{Water Quality: Phosphorus Driven}

Nutrient enrichment of aquatic ecosystems causes higher biological productivity and alters water quality through algal blooms and oxygen depletion, referred to as eutrophication (18). Eutrophication can then interfere with the use of water for domestic and industrial purposes, for instance water treatment, irrigation, recreation and fisheries. Generally, $\mathrm{P}$ is the limiting nutrient for maximum algal biomass reached in freshwater ecosystems. Common sources of $\mathrm{P}$ to the system include runoff from the land (direct and indirect), wastewater effluent, and atmospheric deposition including dry fallout (19).

P from agricultural and urban sources is recognized as a major cause of cultural eutrophication (20). Human activities dramatically affect the amount of nutrients 
supplied to water bodies. The phosphorus discharged into an aquatic system is divided into that from point and nonpoint sources. Point sources include wastewater treatment plant pipe effluent, while nonpoint sources of $\mathrm{P}$ are derived from fertilizers and manure applied to land.

The Laurentian Great Lakes are not immune to effects of cultural eutrophication. The effects of this anthropogenic stress have been well-documented including changes in biotic composition, excessive algal growth, turbidity, taste and odor problems and depletion of oxygen $(21)(22)(23)(24)$. This eutrophication of the Great Lakes can be seen in small to large scales in embayments (Saginaw and Green Bay) to wide-scale lake eutrophication in Western Basin of Lake Erie (25)(26). In these areas, the ecosystem produces an increase in organic matter due to increases in nutrients supplies, which results in an increase in oxygen consumption. The initial rise in eutrophication, resulting in the dead zone in Lake Erie, was directly related to phosphorus detergents in the 1960s.

As cultural eutrophication degraded the quality of the Laurentian Great Lakes in the 1960s, the Great Lakes Water Quality Agreement (GLWQA) was established between Canada and the United States. This agreement was developed to "restore and maintain the chemical, physical, and biological integrity of the Great Lakes" (27). During the International Joint Commission's assessment in 1973, 42 Areas of Concern (AOC) were identified as beneficial use impairment sites that included 16 impaired by eutrophication issues. These impairments also included degraded aquatic communities, toxic contamination, and fish advisories (27).

Due to the excessive eutrophication and degradation in water quality, the two countries signed a new GLWQA in 1978 focusing on controlling phosphorus loading. This revision illustrated the scope of pollution problems in the Great Lakes and called for defining phosphorus target loads, which would restore and enhance the water quality throughout the basin. This agreement was again revised in 1983 to include a phosphorus load reduction defined by P loads and further limit phosphorus loads (28). 
This act was charged with providing a systematic approach to managing the ecosystem whereby identifying sources, pathways, and concentrations of critical pollutants.

These strategies have reduced total nutrient lake loading (29), although there are rising eutrophication problems in coastal areas and embayments in the form of cladophera, microcystisis, and other algal blooms (24)(30). To target these areas of significant cultural eutrophication, the Great Lakes Restoration Initiative (GLRI) was implemented in 2010. Efforts associated with this initiative track the progress of achieving in-lake nutrient standards, which also requires documentation of nutrient sources, upstream loading and tributary loads (15).

For over many decades, nutrients exported from agricultural, urbanized, and forested lands have directly affected the water quality of downstream rivers and lakes, and coastal Great Lakes wetlands (13). Despite tremendous reduction in P application and loading through policy and management, $\mathrm{P}$ is continuing to cause local and regional water quality problems because of both point and nonpoint sources. The current paradigm is that high phosphorus loads from the Great Lakes watersheds are causing increases in nuisance algal blooms and other ecosystem characteristics including changes in biota (15)(31). The loading of phosphorus from the many watersheds and tributaries across this Great Lakes Basin drives much of the water quality management problems.

\subsection{Motivation}

Detailed understanding of how anthropogenic, climate, and policies effect $\mathrm{P}$ loading is needed to define future management for clean water quality in the Laurentian Great Lakes. There is a need to understand the relationships between anthropogenic stresses and water chemistry in Great Lakes watersheds to combat further declines in water quality and increased eutrophication. The Great Lakes tributaries are the linkage between land and upstream loading that transport nutrients into the vast 5-lake ecosystem. Increasingly, there is a growing awareness that the condition of these coastal and lake ecosystems is tightly linked to land use practices in 
their watersheds. With the watershed and coastal ecosystems tightly coupled, there is a need to model and manage the watersheds for maintenance and repair of the coastal and lake ecosystems as directed by the GLQWA. As land use changes across the basin, this watershed to lake linkage may become even more important in understanding of phosphorus dynamics and water quality management.

The Great Lakes Basin exhibits large variation in the intensity of agriculture, urban development, and amount of atmospheric deposition. The results suggest that water quality is strongly influenced by upstream agricultural and urban processes (10). Numerous studies have indicated the strong relationship between land use and nutrient export for nitrogen and phosphorus, especially elevated soluble reactive phosphorus downstream of urban centers. Additionally, hydrology, geology and land use are prevailing factors influencing water quality (32).

Five classes of anthropogenic stress have been developed in the Great Lakes Basin that include agriculture, atmospheric deposition, human population, land cover, and point source pollution (11). Regional scale efforts to understand human disturbance and ecosystem response are critical for managing the Great Lakes Basin. To understand these stresses, studies need to focus on how land use, climate and policy changes will affect the future water quality in the watersheds and lakes in the Great Lakes Basin. Currently, climate change, impact of land management, and largescale flooding are motivating the development of integrated large area hydrologic models (33). These models are useful for understanding the need for water, the policy to meet these needs, and the management to implement this policy.

This dissertation addresses research questions of three major phosphorus management areas: land use, climate and monitoring management. Each chapter is developed into a manuscript and discussed below:

Chapter Two: Future Urban and Biofuel Crop Expansion Will Increase Riverine Export of Phosphorus to the Laurentian Great Lakes: Coupled Model Simulations for the Period 2010-2040 
Chapter Three: Climate Induced Changes on Phosphorus Export into the Great Lakes: Development of Linkages between Extreme Weather Events and Tributary Phosphorus Loading

Chapter Four: Phosphorus Monitoring in the U. S. Portion of the Laurentian Great Lakes Basin: Drivers and Challenges

\subsection{Chapter Summaries}

\section{Chapter Two}

Chapter 2 predicts the future changes of phosphorus export from land-based nutrients for 2010 through 2040. The basin has already experienced historical changes in agricultural and urban activities that have increased P loading in tributaries to the Great Lakes and caused eutrophication problems especially in many small bays and throughout most of Lake Erie, most notably in the western basin (20)(21)(22)(23)(25). Future changes could increase this loading.

This research examines the factors affecting P delivery to downstream aquatic systems, developing models that predict future P export that account for these possible future anthropogenic changes. The Great Lakes region of the U.S. (Midwest) is expected to experience a doubling of urbanized areas along with a $10 \%$ increase in agricultural activities (associated with biofuels) over the next 40 years (34)(35)(36). Utilizing HydroSPARROW, a forecasting tool that enables the SPARROW model (SPAtially Referenced Regression On Watershed attributes), to simulate the effects of various land-use scenarios to describe the effects of changes in land use and nutrient sources, including altering fertilizer use and point source intensity (15).

Two land use scenarios are developed with The Land Transformation Model, a spatially explicit land change model used to predict future land changes across the Midwest (37). The first scenario used in this analysis was an urban expansion scenario that estimates urban growth at county and city scales from 2010 to 2040 based on 
historical expansion rates (38). The second scenario simulates a "biofuel future" (BF) that builds on the urban expansion scenario to predict the effects of increasing corn cultivation needs based on future demands for biofuels from USDA projections (38)(39). Land-use changes from 2010 to 2040, and the associated changes in fertilizer use and point source intensity, were input into the HydroSPARROW model for 2010, 2020, 2030, and 2040.

From 2010 to 2040, the P inputs from the U.S. part of the basin of each of the Great Lakes increase by 0.5 to $7 \%$, except in Lake Ontario where P loading decreases by $1 \%$. The majority of the basin experiences an increase in urban area sources due to urban expansion while the agriculture intensity and forest sources of $\mathrm{P}$ decreases. This decrease in agricultural land may be offset by future predictions of biofuels expansion with an increase in loading in 2040. The results are useful for defining management and monitoring strategies to reduce the extent and severity of nutrient loading and eutrophication in the Great Lakes and other aquatic systems (40).

\section{Publication of This Work}

This work has been submitted to Environmental Science and Technology. In addition, the results were presented at two conferences:

LaBeau, Meredith B., Robertson Dale M., Mayer, Alex S., Pijanowski, Bryan C., and Saad, David A. (2011) Forecasting Future Phosphorus Export to the Laurentian Great Lakes from Land-Derived Nutrient Inputs. American Geophysical Union Fall Meeting, December 2011.

LaBeau, Meredith B., Robertson, Dale M., and Mayer, Alex S. (2011) Forecasting Future Phosphorus Loading in the Great Lakes Region from Changing LandDerived Nutrient Inputs. International Association of Great Lakes Research, June 2011 


\section{Chapter 3}

Climate change can profoundly change nutrient dynamics, water quality and required management of watersheds and lake ecosystems (41)(42)(43). The water quality of the Great Lakes integrates the effects of anthropogenic activities and climate (44). This ecosystem has suffered the effects of phosphorus loading that are significantly linked to extreme flow events $(45)(46)(47)$. The increased frequency and magnitude of intensive rain or other climate-related extreme events that have been predicted as a result of the changing climate may increase nutrient loadings dependent on changes in flow.

This paper examines the effects of predicted future changes in high precipitation events around the tributaries of the Great Lakes. Specifically, these climatic projections will lead to changes in frequency, timing, and magnitude of phosphorus loading events within the Great Lakes watersheds. This work postulates changes in climate will produce changes in phosphorus loading from the tributaries of the Great Lakes thereby ultimately altering the Great Lakes ecosystem. Specifically, these climatic changes will lead to changes in frequency, timing, and magnitude of phosphorus loading events within the Great Lakes watersheds (48)(49)(50).

To understand how these changes will occur, this study develops load regression models for a mixture of various monitored watershed in the U.S. Great Lakes Basin based on data availability and land use characteristics. We then employed a chi-square test to develop seasonal regression models of load versus flow for 14 watersheds across the U.S. Great Lakes Basin (51). Computations of the flow-load regressions were developed for each tributary based on statistical relations between the $\mathrm{P}$ load and the predictor variable streamflow (Equation 1-1):

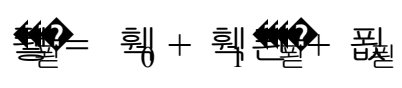

\section{Equation 1-1}


The water-quality regression model relates the logarithm of load (

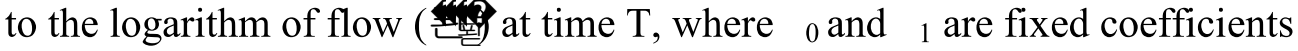
estimated for each site by the ordinary least squares method, and the model error, $\mathrm{e}_{\mathrm{T}}$ is assumed to be independent and normally distributed with a mean of 0 and a variance of ${ }^{2}$. These regression models were used in conjunction with flows generated for future climate scenarios for the Great Lakes to understand future phosphorus loads and extreme loading events.

This research utilized output from a suite of Regional Climate Models for prediction of future climate projections. The Coupled Model Intercomparison Project phase 3 (CMIP3, (52)) generates downscaled climate change projections that are input in the Large Basin Runoff Model (LBRM) (53), that then drives the statistical P models and ultimately yields estimates of total phosphorus loads. These projections span two 20-year prediction periods from 2046-2065 (near future) and 2081-2100 (far future) that are compared against the historical flows from 1961 to 1999. We selected nine of the 53 downscaled climate projections to represent average and extreme conditions for normalized changes in precipitation and temperature combinations in four categories: dry-warm, wet-warm, dry-cool, wet-cool (scenarios: s20, s25, s5, s33, s41, s27, s39, s10) and one extreme outlier of cool-wet (s51). The projected daily precipitation, maximum temperature and minimum temperature from the climate projections for each prediction period (2046-2065 and 2081-2100) were used as inputs to the Large Basin Runoff Model (LBRM) for the Great Lakes Basin. Probability distributions of future flow from Regional Climate Models were developed to determine phosphorus loads based on historical seasonal regressions. Using historical regression relationships on phosphorus concentrations, these 14 key Great Lakes tributaries are analyzed to determine the effect of changing flow regimes on peak phosphorus loading.

The simulation results showed that climate change scenarios can alter $\mathrm{P}$ loading in the near and far future periods. Depending on the projection, climate change either decreased or increased flows, which in-turn should significantly alter the 
loading, especially in watersheds with a high discharge to flow ratio developed by the seasonal regression models. The use of seasonal models allowed us to isolate different load-discharge relationships across the annual cycle. The seasonality of the model also provides increased evidence of the impact of discharges on loads throughout the year from relatively forested watersheds to highly human-altered watersheds. The watersheds with increased human activities (i.e. agriculture or urban expansion) strongly influenced the vulnerability to climate-induced changes, particularly in the Maumee and Cuyahoga watersheds as their distribution of high flow events increases into the future, causing greater loading in already vulnerable watersheds.

The future simulations of climate-induced changes on discharge in the 14 selected Great Lakes watersheds indicate that climate change can affect P loading. For watersheds like the Cuyahoga, that is simulated to experience increases in loading across various scenarios, including increases in the high-flow events, mitigation policies should focus on reducing the impacts of climate change through land use planning to increase the resilience of the system. This increase in high loading events suggests that many watersheds may be vulnerable to high loading events, which can cause increase eutrophication of the Great Lakes.

\section{Publication of This Work}

This work is in preparation for submittal to the Biogeochemistry Journal. 


\section{Chapter 4}

This work examines the current tributary monitoring network in place to estimate P loading in part of the U.S. Great Lakes Basin. The Laurentian Great Lakes Basin is home to a vast human population and ecosystem with competing demands for land and water. A major ecosystem health issue is the eutrophication of the Great Lakes, which is caused largely by increased loadings of nutrients, most notably phosphorus. According to the IJC, the watersheds of the Great lakes are being subjected to numerous stressors, including land use and climate change (54), potentially resulting in greater quantities of phosphorus entering the lakes because of increased stream flow flashiness, decreased soil infiltration rates, and greater soil erosion (55).

Researchers utilize models to characterize and predict phosphorus loadings from tributaries into the Great Lakes. These models are driven by available data over a range of streamflows $(56)(57)(58)(59)(60)(61)(62)$ to increase the accuracy of estimates of $\mathrm{P}$ loading delivery during high-flow events. But, current trends suggest a decrease in funding of monitoring, and therefore a decreasing number of tributary $\mathrm{P}$ samples (62).

The research herein focuses on the challenges faced by the agencies and organizations responsible for maintaining a tributary monitoring network. Data generated by this network is needed to detect trends at specific locations and as input to basin-wide water quality models. Such models are vital for estimation of loads, and predicting how changes in land use and climate have and will affect nutrient concentrations in the Great Lakes (15).

Here, we examine the challenges associated with maintaining a network of tributary phosphorus monitoring sites in the Laurentian Great Lakes. To understand the historical, current, and future status and trends in water quality monitoring within the Great Lakes Basin, we investigated why and how agency stakeholders develop, manage, and fund water quality monitoring programs. Our primary objective was to better understand the practice of monitoring in the Great Lakes Basin and identify 
potential ways to improve the ability of the existing network to generate data useful for researchers interested in lake-wide P loading.

The primary drivers and challenges associated with effective phosphorus tributary monitoring programs were investigated through interviews with the stakeholders responsible for some part of the monitoring networks for the Great Lakes. Interviews, which were recorded and transcribed, consisted of ten multi-part, openended questions. These interviews were conducted with program managers, coordinators, and directors who had direct knowledge of the monitoring sites, program, and funding. With the exception of one program, Heidelberg College, all the other programs were managed by government agencies. We interviewed 9 tributary monitoring programs across part of the U.S Great Lakes Basin, accounting for 128 phosphorus monitoring sites (62).

Based on these interviews, the authors identified three issues that policy makers interested in maintaining an effective phosphorus monitoring network in the Great Lakes should consider: 1) that the policy objectives driving different monitoring programs vary across the region, which results in different patterns of sampling design and frequency; 2) that these differences complicate efforts to encourage collaboration and to make use of the available data in lake-wide models; 3 ) that methods of funding sampling programs vary from agency to agency, further complicating efforts to generate sufficient long-term data to improve our understanding of $\mathrm{P}$ inputs in the Great Lakes. Given these issues, we recommend the following actions for improving monitoring networks for assessing phosphorus loads into the Great Lakes:

1. Develop lake-level policies with consistent goals, which will help program managers develop an integrated plan of characterizing the phosphorus loads in the Great Lakes Basin by establishing similar sampling frequencies and site selections criteria and by engaging in inter-agency collaborations to secure funding for long-term monitoring.

2. Develop funding mechanisms consistent with the policy goals. If the policy goal is to generate data for the long-term monitoring of phosphorus loads, the 
funding mechanism must be sufficient to meet those goals, as is now the case with the MI and MN models.

3. Develop tributary monitoring protocols that include sufficient samples to identify trends, quantify loads and develop ecosystem models. This sampling design should include data from a range of flows and seasons.

Incorporating these recommendations into monitoring programs will provide a bettercoordinated system for providing adequate data for researchers who are investigating science questions and for natural resource managers attempting to prioritize ecosystem restoration efforts.

\section{Publication of This Work}

This manuscript has been submitted to the Journal of Great Lakes Research and is in the review process. 


\section{Future Urban and Biofuel Crop Expansions Will Increase Riverine Export of Phosphorus to the Laurentian Great Lakes: Coupled Model Simulation for the Period 2010-2040 ${ }^{1}$}

\subsection{Introduction}

The Laurentian Great Lakes, the largest freshwater system in the world, contain $18 \%$ of the available global fresh surface water. Approximately $10 \%$ of the U.S. population lives in their contributing watersheds supporting a non-farm economy of $\$ 3.7$ trillion GDP, which is $30 \%$ of the GDP for the U.S. and Canada combined (2)(3)(5)(63). The Great Lakes receive nutrients from watersheds ranging from forested areas, to agriculturally intensive areas, and large urban centers. Nutrient enrichment of aquatic ecosystems can cause increased biological productivity, harmful algal blooms (HABs), and oxygen depletion (18). These phenomena can interfere with the use of water for domestic and industrial supplies, recreation, and fish harvests. Generally, phosphorus $(\mathrm{P})$ is the limiting nutrient for algae to reach maximum biomass in freshwater ecosystems. Common sources of $\mathrm{P}$ to the system include runoff from the land (direct and indirect), wastewater effluent, and atmospheric deposition or dry fallout (19).

$\mathrm{P}$ from agricultural and urban sources is recognized as a major cause of anthropogenic eutrophication (20). The Laurentian Great Lakes are not immune to effects of anthropogenic eutrophication, which include changes in biotic composition, excessive algal growth, turbidity, taste and odor problems and depletion of oxygen (21)(22)(23)(24). The extent of eutrophication in the Great Lakes varies from embayments (e.g. Saginaw Bay and Green Bay) to wide-scale lake eutrophication in the Western Basin of Lake Erie (25)(26). The eutrophication observed in the 1960s and 1970s, which led to an anoxic zone in Lake Erie, was believed to have been caused by P from detergents in the 1960s. Despite reductions through policy and management in the 1970 s and 1980 s, $P$ is continuing to cause local and regional water

\footnotetext{
${ }^{1}$ Most of the material contained in this chapter has been submitted to Environmental Science and Technology.
} 
quality problems, especially in the Western Basin of Lake Erie. The current paradigm is that increases in P loads from the Great Lakes watersheds are primarily derived from non-point agricultural sources (15)(31); however, at a local scale, inputs from point sources are still significant (15).

Land use in the Great Lakes Basin has changed dramatically over recent decades and if trends continue, land use changes may have significant repercussions on future water quality and subsequent water resource management approaches for this area. From the 1970s to 2000, (63) found that in these five major metropolitan areas of the Upper Great Lakes Basin (Detroit, Chicago, Milwaukee and Twin Cities areas, along with the Muskegon River watershed), urban land approximately doubled while agricultural land decreased in their watersheds. This trend is consistently found in other studies (64)(65). If urban and population growth trends continue in the future, nutrient export in the future could significantly increase $(34)(35)(66)(67)(68)$. The potential increase in bioenergy crops for alternative energy could counteract recent regional decreases in agricultural land (38) further complicating and increasing estimates of P loading to Great Lakes water bodies due to future land use change.

Policies and programs put into place to protect the quality of the water in the Great Lakes date to 1972 with the Great Lakes Water Quality Agreement (GLWQA) signed jointly by the U.S. and Canada. Amended in 1978, 1987, and most recently in 2012, the GLWQA (69) addresses 13 environmental goals, one of which seeks to set P targets for surface waters and enact policies that reduce harmful algae blooms occurring in the lakes and embayments. Predictive tools are needed to help understand the complex interaction of land use change, human activities and water quality if we are to protect these natural resources for future generations. Given limited resources for restoration and mitigation, tools need to be used to identify high impact areas across the basin, to prioritize management efforts.

In this paper, we estimate $\mathrm{P}$ sources and riverine $\mathrm{P}$ exports and loadings for the watersheds across the Upper Midwest part of the U.S., including the Great Lakes Basin, for 2010, 2020, 2030 and 2040. The HydroSPARROW model (application of 
the Major River Basin 32002 calibrated SPARROW model with modified hydrology and/or nutrient inputs) is used in this study to estimate future changes in watershedbased nutrient transport, not including inputs from Canadian watersheds, direct atmospheric deposition, or interbasin transfer, and does not attempt to simulate the effects of future changes in precipitation. We employ and couple the Land Transformation Model V1.1 (36), with one set of plausible futures that follows historic and future growth trends, to predict land use change for two scenarios: urban expansion (UE) and expanded biofuel feedstock cultivation (BF). We link land use categories and population to estimate future P sources used in SPARROW and use the Upper Midwest SPARROW model to predict future P loading, based on the two land use scenarios. The P loads are examined at several spatial scales, including lake basins and Hydrologic Unit Code 8 (HUC8s) (70) watersheds to understand spatial variability in P loads across the basin. Finally, we identify the sites most vulnerable to future loading conditions, to provide policy makers priorities for funding restoration or mitigation measures.

\subsection{Background}

Traditional analytical approaches for assessing the impacts of human activities on water quality have been based on the development of detailed, predictive models (71). Modeling nutrient loads in watersheds typically relies on one of two techniques: deterministic or statistical modeling. Deterministic models attempt to describe process-based nutrient transport through complex sub-models. In contrast, statistical models provide regressions that establish relationships between flows, P loads and environmental characteristics (72). The export coefficient modeling approach explicitly links nutrient loads to land use categories $(71)(73)(74)(76)$.

Many studies have used deterministic models to simulate water quality at the catchment scale in the Great Lakes Basin including the Soil and Water Assessment Tool or SWAT (33). Only a few studies have modeled the entire basin. In 2005, Ouyang et al. developed a GIS based erosion and sediment delivery model to estimate potential sediment loads for agricultural areas in the Great Lakes Basin. This 
approach assessed and compared the relative loadings, conservation practices, and potential for further reductions (77). The spatially explicit SPARROW (SPAtially Referenced Regression On Watershed attributes) model has been used to model water quality constituents at regional scales (78), including the Upper Midwest (15). The model is spatially explicit because it tracks nutrient transport downstream to the lake via stream reaches throughout the entire Basin. SPARROW is a mass-balance model that uses a hybrid statistical and process-based mass-balance approach to simulate land and in-stream processes, track attenuation of nutrients through tributaries, and estimate mean annual flux of P (15)(68).

SPARROW models have been used to describe the sources, transport and fate of nutrients to the Great Lakes using monitoring data and nutrient inputs throughout the Upper Midwest (15). The 2002 SPARROW model for the Upper Midwest (15) indicated that nutrient inputs from agricultural areas were a significant source of nutrient loading to the Great Lakes, contributing $33-44 \%$ of the P load, with point sources also contributing $14-44 \%$ of $P$ to the watersheds of the U.S. part of the Great Lakes Basin. The watersheds of U.S. side of the Lake Erie Basin contributed the highest $P$ loading due to large nutrient inputs from both the agricultural and urban sectors (15).

Several previous studies in the Great Lakes Basin have used land use forecast models coupled to nutrient loading models to understand how changes in a certain land use, such as urban, impact water quality. In 2002, Pijanowski et. al. used a simple nutrient export coefficient developed by U.S. EPA (79), coupled to the Land Transformation Model, and showed that a doubling of urban areas over 40 years along the western watersheds of Lower Peninsula of Michigan would reduce nitrogen by 10 $15 \%$ for most sub-watersheds. The Long-term Hydrologic Impact Assessment (LTHIA) model (80), which uses a simple curve number (CN) approach, was coupled to the same Land Transformation Model for Michigan's Muskegon River Watershed to estimate runoff volume, nitrogen $(\mathrm{N}), \mathrm{P}$ and 4 metal-based pollutants $(\mathrm{Ni}, \mathrm{Cr}, \mathrm{Cu}$, and $\mathrm{Pb}$ ) between 1978 and 2040. These coupled models showed that $\mathrm{N}$ would increase by 
3\% on average between 1978 and a 2040 low urban growth scenario, but some areas, especially those closest to Lake Michigan, would experience a greater than $20 \%$ increase in $\mathrm{N}$ loading. A high urban growth rate until 2040 scenario would produce a $12 \%$ increase in $\mathrm{N}$, indicating the amount of urbanization influences $\mathrm{N}$ loading amounts and spatial patterns. In 2010, (81) conducted a coupled model study of Michigan's Muskegon River Watershed, including the Land Transformation Model, a climate model, and a regression-based nutrient-loading ( $\mathrm{N}$ and $\mathrm{P}$ ) model. The results showed that over the next 100 years, $\mathrm{P}$ would increase by more than $50 \%$ and inorganic $\mathrm{N}$ would increase by $30 \%$, given a business as usual urban expansion rate. Reducing urban areas by half would reduce the $\mathrm{P}$ increase to $6 \%$ from current land use patterns and $\mathrm{N}$ to $20 \%$.

Limitations of these studies thus far are that they do not examine the impacts of expanding agriculture on nutrient loadings and $\mathrm{P}$ estimates or they employ simple models at relatively small scales. Finally, the nutrient models of (62), although similar in nature to the SPARROW model employed here, does not allow separate parameterization land use classes, limiting the ability to examine relative contributions of urban and agricultural land uses to loadings and to discriminate contributions from non-point and point sources of $P$.

\subsection{Methods}

The SPARROW model is a GIS-based regional watershed model that utilizes a non-conservative transport and mass-balance approach to predict annual loads of $\mathrm{P}$ (units of $\mathrm{kg} / \mathrm{yr}$ ) based on P sources and transport and loss processes, in terrestrial and aquatic ecosystems (15)(37)(78). SPARROW models are used to estimate nutrient source delivery to streams via "land-to-water" pathways based on statistically significant landscape parameters (such as climate, soil, slope, and artificial drainage). The $\mathrm{P}$ sources (expressed as mass variables or absolute quantities) represent the amount of $P$ transported to the stream via spatially variable "land-to-water" delivery factors. $\mathrm{P}$ is then delivered downstream via a stream network where attenuation or decay may occur, accounting for partial P loss (15). 
SPARROW models have been developed for several large regions in the US. The SPARROW model used here was developed for the Upper Midwestern US, a region designated as Major River Basin 3 (MRB3) (15). This region includes the US portion of the Great Lakes Basin (Figure 2-1) and comprises a variety of land uses including primarily forested lands in the north, heavily agricultural areas in the west and central region, and includes several major metropolitan centers including Chicago, IL, Cleveland, OH, and Detroit, MI. The MRB3 SPARROW model was calibrated with $810 \mathrm{P}$ load observation sites (each average load was estimated using a regression approach using data from 1971 to 2006; (15)). MRB3 SPARROW model calibration and predictions occur in over 11,000 catchments, ranging in size from $45 \mathrm{~km}^{2}$ to $44,000 \mathrm{~km}^{2}$.

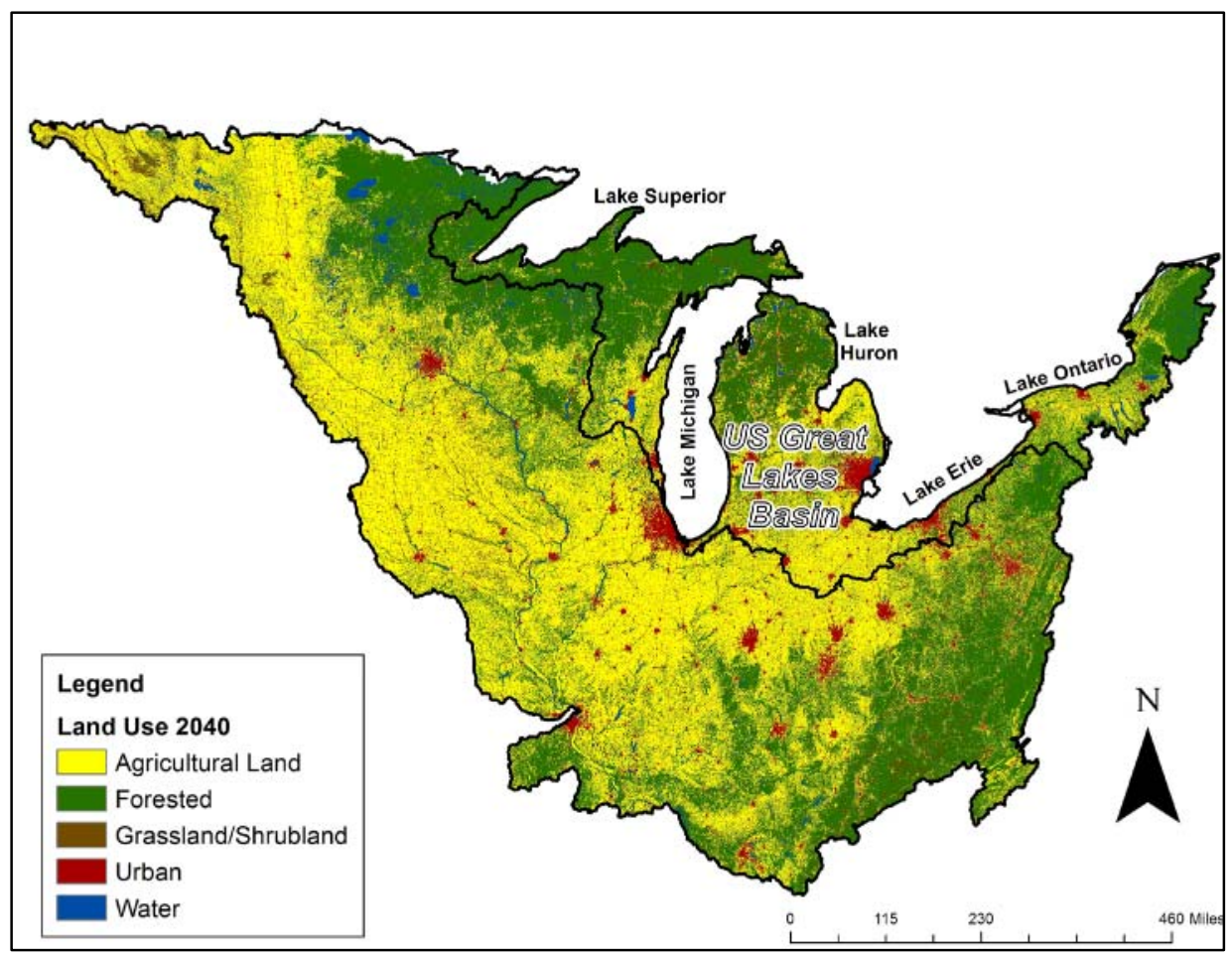

Figure 2-1: 2040 Land Use and Cover Across the Major River Basin 3 including the Great Lakes Basin (US Great Lakes Basin and Lake Drainage, (Figure created by author using data from (7))).

The MRB3 SPARROW model includes six P sources: point sources, urban lands, forested lands (including wetlands), manure from confined animals (confined 
manure), manure from unconfined animals (unconfined manure), and farm fertilizers, which are all allocated at the catchment level. Nutrient inputs from urban areas are represented by the combination of urban land acreage (high, medium, and low density and open space) in each catchment. Urban land sources are a surrogate for various diffuse $P$ sources including, urban runoff, fertilizers, and septic systems (15). The P associated with manure and farm fertilizers were estimated from county application rates and county animal totals (82). $\mathrm{P}$ inputs from forested areas are estimated from the amount of forest and wetland acres in each catchment. The forested areas source is a surrogate for background $\mathrm{P}$ inputs into the riverine system. Finally, urban point sources (including wastewater treatment and commercial/industrial effluent) were estimated from data in the USEPA's PCS database supplemented with data obtained directly from state agencies (15). The model includes coefficients that describe land to water delivery of $\mathrm{P}$ (based on soil permeability and percent of the area with tile drains that captures $\mathrm{P}$ ), and instream and reservoir $\mathrm{P}$ decay (first order decay). A detailed description of the MRB3 SPARROW model is given in (15).

The Land Transformation Model V1.1 (LTM) predicts land-use and land-cover for 2010, 2020, 2030 and 2040 at a discretization of 30m pixels (38). The model uses population growth projections, transportation factors and landscape features derived from remote sensing and geographic information systems analysis as inputs. Predictions are then based on a series of calibrated artificial neural network models. The LTM model has been applied and validated in a variety of locations within the Great Lakes and around the world to understand the important factors of land-use change past, present and future (36)(80)(81)(83).

Two scenarios were generated by the LTM for the Upper Midwest part of the U.S.: "urban expansion" (UE) and "biofuel future"(BF). The UE scenario estimates urban growth at the county and city scales using factors such as U.S. census population growth, urban density and proximity to roads, highways, residential streets, rivers, Great Lakes coastlines, recreational facilities, inland lakes, agricultural density and quality of views (36) from 2010 to 2040 . The BF scenario builds on the urban 
expansion model by developing predictions for the amount of additional area of corn cultivation needed to meet estimated, future demand for required biofuels need from USDA projections (39). The location of the additional corn cultivation is based on land slope and projected distance to existing and new ethanol plants from 2010 to 2040 (38). Results of the 2010 UE simulation (36) are used as the base year for comparisons in this study.

The forecasted HydroSPARROW predictions were made using estimated $\mathrm{P}$ sources for 2010, 2020, 2030 and 2040, assuming that flow remained static to the calibrated 2002 SPARROW model. P inputs from urban point sources were related to population, with the assumptions that per capita generation of $\mathrm{P}$ from these point sources remains constant and locations of point sources remain fixed, all based on the 2002 calibrated MRB3 SPARROW model. Predicted point sources were calculated using county population projections for 2010 to 2040 (84). Changes in inputs from urban areas were made by multiplying the urban area by the fractional increase amount of urban land predicted by the LTM for 2020, 2030, and 2040 compared to that in 2010.

Present and future $\mathrm{P}$ inputs from forested areas were made by multiplying the forested area of each by the percent increase/decrease in the amount of forested land predicted by the Land Transformation Model for 2020, 2030, and 2040 compared to that in 2010 for each catchment. Inputs from fertilizers and manure were estimated based on the amount of future agricultural land. Fertilizer, confined manure and unconfined manure application rate catchment coefficients were developed from the 2002 SPARROW model based on each catchment's fertilizer and manure use. This application rate coefficient was then applied to the percent change in forecasted agricultural land in each catchment for 2010, 2020, 2030, and 2040. 


\subsection{Results and Discussion}

\section{Projected Changes in Land Use, Population, and P Sources.}

Table 2-1 illustrates the changes in population and land use across the US part of the Great Lakes Basin that affect the P source terms in the HydroSPARROW model. Urban areas are predicted to increase throughout the Great Lakes Basin, whereas population will increase only modestly from 2010 to 2040 . The increase in urban land produces an increase in $\mathrm{P}$ input from this area. Input from urban areas is quantified in SPARROW using area of urban land; therefore, the actual P input from urban areas is not presented here. For the UE scenarios, inputs from point sources are expected to increase from 2010 to 2040 by 5\%, due to a 5\% increase in population over the 30-year period. The predicted $\mathrm{P}$ input from agricultural sources (manure confined, manure unconfined, and farm fertilizers) decreases from 2010 to 2040 by $7 \%$, whereas inputs from forested land decreases by $5 \%$, all driven by a $41 \%$ increase in urban land. In the BF scenario, the amount of $\mathrm{P}$ input associated with agricultural sources increase $7 \%$ over the whole US portion of the Great Lakes Basin as compared to 2010 , driven by an overall increase in agricultural land by $14 \%$ from the UE scenario. 
Table 2-1: Base Year and Changes in Population and Land Use to 2040 across the US Portion of the Great Lakes Basin.

\begin{tabular}{llll}
\hline & & 2040 & \\
\cline { 3 - 4 } Category & 2010 & $\begin{array}{l}\text { Urban } \\
\text { Expansion } \\
(\% \text { change })\end{array}$ & $\begin{array}{l}\text { Biofuels } \\
\text { Future } \\
(\% \text { change })\end{array}$ \\
\hline Population (millions) & 35 & $37(5 \%)$ & $37(5 \%)$ \\
Urban land area $\left(1,000 \mathrm{~km}^{2}\right)$ & 33 & $47(41 \%)$ & $47(41 \%)$ \\
Agricultural land $(1,000$ & & & $107(7 \%)$ \\
$\left.\mathrm{km}^{2}\right)$ & 100 & $93(-7 \%)$ & $126(-14 \%)$ \\
Forested land $\left(1000 \mathrm{~km}^{2}\right)$ & 146 & $139(-5 \%)$ & \\
\hline
\end{tabular}

\section{Phosphorous Delivery to the Great Lakes.}

Table 2-2 indicates that in 2010 (base year), the US side of the Lake Erie and Michigan watersheds contribute the highest amount of $\mathrm{P}$ to the Great Lakes and the Lake Superior watershed contributes the lowest loads. The ranking of yields (loads normalized by drainage areas) relative to loads shifts, with highest $\mathrm{P}$ yields from the Lake Ontario watershed, partially due to its relatively small drainage and high amount of point sources (Table 2-2). Figure 2 summarizes loadings for each lake by source category. In general, the highest relative contributions to the loads are from point sources. Urban area sources, which account for diffuse P sources, are also important contributors, especially in Lakes Michigan and Erie where there are not only highdensity areas that contribute to P loads, but also large areas of urban sprawl. Of the agricultural sources, fertilizers and confined manure are the largest contributors of $\mathrm{P}$.

As a result of the changes in land use from the LTM model, the estimated loadings for 2010 (Figure 2-2) increased by 31\% from the original 2002 SPARROW 
MRB3 modeled loadings for the US portion of the Great Lakes basin. Each lake basin exhibited higher loadings in 2010, except for the Lake Superior basin. Because the differences in estimated loadings between 2002 and 2010 are caused by differences between the land use classifications used to calibrate the SPARROW model and those defined with the LTM model, (during which there was little change documented in observed loads), the future changes are discussed as a percent change from the 2010 baseline simulation.

The fraction of $\mathrm{P}$ reaching the streams that is then delivered to the Great Lakes is expressed as delivery ratio. All of the watershed-wide average delivery ratios are greater than 0.92 (Table 2-2), indicating that at least $92 \%$ of the P delivered to the river systems is ultimately delivered to the Great Lakes. Because the delivery ratio is related to the residence time of the $\mathrm{P}$ in the hydraulic system (rivers and reservoirs), the ranking of delivery ratios is a function of the distance between the $\mathrm{P}$ sources and the drainage outlets, the discharges in the rivers in the drainage area, and the volume of reservoirs in the drainage area. In the case of Lake Erie, with a delivery ratio almost 1 , most urban sources are located at or near the drainage outlets and there is very little reservoir capacity in the drainage areas. The high delivery ratio indicates that, if growth patterns continue in the Lake Erie drainage area, there will be little attenuation of the $\mathrm{P}$ sources before the $\mathrm{P}$ reaches the lake. 
Table 2-2: Estimated Annual Delivered Loads of Total Phosphorous into each Great Lake from 2010 to 2040 for US Drainage Areas

\begin{tabular}{|c|c|c|c|c|c|c|}
\hline \multirow{2}{*}{$\begin{array}{l}\text { Great } \\
\text { Lake }\end{array}$} & \multirow{2}{*}{$\begin{array}{c}\text { U.S. } \\
\text { Drainage } \\
\text { Area } \\
\left(1,000 \mathrm{~km}^{2}\right)\end{array}$} & \multirow{2}{*}{$\begin{array}{c}2010 \\
\text { Load } \\
(1,000 \\
\text { MT })\end{array}$} & \multirow{2}{*}{$\begin{array}{c}2010 \\
\text { Yield } \\
\left(\mathrm{kg} / \mathrm{km}^{2}\right)\end{array}$} & \multirow{2}{*}{$\begin{array}{c}2010 \\
\text { Delivery } \\
\text { Ratio }\end{array}$} & \multicolumn{2}{|c|}{$\%$ Change to 2040} \\
\hline & & & & & $\begin{array}{c}\text { Urban } \\
\text { Expansion }\end{array}$ & $\begin{array}{c}\text { Biofuels } \\
\text { Future }\end{array}$ \\
\hline Superior & 44 & 0.7 & 16.5 & 0.97 & 4.3 & 4.3 \\
\hline Michigan & 116 & 4.9 & 42.4 & 0.92 & 4.0 & 8.0 \\
\hline Huron & 41 & 1.0 & 25.3 & 0.95 & 6.3 & 9.1 \\
\hline Erie & 55 & 5.0 & 89.6 & 0.99 & 0.3 & 2.4 \\
\hline Ontario & 36 & 3.4 & 96.3 & 0.96 & -1.1 & 1.1 \\
\hline Total & 293 & 15.1 & 51.6 & 0.96 & 1.8 & 4.5 \\
\hline
\end{tabular}

Total annual P delivered to the lakes (U.S. contribution only) increased $1.8 \%$ and $4.5 \%$ from 2010 to 2040 with the urban expansion (UE) and biofuels future (BF) scenarios, respectively (Table 2-2). The 2010 yield is presented in Table 2-2 is measured by the total load over the U.S. drainage area for that Great Lake. The yield normalizes the load based on area for use in comparison across the basins. The increase in $\mathrm{P}$ loadings for the UE scenario was primarily caused by an increase in urban land (associated with diffuse sources), as opposed to increases in population (associated with point sources) (Figure 2-2(b)). The additional increase in P loadings for the BF scenario, as expected, is roughly equivalent to the expected increase in agricultural land across the basin of $14 \%$. 
A. 2010
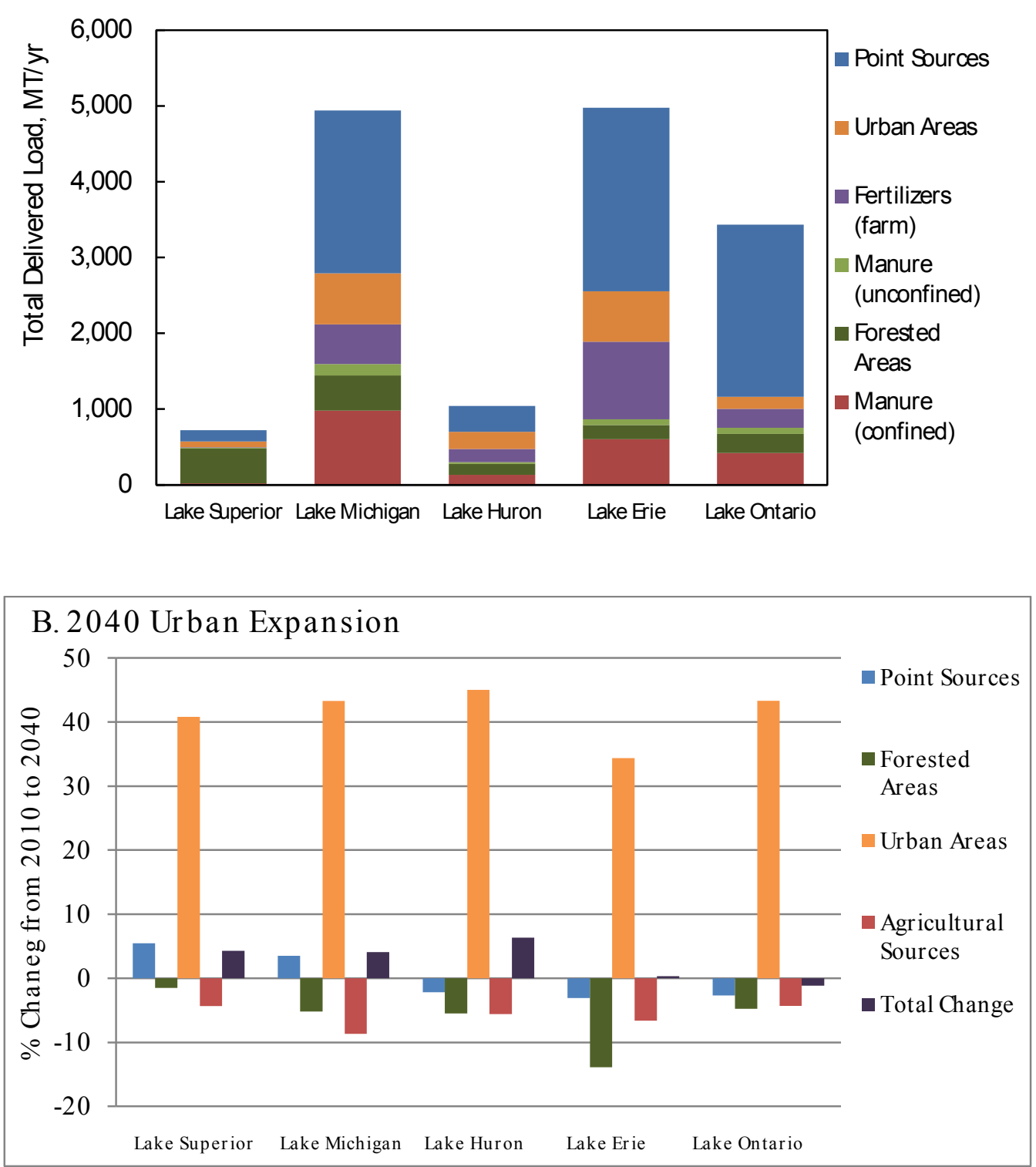


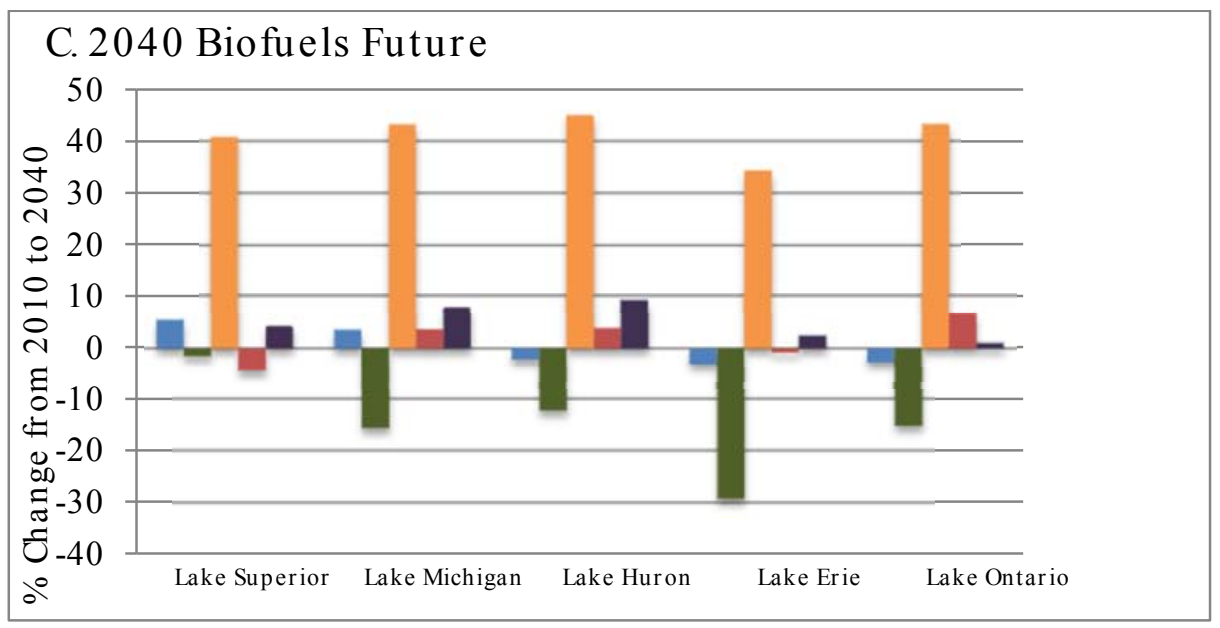

Figure 2-2: (a) Total Annual Delivered TP Load to Each Great Lake for 2010 and increases from 2010 to 2040 for (b) the urban expansion scenario (c) the biofuel future scenario, subdivided by source (Sources of boundaries, 41).

The highest and lowest increases in loadings occur in Lakes Huron and Erie, respectively, for the UE scenario (Table 2-2 and Figure 2-2). The Lake Erie drainage area is already highly urbanized and cannot support as large an increase as other areas. Loadings associated with point sources actually decrease in three of the five lake drainage areas, because populations are expected to decrease or stay the same in much of the US portion of the Great Lakes, with the exception of population growth in Lake Michigan and Superior by $12-15 \%$. Although P loadings from urban areas are projected to increase rather dramatically, (from $35 \%$ to $44 \%$ ), this input has only a small effect on the overall loads because this source only contributed a small percentage of the overall load, as opposed to the urban point sources which contributed a higher percentage (Figure 2-2(a)). For Lake Ontario, the $42 \%$ increase in loading caused by increases in urban areas is more than offset by predicted decreases in urban point sources and agricultural land, resulting in an overall decrease of $1.1 \%$.

For the BF scenarios, the greatest increases in loading relative to the $\mathrm{UE}$ scenario occur in Lakes Michigan and Huron (additional 4.0\% and 2.8\% increase, respectively). These results reflect the relatively large expected increases in agricultural land in these areas, due to higher quality agricultural land that would support nearby ethanol production plants. For Lakes Ontario and Erie, the predicted 
increases in loading for the BF scenario relative to the UE scenario are $2.2 \%$ and $2.1 \%$, respectively. The smaller increases for these lakes are a result of less land area available for new agricultural production, given the relatively high urbanized areas in these lake basins.

\section{Changes in Phosphorus Yields by HUC8 Watershed.}

To examine P changes at a smaller scale, HUC 8 basins in each Great Lake are examined based on annual load and yield and change from 2010 to 2040 (Figure 2-3). Note that in Figure 2-3, a different color scale is used for each Great Lake watershed. The HUC8 scale was chosen because watershed management plans and decisions are developed based on this scale in much of the Great Lakes Basin. All total loads and yields, with their ranking for each basin are listed in the Appendix A.

A.

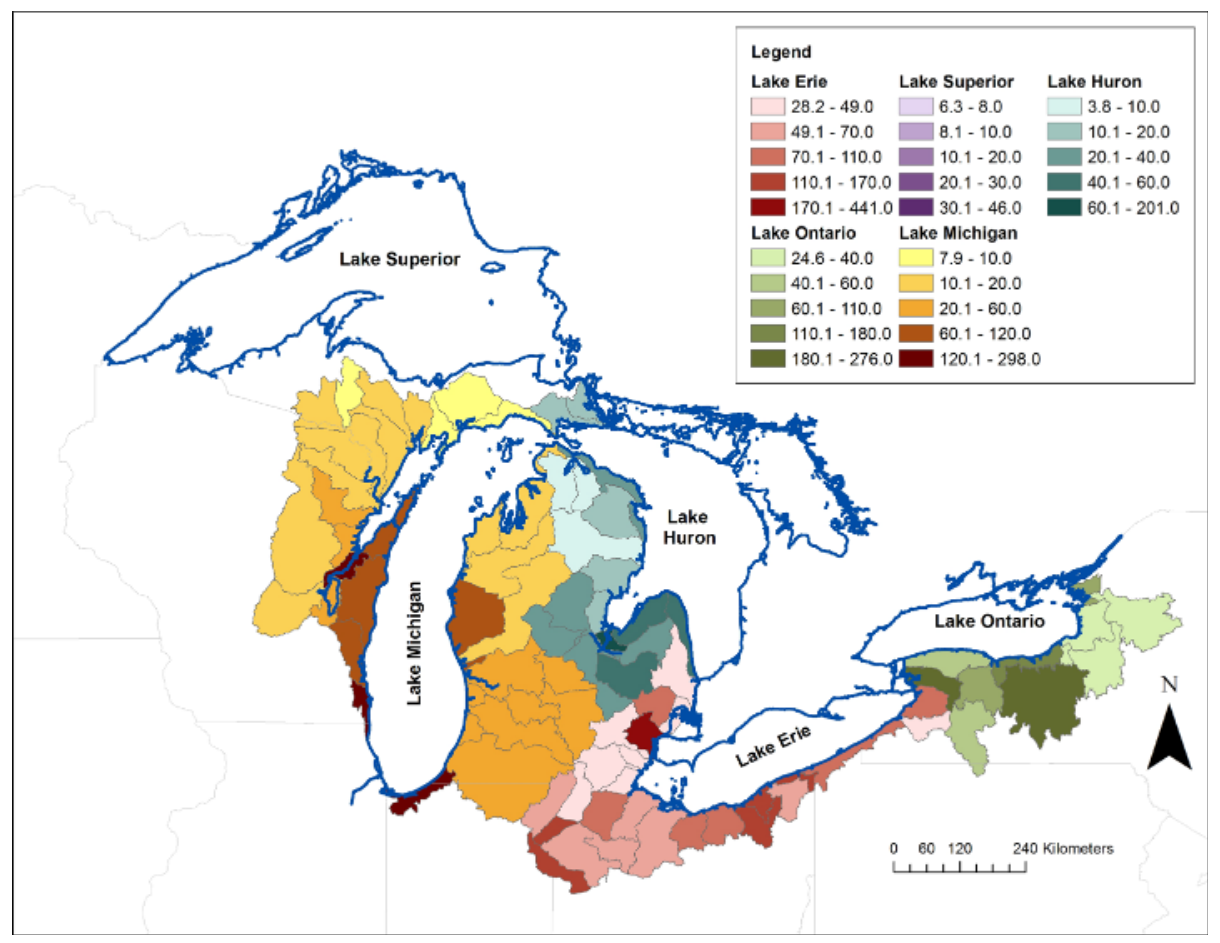


B.

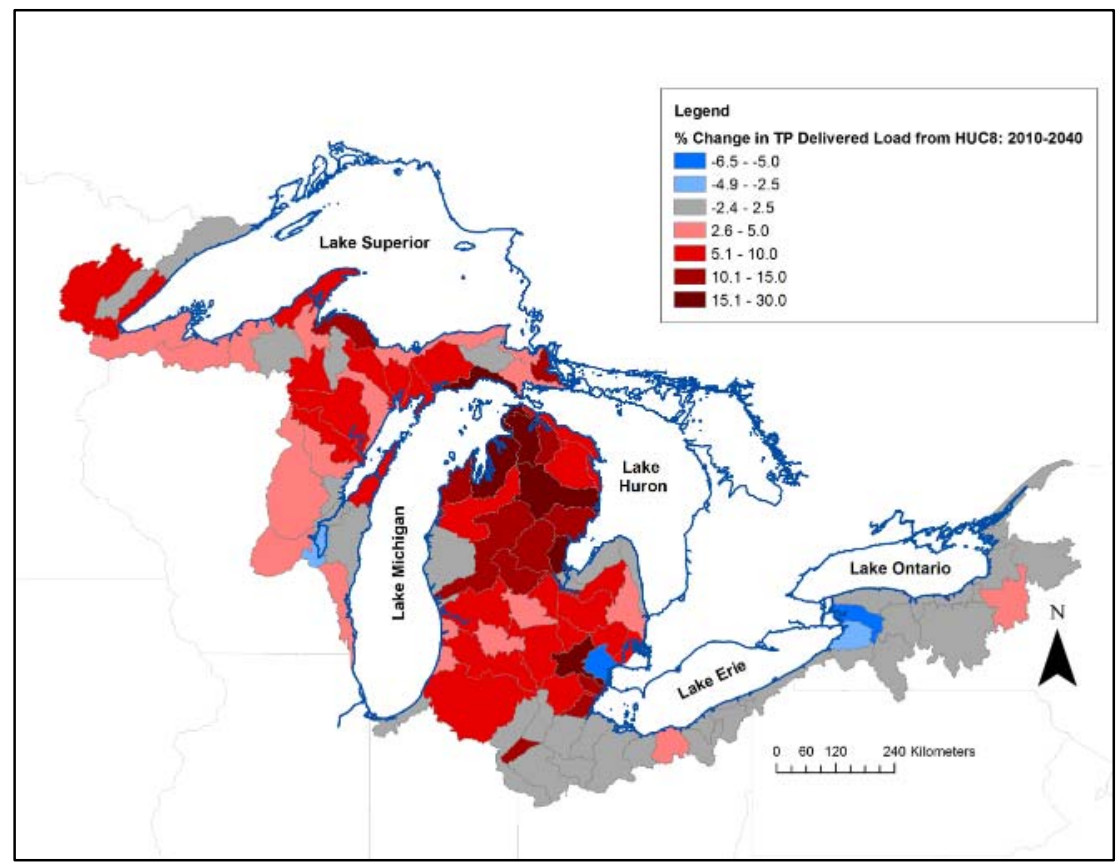

C.

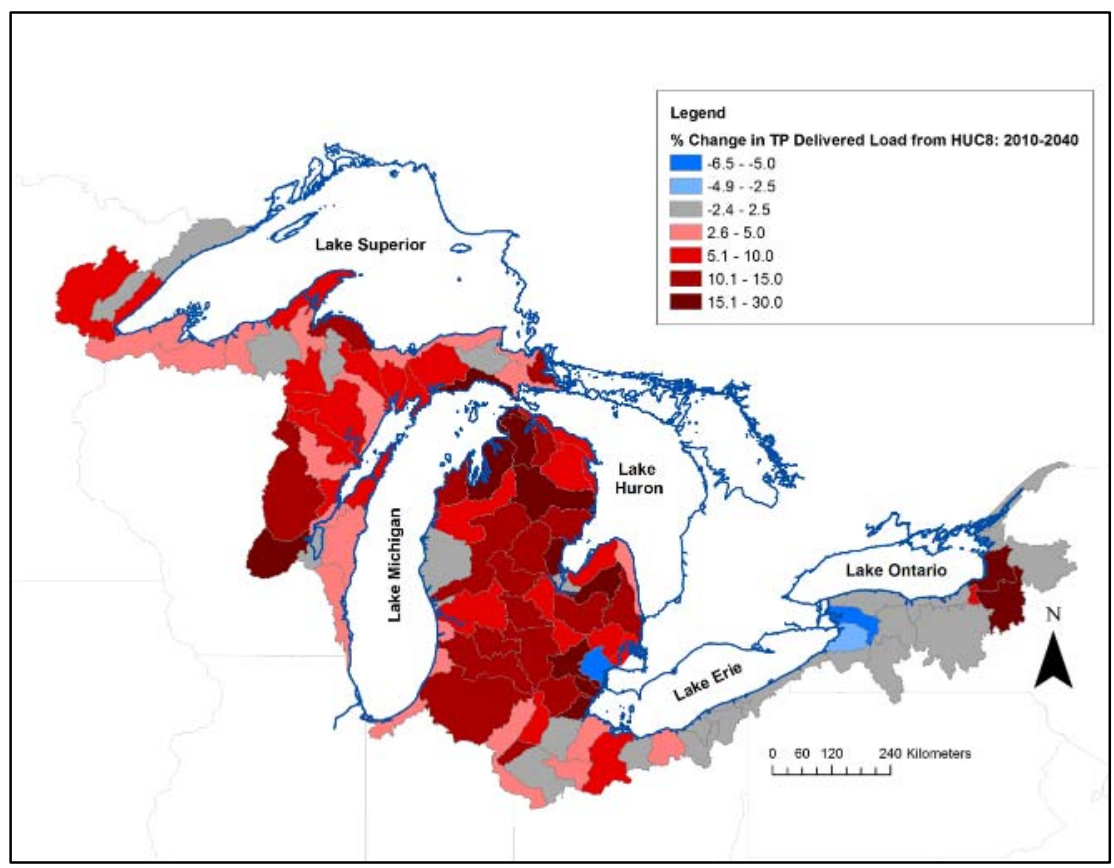

Figure 2-3:Total Delivered TP Yield in $2010\left(\mathrm{~kg} / \mathrm{km}^{2}\right)$ (a) and \% change in 2040 urban expansion scenario (b) and 2040 biofuels future scenario (c). Note that color scheme in (a) is adjusted to normalize for each Great Lake basin. (Figure created by author using data from (41)) 
In the base year of 2010 (Figure 2-3 (a)), the highest P yields across the entire Great Lakes Basin were from the Detroit (Lake Erie), Pike-Root (Lake Michigan), Niagara (Lake Ontario), Little Calumet-Galien (Lake Michigan) and Saginaw (Lake Huron) HUC8s. In the Lake Ontario and Michigan watersheds, the highest ranked HUC8 for delivered P yield are the St. Joseph HUC8 for Lake Michigan and the Seneca HUC8 for Lake Ontario. The St. Joseph HUC8 is a highly intensive agriculture region, while the Seneca watershed is dominated by point sources (82\%). For Lake Erie, the highest ranked HUC8s were the Detroit (high point source contributions), Cuyahoga (mix of intensive point and agricultural sources), and Sandusky (intensive agricultural sources) HUC8s. For Lake Huron, the Flint and Saginaw HUC8s had the highest P yields, because of large point source contributions. For Lake Superior, the Beartrap-Nemadji and St. Louis HUC8s had the highest P yields because of large point sources and urban areas.

In the UE scenario, the relative yields generally increased; however, yields in a few areas decreased (Figure 2-3 (b)). The largest relative increases in loads/yields occurred in Lake Superior (Dead-Kelsey, Beaver-Lester, St. Louis, and Keweenaw Peninsula HUC8s) and northern and central Michigan (Brule, Escanaba, Muskegon, Betsie-Platte, Boardman-Charlevoix and Brevort-Millecoquins HUC8s), especially in areas that are more pristine today, but are expected to experience increases in urban area and population. Loads and yields are expected to decrease in the Detroit HUC8 because of decreases in population and there is no more area available for increases in urban land. Loads in the surrounding, ex-urban watersheds (Clinton, Huron, Cass and St. Clair HUC8s) are expected to increase as a result of increases in urban land. For Lake Erie, the Huron HUC8 is projected to have a $22 \%$ increase in P yield because of increases in urban areas and population. Decreases in yields are predicted near the Buffalo area (Niagara \& Buffalo-Eighteenmile HUC8s), because populations are expected to decrease in this area.

Figure 2-3 (c) shows the overall expected changes in loads and yields in HUC8 basins for the BF scenario from 2010 to 2040. The difference between Figure 2-3 (b) 
and (c) reflects changes in P yields and loads associated with increased agricultural activity from expanded biofuel crop cultivation. HUC8s with the largest increase in the BF scenario (Figure 2-3 (c)) are in the western and southeastern part of the Lake Michigan, western Lake Erie, and eastern Lake Ontario watersheds. In the Lake Michigan watershed, the Upper Fox (18\%), Thornapple (17\%), Lake Winnebago (15\%), and Kalamazoo (7\%) HUC8s exhibit the largest increases in P yields with the UE scenario. Yields from Lake Huron, the Pigeon-Wiscoggin, Birch-Willow, and Flint HUC8s are expected increase 5\%, 4\% 3\%, respectively from 2010 to 2040 . Finally, the BF scenario results in a $23 \%$ increase in the Salmon-Sandy HUC8 near Lake Ontario. These HUC8s exhibit large increases in loading because of their proximity to potential biofuel plants and the availability of agricultural land, especially for the watersheds in the Lakes Michigan and Huron watersheds. Over half of the HUC8s in the Great Lakes Basin could experience changes of 5\% or greater in delivered $\mathrm{P}$ yield from 2010 to 2040. On the other hand, loadings from Lake Erie watersheds are expected to change little over the next 30 years.

\section{Importance of Phosphorus Loading Predictions for Watershed Planning.}

P loading can result in eutrophication problems throughout the Great Lakes, as recently noted in the Western Basin of Lake Erie and Green Bay (18)(31). Prediction of $\mathrm{P}$ loading at several scales can assist natural resource managers in prioritizing funding for areas where practices to reduce $\mathrm{P}$ inputs would have the greatest impact on overall loads to each Great Lake, as is recommended in the recent Great Lakes Commission report on P reduction (40). By identifying contributions by source, e.g. agricultural vs. urban, policy makers can determine the most important sectors to target for $\mathrm{P}$ input reduction.

Because the scenarios simulated here are just one set of many possible population and land use change projections, it is worth describing more generally how watersheds vary in their capacity to export P. In SPARROW, losses of P from the landscape are based on the input of $\mathrm{P}$ to the watershed, land-to-water delivery factors, and losses during downstream transport and reservoir retention. The land-to-water 
delivery factors determine the amount of each source of $\mathrm{P}$ (manure, fertilizer, and urban-based diffuse sources) that reaches the stream. The land-to-water delivery factors in this model include two land characteristics: soil permeability and the percentage of land underlain by tile drains (15). Losses during downstream transport are a function of the in-stream removal rates and water impoundments. The combination of factors differs throughout the catchments of the Great Lakes Basin and results in a range on vulnerability to changing land-use based on their ability to retain P.

Based on the removal (land-to-water delivery) factors, catchments with lower permeability soils, lower areas of land with tile drains, short travel time and no intercepting lakes are more likely to produce greater downstream P loadings than watersheds with high soil permeability and a high percentage of tile drainage with a long travel time. Catchments with long travel paths and intercepting lakes with significant volumes exhibit greater retention of $\mathrm{P}$, and may be less vulnerable to changing nutrient inputs in the future. To illustrate this point, we chose two agricultural areas, one upstream of Lake Winnebago on the Fox River, and the Grand River in the Upper Grand River watershed. Although loading rates are relatively high from agricultural areas upstream of Lake Winnebago, only a small fraction of $\mathrm{P}$ loadings travel downstream to Green Bay, since Lake Winnebago has a high volume. On the other hand, areas downstream of the Grand River are highly vulnerable because the contributing watershed has lower permeability soils, little-to-no tile drainage, and no lakes to retain $\mathrm{P}$. Another example of geographic factors interacting to retain $\mathrm{P}$ is in the upper Maumee catchments. These catchments exhibit relatively low delivery fractions of $\mathrm{P}$ because of a large percentage of tile drains and long travel path to Lake Erie. In the future, watersheds that are more vulnerable to $\mathrm{P}$ input and transport, for any land use or climate scenario, will be areas on which to focus watershed planning and management. The spatial variability of these geographic factors is illustrated in the Appendix A. 


\section{Limitations of Approach.}

The modeling approach used here assumes that watershed hydrology will remain the same as that used in the original 2002 SPARROW model, which may not be valid given the potential for the forecasted land use changes and climate change to modify the hydrology of the area. Land use change could influence the timing of water transport, for example, increased urbanization would be expected to result in higher peak stream discharges, which could, in turn, be expected to produce greater P loads. Thus, the changes in P loads predicted for the urban expansion (UE) scenario for HUC8s such as the Brevoort-Millecoquins, Brule, Black, Upper Fox, KawkawlinPine, and Betsie-Platte, which are projected to experience relatively high increases in urban land, are likely to be underpredicted. P loads into Lake Huron and Michigan watersheds, which are expected to have the greatest increases in urban land of the Great Lakes, would also be likely to be higher than predicted here.

In addition, most studies indicate changes in climate in the Great Lakes region could produce increased high flow events, which in turn are likely to generate greater P loading (41)(48)(49). It is likely that areas that already have precipitation frequency distributions that are skewed towards high flow events will be affected the most by climate changes. In Lake Michigan watersheds, both mean annual flow and peak flows are projected to increase (50). Changes in P loads in these watersheds, then, could be significantly underestimated.

The LTM predictions of land use change presented here provide only one set of plausible future scenarios. Recent work examining patterns of agricultural change in response to biofuel demand indicates that increases in corn production are occurring with a decrease in the amount of corn rotation with soybeans (38). Changing the allocation of corn and soybeans from the traditional 50:50 footprint could result in large increases in nutrient loadings to waterways, especially N. The Energy Independence Security Act of 2007 set Renewable Fuel Standards to the year 2022 requiring that more than $50 \%$ of the nation's ethanol be produced from cellulosic (nonfood based sugar) stocks. However, processing plants are not likely to be built that 
reach these cellulosic-based goals (85). Thus, future scenarios may need to also examine how crop rotations and/or biofuel source stocks affect nutrient loadings to the Great Lake surface water bodies. Finally, much of the forested areas in the Great Lakes basin are secondary-aged stands; by 2040 many will be more mature and likely sequester nutrients differently than current forests.

\subsection{Acknowledgements}

This work was supported by award CBET- 0725636 from the National Science Foundation. Dr. Burak Pekin of the Human-Environment Modeling \& Analysis Laboratory at Purdue University provided output from the Land Transformation Model. LTM work was supported by the USGS National Fish Habitat Assessment Project and research on agricultural expansion funded by a GLRI grant to IISG/NOAA. 


\section{Climate Induced Changes on Phosphorus Export into the Great Lakes: Development of Linkages between Extreme Weather Events and Tributary Phosphorus Loading ${ }^{2}$}

\subsection{Introduction}

Climate change can alter the hydrologic processes that affect the processing and transport of nutrients in watersheds (41)(42)(43). These impacts can either be indirect by affecting the processes that regulate transport dynamics or direct through the alteration of water flows. Shortening the period of frozen ground, prolonging periods of intensive rain, and other extreme climatic events, accompanied by changes in land use will alter the losses of phosphorus, $\mathrm{P}$, from watersheds (86). These changes have been illustrated by (87) where combined changes in temperature and precipitation may cause a 60 to $70 \%$ increase in discharge. Meyer and Pulliam (1992) illustrated the significance of increases in winter flooding and decreases in summer runoff, which affect the amount and timing of constituent transport in the Delaware and Sacramento Watersheds. Prolonged seasons of rain may be marked by increases in the transport of $\mathrm{P}$ throughout northern hemisphere landscapes. Likewise, the potential increase in the frequency and magnitude of intensive rain or other related extreme events, predicted as a result of the changing climate, may either increase loadings for constituents that increase with flow (41) or dilute concentrations for constituents that are independent of flow (89).

The water quality of the Great Lakes integrates the effects of anthropogenic activities and climate changes. This ecosystem has suffered the adverse effects of eutrophication from high P discharges (44). Over the past 5-10 years, changes have occurred in the Great Lakes from variable nutrient loading (45)(46)(47)(90). Climate change is predicted to result in increases and/or decreases in precipitation, warmer temperatures and greater incidences of large rain events in the Great Lakes region (34). Large precipitation events will increase storm discharge resulting in potentially

${ }^{2}$ The material contained in this chapter is in preparation to Biogeochemistry. 
increased influxes of nutrients into the ecosystem. According to Trefry, et. al. (2005), the frequency of daily precipitation events that exceed 51 millimeters has increased from 1927 to 1997. Similarly, other research indicates increases in the frequency of large rain events throughout the upper Midwest (49)(91), which can alter nutrient dynamics, especially P. Also, there is evidence that seasonality may be altered due to shorter winters and prolonged summers (92).

Knowledge of the temporal distribution of nutrient loadings is critical for ecosystem management. Water quality management policies and practices are influenced by hydrological conditions as well as the timing and seasonal magnitude of constituent contributions (93)(94)(95).

Methods for estimating loads over annual to seasonal to daily time scales are generally divided into two primary categories: 1) methods employing empirical relationships between loads and discharges (i.e. averaging methods, ratio estimators, and regression (60)(96)(97), and 2) methods employing process based models (i.e. Soil and Water Assessment Tool (5)(98)) or Generalized Watershed Loading Function (99)). The empirical approaches for estimating nutrient loads at various temporal scales include regression analysis of concentration/load vs. flow (58). The empirical approach estimates concentrations/loads from streamflow measurements (41)(101) while many process-based approaches require much ancillary data and parameter calibration. Most of these approaches for modeling nutrient loading account for temporal scales, since total P concentrations may be temporally correlated not only to discharge but also to natural and anthropogenic factors that vary throughout the year, including cultivation practice such as tilling and fertilizer application and responses of the landscape to nutrient during rain and snowmelt. This temporal resolution is required to understand the nutrient contributions, specifically $\mathrm{P}$ in the Great Lakes, during the plant and algal growing season when eutrophication most likely occurs (102).

Robertson (1997) used a regression approach with flow and time of year to predict daily total P loads in tributaries of Lakes Michigan and Superior. Royer et al., 
(2006) illustrated that in the upper Midwest watersheds, the majority of P export occurred between mid-January and June when cultivation practices of intense fertilization occur and during discharges events greater than the median discharge, thus including extreme discharges. Therefore, nutrient loading may be correlated to anthropogenic and natural factors of fertilization application and the timing and intensity of discharge events.

The above approaches describe loads as a function of daily flow, but in general do not clearly show the effects of large storm flow on loads. The P load transported during extreme flow events increases dramatically (14)(104)(105). According to Dorioz (1986), wet periods with rain storms produced an increase in river transport of $\mathrm{P}$, while intensive rains during dry periods produced greatest increases in total P load. A closer look at the temporal distribution of small watersheds in Wisconsin provides evidence that only a few storms a year dominated the annual total P loading, with half the annual load being reached in the 14 highest loading days (95). Robertson (1997) demonstrated that much of the total P and sediments loads in selected tributaries in the Lakes Michigan and Superior can occur during low-frequency, high-flow events.

This work hypothesizes that changes in climate will produce changes in $\mathrm{P}$ loading from the tributaries to the Great Lakes thereby potentially altering the Great Lakes ecosystem. Specifically, climatic changes will lead to changes in frequency, timing, and magnitude of P loading events from Great Lakes watersheds. To understand how these changes may occur, this study develops load regression models for 14 selected monitored sites in the U.S. Great Lakes Basin and then applies these models with simulated flows generated for future climate scenarios to simulate future P loading patterns for 2046-2065 (near future) and 2081-2100 (far future) compared to the historical loading period from 1961-1999. We utilize output from a suite of Regional Climate Models to develop future climate projections. The Coupled Model Intercomparison Project phase 3 (CMIP3, (52)) generated downscaled climate change projections that are input into the Large Basin Runoff Model (LBRM) (53), that are then input into statistical P models to ultimately estimate changes in total P loads. 


\subsection{Methodology}

\section{General Approach}

Future P loading was predicted for 14 select sites in the Great Lakes Basin with long-term water quality data. First, seasonal load-discharge regressions were developed for each site. Then representative future climatic projections for the entire Basin were selected for three periods: historical standard bias correction and calibration period for CMIP3 model projections (1961-1999), near future (2046 to 2065), and far future (2081 to 2100) periods. Future climatic projections were obtained from the hydrologic model (LBRM) and used to calculate future discharges for both the near and far future. These discharges were then input into the site specific, seasonal load-discharge relationships to develop predictions of future P loading patterns that were compared to historical loading patterns from 1961-1999.

\section{Study Area}

14 sites from across the U.S. part of the Great Lakes Basin were selected to describe spatial variation in loads across all five Great Lake Basins, and to represent range of land uses and human impacts in the Basin (Table 3-1; Figure 3-1). Land uses in the watersheds of these sites range from intensively agriculture, to forest dominated, to large urban areas. 


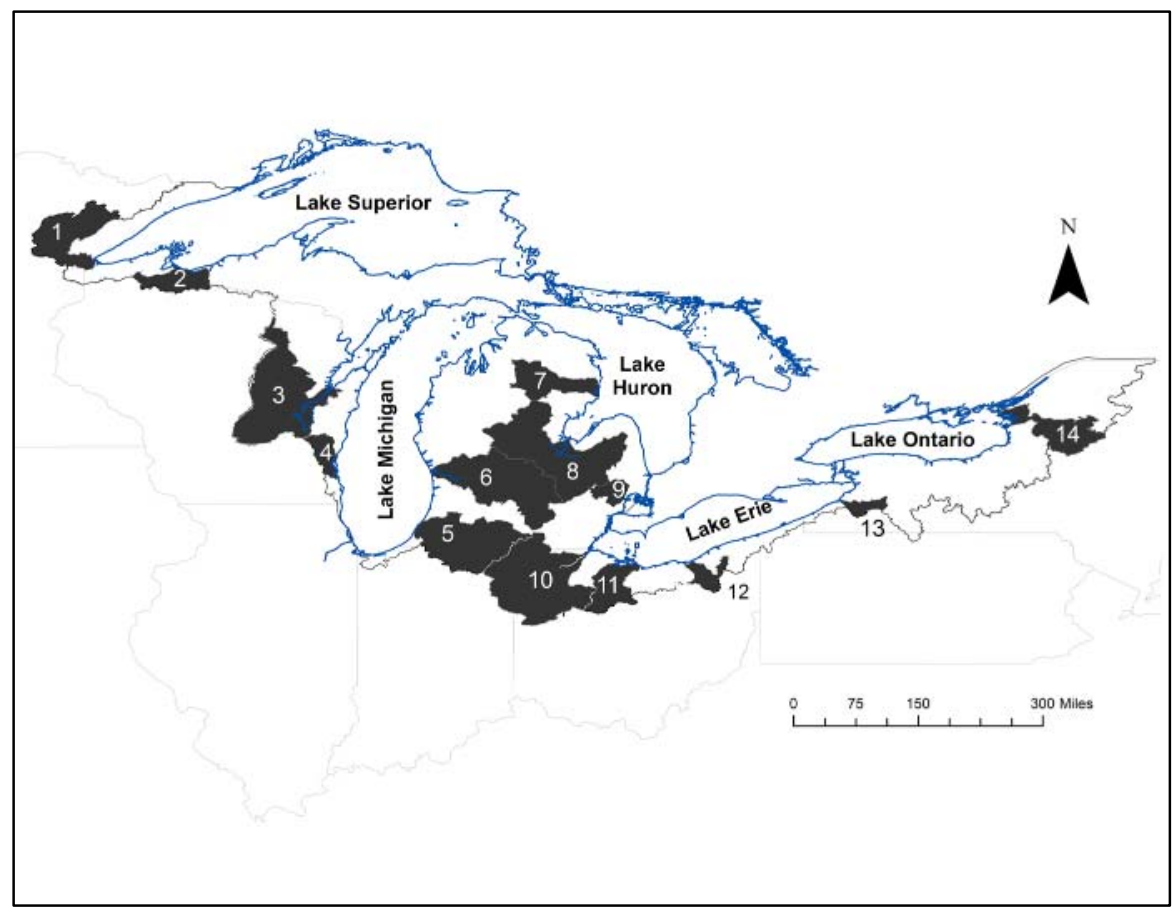

Figure 3-1: Location of the 14 selected Great Lakes Watersheds. The legend for the ID is found in Table 3-1. (Figure created by author using data from (7)).

Water quality and flow data for each of these sites were compiled primarily from the USGS National Water Inventory System, although some data were obtained from the National Center for Water Quality Research, Wisconsin Department of Natural Resources and Michigan Department of Environmental Quality databases. Each site had over 80 P samples from 1975-2012 with corresponding flow estimates available for load calculations. At many of these sites, data collection ceased, and monitoring re-started in 2011(Table 3-2). Both sets of data were used to develop the regression models for each site. 
Table 3-1: General characteristics of the 14 selected Great Lakes watersheds (Agr.: Agricultural Land, For: Forested Land, Urb: Urban Land, $\mathbf{k m}^{2}$ : square kilometers, kg: kilograms)

\begin{tabular}{|c|c|c|c|c|c|c|c|c|c|}
\hline \multirow[t]{2}{*}{ ID } & \multirow[t]{2}{*}{ Site } & \multirow[t]{2}{*}{ State } & \multirow{2}{*}{$\begin{array}{l}\text { USGS } \\
\text { Gaging } \\
\text { Station }\end{array}$} & \multirow{2}{*}{$\begin{array}{c}\text { Drainage } \\
\text { Area } \\
\left(\mathbf{k m}^{2}\right)\end{array}$} & \multirow[t]{2}{*}{$\begin{array}{l}\text { Lake } \\
\text { Basin }\end{array}$} & \multicolumn{3}{|c|}{$\begin{array}{l}\text { \% Land Use } \\
\text { 2006 }^{1}\end{array}$} & \multirow{2}{*}{$\begin{array}{c}\text { 2002 Long- } \\
\text { Term } \\
\text { Average } \\
\text { Detrended } \\
\text { Load (kg) } \\
(15)\end{array}$} \\
\hline & & & & & & Agr & For & Urb & \\
\hline 1 & St. Louis & MN & 04024000 & 8,884 & Superior & 5 & 88 & 4 & 110,771 \\
\hline 2 & $\mathrm{Bad}$ & WI & 04027595 & 2,512 & Superior & 6 & 88 & 4 & 55,058 \\
\hline 3 & Fox & WI & 04085139 & 16,395 & Michigan & 43 & 43 & 8 & 462,782 \\
\hline 4 & Milwaukee & WI & 04087000 & 1,803 & Michigan & 45 & 25 & 29 & 87,147 \\
\hline 5 & St. Joseph & MI, IN & 04101500 & 12,095 & Michigan & 59 & 24 & 14 & 432,433 \\
\hline 6 & Grand & MI & 04119300 & 13,546 & Michigan & 54 & 29 & 15 & 623,305 \\
\hline 7 & Au Sable & MI & 04137500 & 4,504 & Huron & 13 & 77 & 8 & 40,916 \\
\hline 8 & Saginaw & MI & 04157000 & 15,695 & Huron & 48 & 38 & 13 & 424,307 \\
\hline 9 & Clinton & MI & 04165500 & 1,901 & St. Clair & 21 & 24 & 52 & 151,282 \\
\hline 10 & Maumee & $\mathrm{OH}$ & 04193500 & 16,395 & Erie & 78 & 9 & 12 & $1,108,680$ \\
\hline 11 & Sandusky & $\mathrm{OH}$ & 04198000 & 3,240 & Erie & 79 & 10 & 10 & 233,945 \\
\hline 12 & Cuyahoga & $\mathrm{OH}$ & 04208000 & 1,831 & Erie & 18 & 33 & 46 & 182,041 \\
\hline 13 & Cattaraugus & NY & 04213500 & 1,129 & Erie & 36 & 59 & 4 & 42,311 \\
\hline 14 & Black & NY & 04260500 & 4,828 & Ontario & 18 & 76 & 2 & 129,150 \\
\hline
\end{tabular}


Table 3-2: Period of Record and Sample size for the selected 14 watersheds

\begin{tabular}{ccc}
\hline Site & \# Of Samples & Period of Record \\
\hline St. Louis & 224 & $1970-1994$ \& 2011-2012 \\
Bad & 147 & $1974-1993$ \& 2011-2012 \\
Fox & 125 & $1994-1995$ \& 2005-2012 \\
Milwaukee & 414 & $1990-2009$ \\
St. Joseph (MI \& IN) & 274 & $1967-1992$ \\
Grand (MI) & 94 & $1979-1994$ \\
Au Sable & 229 & $1978-1994$ \& 2007-2012 \\
Saginaw & 163 & $1974-2005 \& 2011-2012$ \\
Clinton & 164 & $1974-1995 \& 2011-2012$ \\
Maumee & 16199 & $1975-2012$ \\
Sandusky & 17065 & $1975-1991-2012$ \\
Cuyahoga & 13443 & 161 \\
Cattaraugus & 216 & \\
Black (NY) & $19011-2012$ \\
\hline
\end{tabular}

\section{Climate Change Projections and Future Flow Calculations}

Climate change projections were obtained from multiple General Circulation Models (GCM) simulations of specific future scenarios stored in the multiple-model ensemble in the WCRP CMIP3 (World Climate Research Programme's Coupled Model Intercomparison Project Phase 3) (52). These climate projections were downscaled to $1 / 8$ degree or around $12 \mathrm{~km}$ resolution to be used in driving hydrologic models and were adjusted for regional biases (109)(110)(111). 
The CMIP3 Bias Corrected Constructed Analogs (BCCA) ensemble climate projections were used to simulate and bias correct the hydrological flow for the historical (1961-99), near future (2046-2065) and far future (2081-2100) periods. These BCCA projections were further bias-corrected to the observed historical precipitation record from 1961-1999 through the use of the delta method where the change in precipitation is corrected by a ratio of the future and current precipitation averaged over the entire period of current and future projections. These projections were developed from nine CMIP3 GCM models simulating the effects of select future greenhouse gas emissions scenarios. In addition, some of the models simulations featured unique initial conditions. Therefore, 53 distinct climatic projections were obtained from the $9 \mathrm{GCM}$ models and various future scenarios. The predicted changes in precipitation and temperature, averaged over all 53 model projections and 14 sites are $+7.0 \%$ and $+3.5 \mathrm{C}$ different than the 1961-99 period, respectively. Figure 3-2 and Figure 3-3 show the average predicted changes in precipitation and temperature, respectively, for each of the 14 sites and each prediction interval. Figure 3-2 indicates that predicted changes in precipitation vary dramatically among watersheds, because of differences in the response of weather systems across the Great Lakes basin and interacting meteorological variables; however, temperatures (Figure 3-3) are predicted to increase almost uniformly across the Great Lakes Basin. 


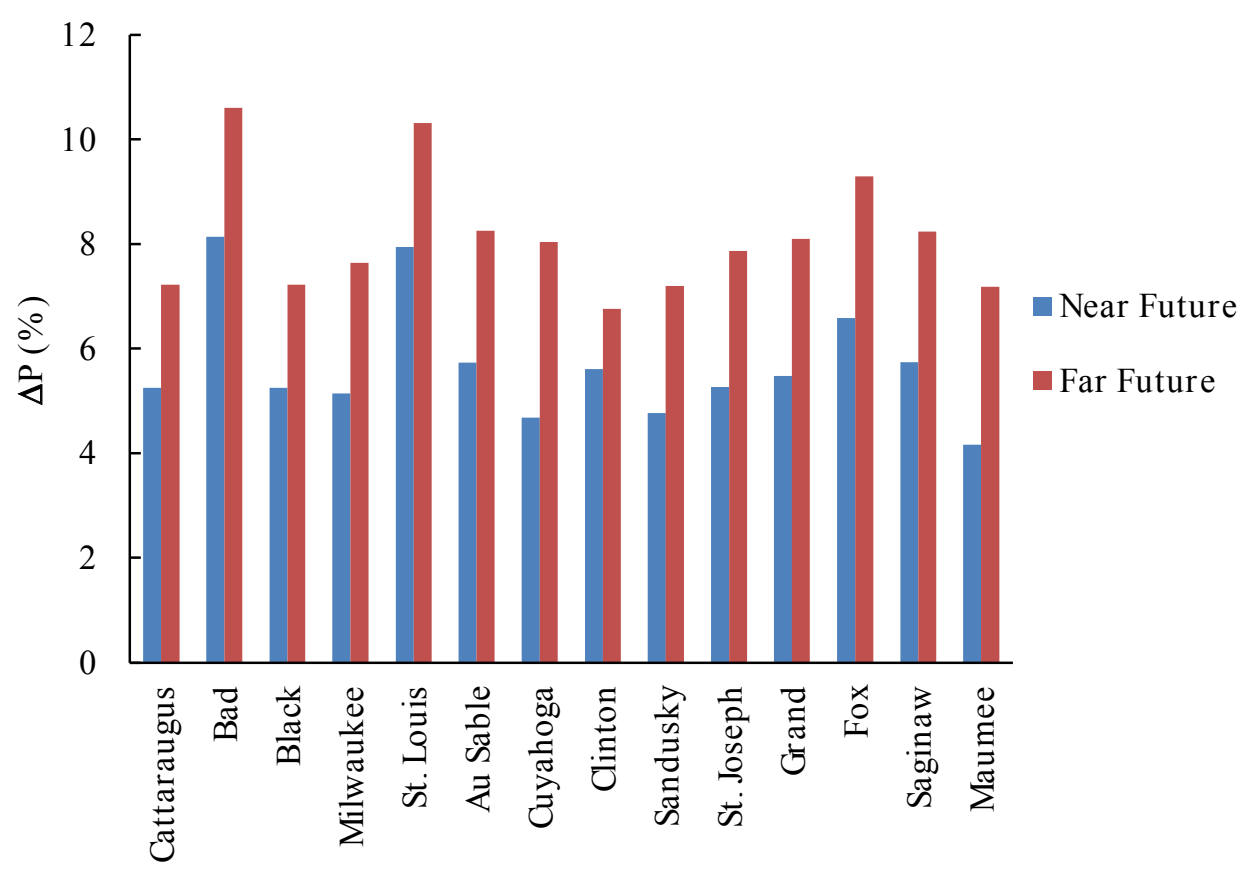

Figure 3-2: Predicted changes in precipitation by watershed averaged over 53 CMIP projections and prediction interval compared to the 1961-1999 period.

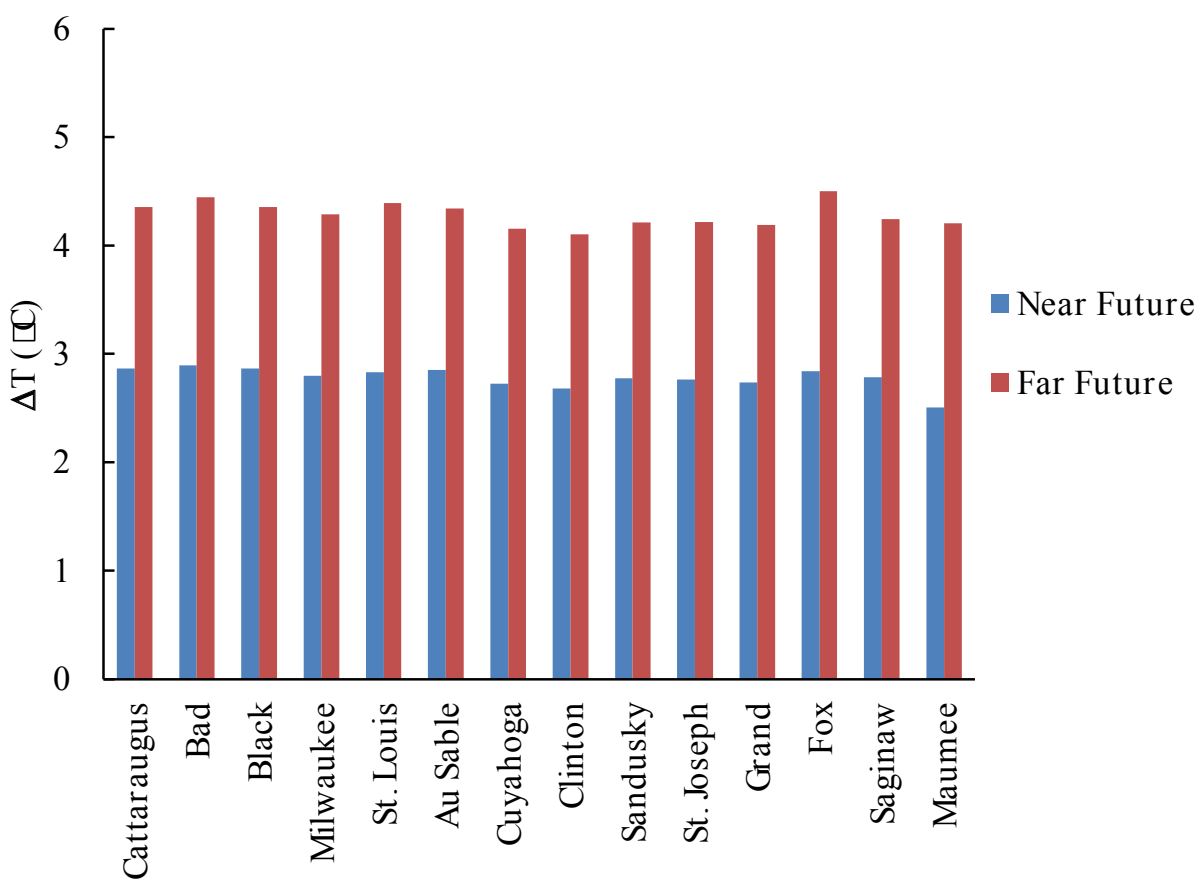

Figure 3-3: Predicted changes in temperature by watershed averaged over 53 CMIP projections and prediction interval compared to the 1961-1999 period. 
In Figure 3-4, the changes in temperature and precipitation averaged over the two future prediction periods and all sites are plotted for each of the 53 projections. Each value was normalized against the minimum and maximum changes by dividing the change in temperature or precipitation by the difference between the maximum change in temperature or precipitation from the minimum change in temperature or precipitation, The center of the plot corresponds to the averaged changes in precipitation and temperature of $+7.0 \%$ and $+3.5 \mathrm{C}$, respectively. Centering the plot at this point divides the plot into four climate change quadrants or categories: dry-cool, dry-warm, wet-cool, and wet-warm. We selected nine of the 53 model projections to represent average (green dots) and extreme conditions (red dots) for each of the four categories: projections s20, s25, s5, s33, s41, s27, s39, s10), as shown in Figure 3-4. We also selected a ninth projection, s51 (yellow dot), which represents an additional extreme cool-wet outlier. 


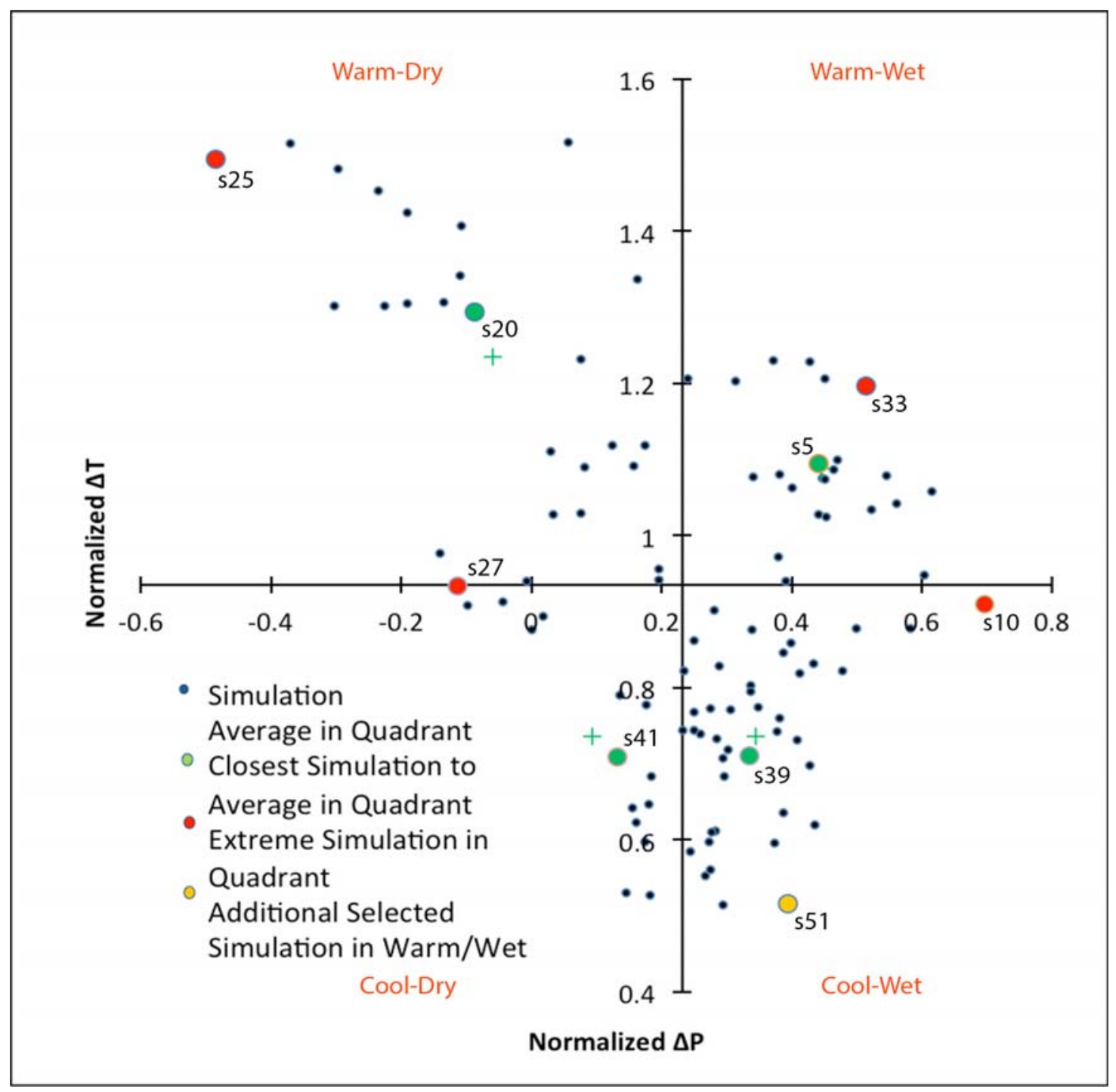

Figure 3-4: Normalized Change in Temperature versus Change in Precipitation Plot of 53 CMIP3 Climate Scenarios across 14 watersheds in both the near and far future projections.

\section{Load-Discharge Regression Model Development}

The R environment for statistical computing (106) was used to calibrate linear regression equations to determine site-specific seasonal relationships between the daily P load and the predictor variable streamflow for each selected tributary:

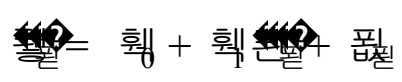

\section{Equation 3-1}


The flow-load regression model relates the logarithm of load (裚) at time $\mathrm{T}$ to the logarithm of flow ( estimated using the ordinary least squares method. The model error $\mathrm{e}_{\mathrm{T}}$ is assumed to be independent and normally distributed with a mean of 0 and a variance of ${ }^{2}$. Measured loads, used for calibration, were computed by multiplying the instantaneous concentration by the daily flow for each collection. Since a logarithmic transformation was used, a bias correction method is necessary because a direct retransformation yields a low and inconsistent estimate of the mean. Retransformation bias corrections were derived for each model using nonparametric smearing estimator (107). This correction factor is multiplied after applying the regression equation for computation of loads and transforming the loads into real space.

Seasonal multiple regression models were developed for each site to describe seasonal variability in the flow/load relations. Season refers to a combination of months for this analysis. Seasons were determined using regression models of combinations of months (two, three and four month permutations). The combined monthly flow-load models of the form were developed and compared against an unrestricted model that incorporates dummy variables for each season. For example, the unrestricted model for a three-month permutation is given by:

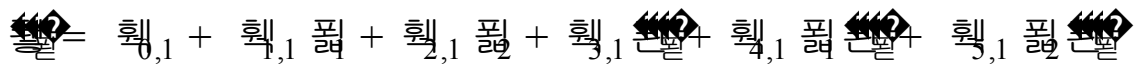

\section{Equation 3-2}

where 훽,1, 훽,1, 훽,1, 훽,1, 훽,1, and 훽,1 are fixed coefficient estimates, 필 and 폴 dummy variables (binary 0 or 1 ), 賠 is the logarithm of load at time $\mathrm{T}$, and logarithm of flow at time $\mathrm{T}$. The addition of

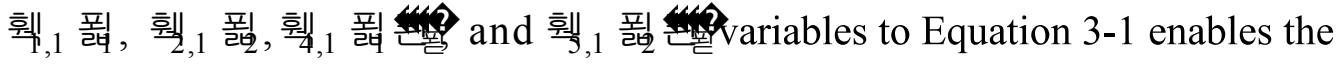
comparison of the effect of the slope and intercept of each season month beyond the fixed effect for the first season by using a combined intercept and slope. This unrestricted model allows for differences in both slope and intercepts between the 
different seasons, wherein the common intercept (훽) and slope coefficient (훽) provide the flow-load relationship for season 1, and the dummy variables provide adjustments of the regression line to improve estimates of loads. This equation isolates the fixed coefficients for each season, so an analysis on seasonal contribution can be computed unlike other models that employ sin and cosine terms to modify the loads based on time of year (14)(15).

The chi-squared test statistic (稁至) with J degrees of freedom (51) was utilized to determine if the restrictions imposed by the combined model are justified for a specific monthly combinations or if the unrestricted model is required:

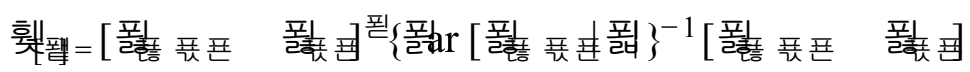

\section{Equation 3-3}

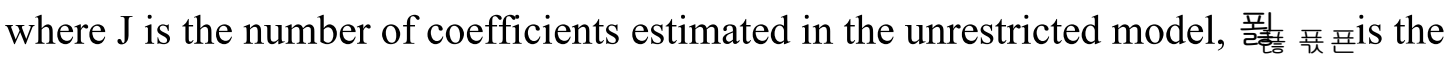

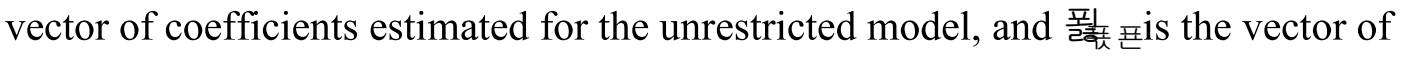
coefficients for the combined months (restricted) model. Seasonal models are justified when the value of the chi-squared test statistic is less than the critical value of a chisquared distribution with $\mathrm{J}$ degrees of freedom and 5\% probability in the upper tail. For sites with less than 500 data points, we used seasons that were composed of two, three or four month combinations, depending of the test results. Seasons created by combing three months were preferred over two and four month permutations. For sites with more than 500 samples, individual models for each month were employed when the restrictions imposed by the combined monthly models were deemed inappropriate by the chi-squared test.

The season-determined regressions were then compared against annual models (Equation 3-1) and models based on seasons defined through past studies in literature that divide the year into late winter (February through March), spring (April through May), early summer (June through July), late summer (August through September), fall (October through November) and early winter (December through January) (95). 
For each site, the models derived using the season-determined, annual, and defined seasons approaches were compared with the Nash-Sutcliffe efficiency (NSE), which has been used to determine the "goodness of fit" for constituent loading-flow models (108). The NSE coefficient for a given model is calculated using the following equation:

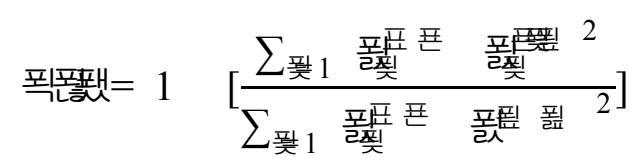

\section{Equation 3-4}

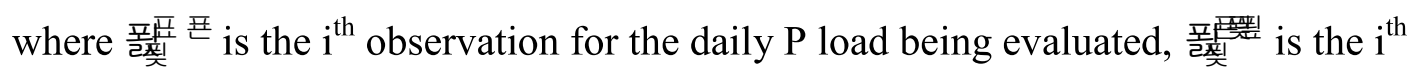
simulated value being evaluated, 폴필 필 is the mean of the observed data, and 퐇 is the total number of observations. NSE coefficients equal to 1 indicate a perfect fit between the observed and predicted values, while values equal to 0 indicate the model is no better than using the average of the observed data. For each site, the model yielding the highest NSE best reproduces historical loads, and was subsequently used to determine loading at that site.

Daily precipitation, maximum temperature and minimum temperature from the climate projections for each of the nine selected projections for the two prediction intervals (2046-2065 and 2081-2100) were used as inputs to the previously calibrated Large Basin Runoff Model (LBRM) for the Great Lakes Basin. The LBRM also was used to simulate discharges for a historical reference period (1961 to 1999). The LBRM developed by the Great Lakes Environmental Research Laboratory (GLERL) of the National Oceanic and Atmospheric Administration (NOAA) is a calibrated large-scale hydrologic model that was used estimate discharges for the 121 large watersheds surrounding the Great Lakes. The LBRM is a calibrated, physically based, lumped-parameter model that simulates outflow at a daily time scale (53). While the calibrated LBRM model has shown excellent agreement with a validation data set of discharges, it has been shown that the predicted, summertime evapotranspiration (ET) 
may be over-predicted, and thus provide underestimates of future discharge (112). The potential overestimation of ET is a result the use of temperature as a proxy to calculate ET.

\section{Future Flow-Load Calculations}

The calibrated LBRM predicts daily discharges at defined outlets, which did not necessarily coincide with the sites used to develop the load-discharge regression models and used to examine changes in loading. The LBRM-predicted discharges for each of the nine selected climate projections were converted to discharges at the prediction sites by multiplying area-normalized discharges by the drainage areas upstream of the prediction sites (Table 3-3). This approach essentially assumes that the climate-discharge relationships calibrated at the LBRM basin outlets have a linear relationship with basin size.

The load-discharge regression models were used to estimate future P loads based on the simulated discharges for each of the nine projections for the two future periods. The future $\mathrm{P}$ loads are then compared against the annual historical loads averaged over the calibration period for CMIP3 models (1961 to 1999) to understand changes in future loading in the Great Lakes Basin. In this analysis, the top 10\% discharges for each site were calculated to represent extreme loading events and used to estimate the ratio of loading during high flow events to the total load. 
Table 3-3: Comparison of Water Quality Site Upstream Drainage Area and LBRM Basin Area

\begin{tabular}{cccc}
\hline Site & LBRM Basin & $\begin{array}{c}\text { LBRM Basin } \\
\text { Area }\left(\mathbf{k m}^{2}\right)\end{array}$ & $\begin{array}{c}\text { \% LBRM Basin } \\
\text { Area Covered in } \\
\text { Relation to } \\
\text { Prediction Sites }\end{array}$ \\
\hline St. Louis & SUP-1 & 9,707 & $92 \%$ \\
Bad & SUP-3 & 3,427 & $73 \%$ \\
Fox & MI-11 & 16,383 & $100 \%$ \\
Milwaukee & MI-14 & 2,224 & $81 \%$ \\
St. Joseph & MI-16 & 12,114 & $100 \%$ \\
Grand & MI-20 & 14,215 & $95 \%$ \\
Au Sable & HU-7 & 5,159 & $87 \%$ \\
Saginaw & HU-10 & 15,761 & $100 \%$ \\
Clinton & SLC-3 & 1,921 & $99 \%$ \\
Maumee & ER-6 & 16,806 & $98 \%$ \\
Sandusky & ER-8 & 4,607 & $70 \%$ \\
Cuyahoga & ER-11 & 2,070 & $88 \%$ \\
Cattaraugus & ER-16 & 1,427 & 5,768 \\
\hline ONT-7 & & & $89 \%$ \\
\hline
\end{tabular}

\subsection{Results}

The following results focus on indicator sites to demonstrate regression fits and loading changes. The three sites chosen were the Maumee, Cuyahoga, and the St. Louis (Figs. 3-3 and 3-6). The Maumee was selected because it is a heavily humanimpacted agricultural region, which exhibited decreases loads during all the climate projections. The Cuyahoga was chosen because it was a highly urban watershed that 
experienced future increases in loading in all climate projections. Finally, the St. Louis site was selected because it was highly forested with a mix of increasing and decreasing loading events across the climate scenarios, which was representative of the majority of the other sites.

\section{Seasonal Regression Models}

Table 3-4 shows the seasons that provided the best-fit seasonal load-discharge regression models for each site. Models for most sites had four three-month seasonal components. The data-rich sites (Maumee, Sandusky and Cuyahoga) had sufficient data to parse temporal variations at a monthly interval. The Cattaraugus and Milwaukee sites had five and six monthly seasons based on chi-square results. Each of the seasonal models had good fit except in the St. Joseph and Au Sable Rivers where the overall $\mathrm{R}^{2}$ across the seasonal models was below 0.5 .

The Nash-Sutcliffe Efficiency statistics for the three models are presented in Table 3-5. For all of the sites, the seasonal models matched the observed data equally or better than the other models. The seasonal models provide a better fit because they capture the runoff characteristics and anthropogenic activities occurring during the various times of the year. For most of the sites, the NSEs are greater than 0.50, indicating that the models do a good job at representing the observed data. The models with poor NSEs had small data sets without a wide range of hydrologic variability. For the rest of the analysis, since the seasonal models generally provided equal or better fit, we use those regressions for the loading scenarios. Overall the models performed well over a large range of flows.

The models for each of the indicator sites fit most of the data quite well, except for some higher flows, when a few of the models under predict the loads as seen in both the St. Louis and Cuyahoga (Figure 3-5). The St. Louis and Cuyahoga Rivers have outliers during high flows, for which predicted P loads are lower than those observed. The underestimated P loads during high flow may have resulted from inaccurate assumptions about the normality of the residuals, which can be slightly skewed, and/or non-linear relationships in log-log space (113). However, the 
regression model for the Maumee reasonably simulated the loads across the range of data Figure 3-5 (c).

Table 3-4: Watershed Statistics of Developed Seasonal Models from Chi-Squared Test

\begin{tabular}{|c|c|c|c|}
\hline Site & Best-fit Seasons & $\begin{array}{l}1 \text { for Each Season } \\
\text { (Equation 3-1) }\end{array}$ & $\mathrm{R}^{2}$ \\
\hline St. Louis & 4: JFM, AMJ, JAS, OND & $1.0,1.3,1.2,1.5$ & 0.77 \\
\hline $\mathrm{Bad}$ & 4: JFM, AMJ, JAS, OND & $1.7,1.6,1.4,1.3$ & 0.91 \\
\hline Fox & 4: DJFM, AM, JJA, SON & $1.1,1.0,1.0,0.7$ & 0.87 \\
\hline Milwaukee & 6: JFMA, M, JJ, AS, ON, D & $1.1,1.0,1.0,1.3,1.2,1.3$ & 0.85 \\
\hline St. Joseph & 4: JFM, AMJ, JAS, OND & $1.4,1.2,0.7,0.9$ & 0.49 \\
\hline Grand (MI) & 4: DJF, MAM, JJA, SON & $1.3,1.2,1.0,1.0$ & 0.67 \\
\hline Au Sable & 4: DJF, MAM, JJA, SON & $1.8,0.9,1.3,1.5$ & 0.37 \\
\hline Saginaw & 4: DJF, MAM, JJA, SON & $0.7,1.2,1.0,1.1$ & 0.72 \\
\hline Clinton & 4: FMA, MJJ, ASO, NDJ & $0.8,0.8,0.5,0.6$ & 0.50 \\
\hline Maumee & Every month & $\begin{array}{l}1.2,1.1,1.1,1.2,1.2,1.0,1.2,1.1,1.0 \\
1.1,1.3,1.2\end{array}$ & 0.91 \\
\hline Sandusky & Every month & $\begin{array}{l}1.2,1.2,1.3,1.4,1.3,1.2,1.2,1.1,1.2 \\
1.3,1.3,1.4\end{array}$ & 0.92 \\
\hline Cuyahoga & Every month & $\begin{array}{l}0.9,1.2,1.2,1.2,1.1,1.1,1.1,1.0,1.0 \\
0.9,1.1,1.1\end{array}$ & 0.70 \\
\hline Cattaraugus & 5: DJF, MA, MJ, JAS, ON & $2.1,1.7,2.1,2.3,1.8$ & 0.88 \\
\hline Black (NY) & 4: FMA, MJJ, ASO, NDJ & $1.1,0.9,1.2,0.9$ & 0.66 \\
\hline
\end{tabular}


Table 3-5: Nash-Sutcliffe Efficiency of the 14 Seasonal, Annual \& Literature Models for each watershed

\begin{tabular}{|c|c|c|c|}
\hline Site & NSE Season & NSE Annual & $\begin{array}{l}\text { NSE } \\
\text { Seasonal } \\
\text { Combination } \\
\text { from } \\
\text { Literature }\end{array}$ \\
\hline St. Louis & 0.77 & 0.75 & 0.76 \\
\hline Bad & 0.91 & 0.93 & 0.91 \\
\hline Fox & 0.92 & 0.89 & 0.93 \\
\hline Milwaukee & 0.85 & 0.79 & 0.83 \\
\hline St. Joseph (MI \& IN) & 0.49 & 0.40 & 0.52 \\
\hline Grand (MI) & 0.67 & 0.64 & 0.69 \\
\hline Au Sable & 0.32 & 0.26 & 0.33 \\
\hline Saginaw & 0.72 & 0.69 & 0.73 \\
\hline Clinton & 0.50 & 0.47 & 0.52 \\
\hline Maumee & 0.91 & 0.90 & 0.91 \\
\hline Sandusky & 0.92 & 0.40 & 0.92 \\
\hline Cuyahoga & 0.70 & 0.66 & 0.69 \\
\hline Cattaraugus & 0.88 & 0.44 & 0.87 \\
\hline Black (NY) & 0.66 & 0.65 & 0.67 \\
\hline
\end{tabular}

The coefficients associated with the exponent on the discharge ( 1 , in Equation 3-1) vary over the seasons and sites, ranging from 0.5 to 2.1 (Table 3-4). A 1 was calculated for each seasonal model at each site through the regression model. Exponents greater than one indicate that disproportionately higher loads are generated for high discharge events. Exponents closer to one indicate that discharge events generate loads proportional to the log of discharge. Low 1 's generally occurred for 
sites with flow modifications resulting from lakes, reservoirs, and dams in their watersheds.

A.

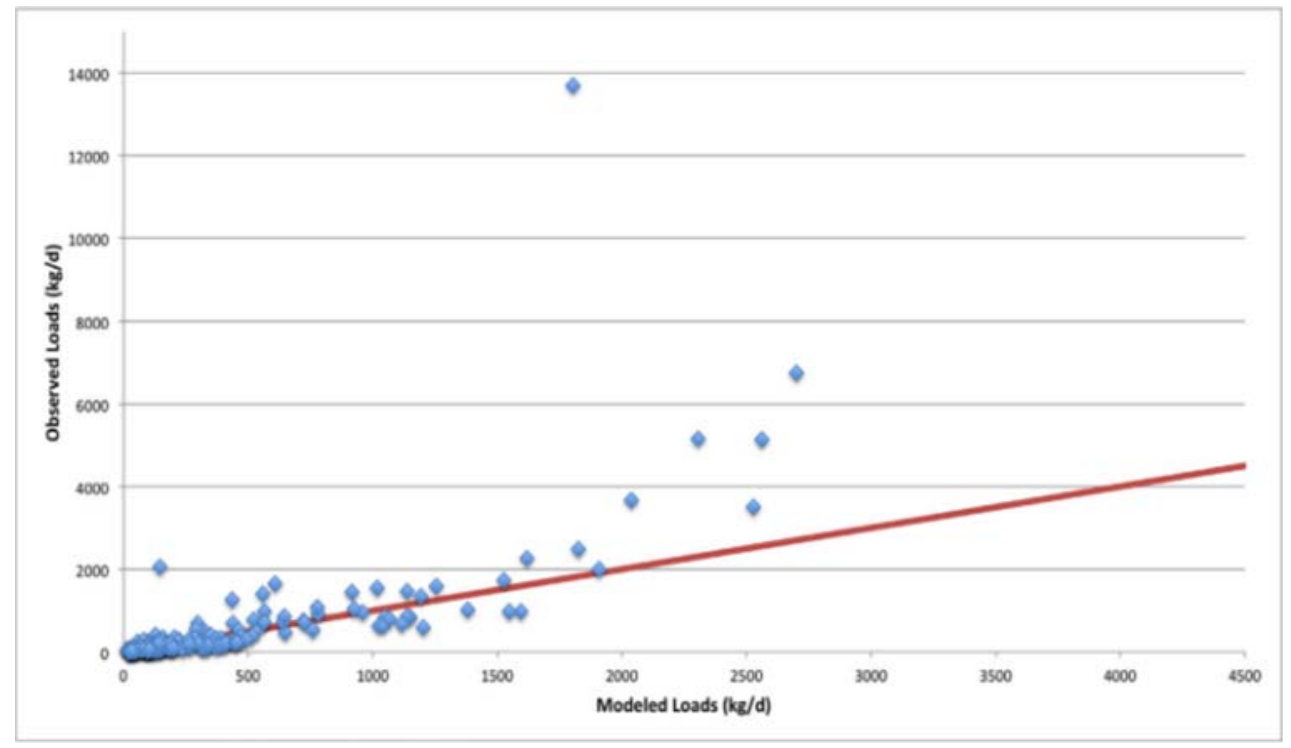

B.

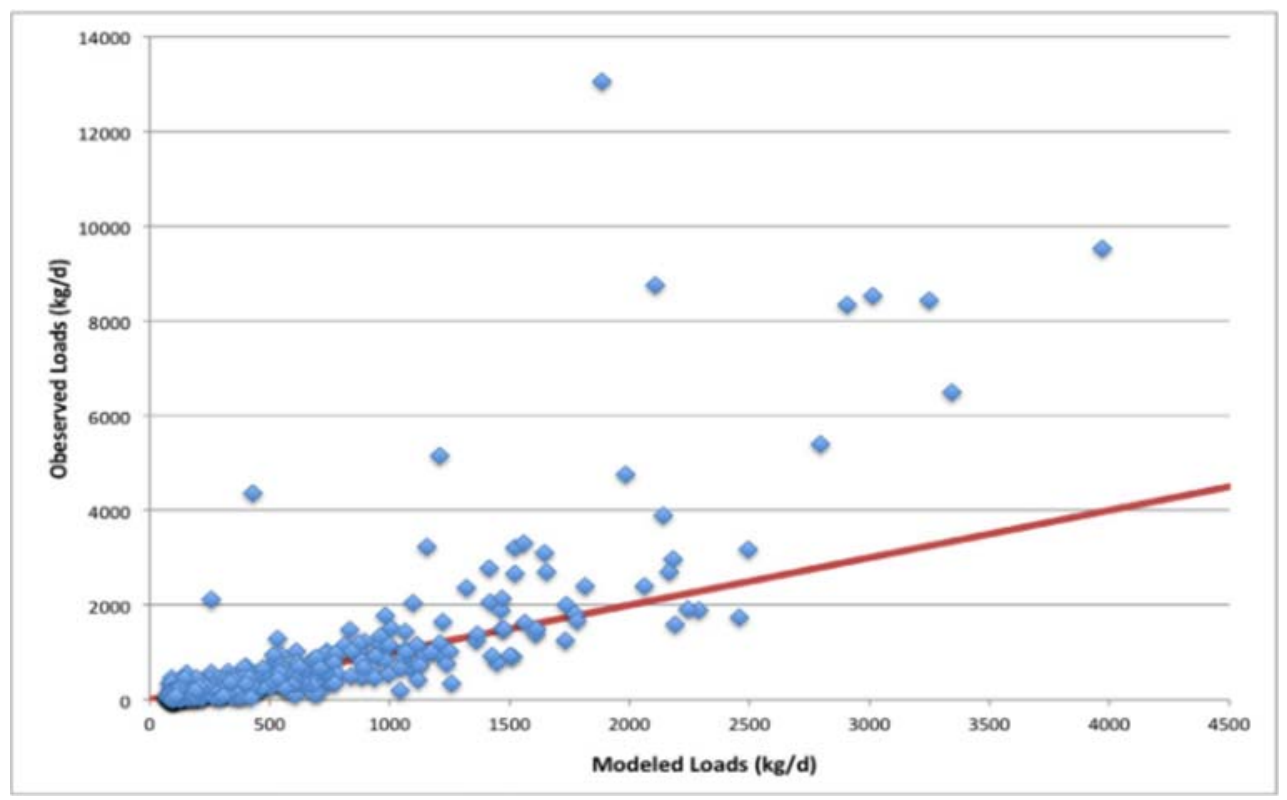


C.

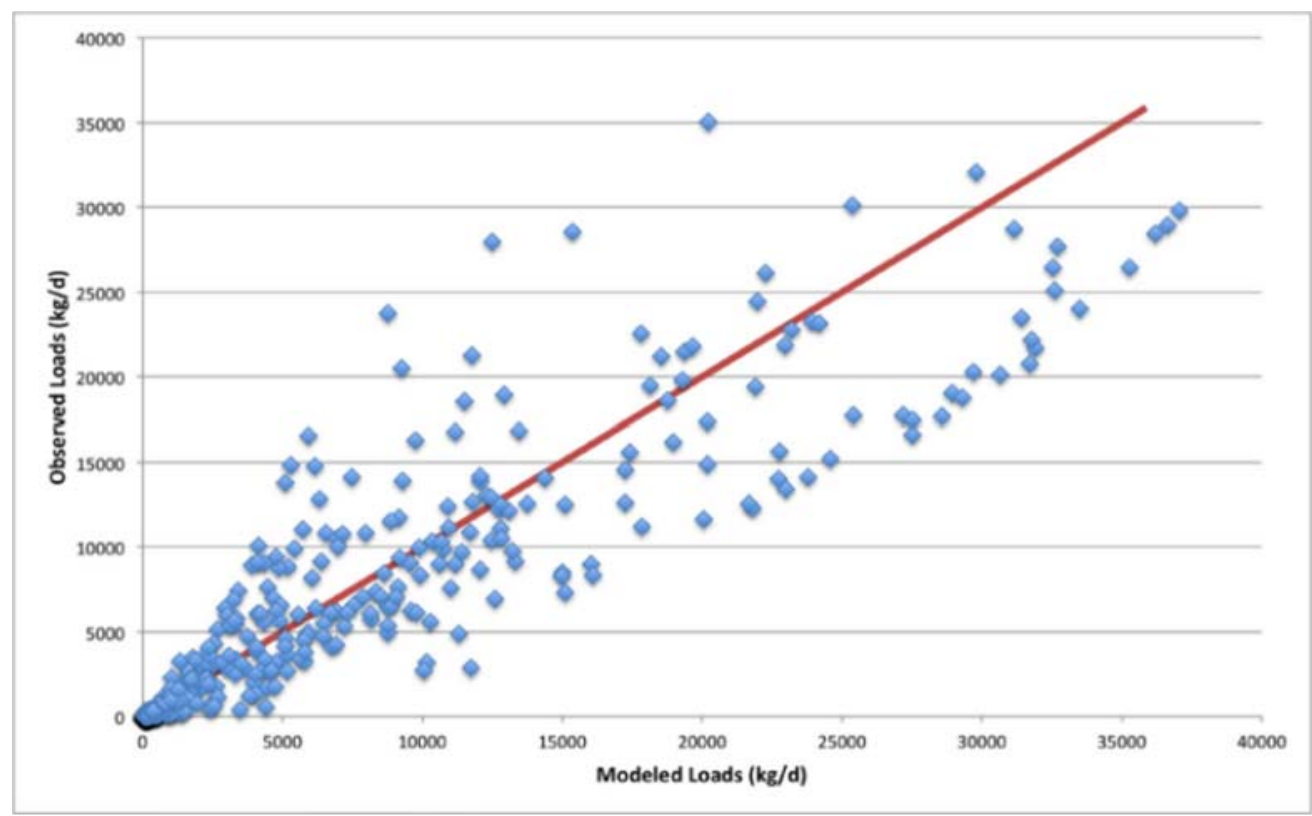

Figure 3-5: Observed load versus modeled load for a) St. Louis River b) Cuyahoga River and c) Maumee River.

\section{Changes in Discharge}

Changes in median discharges averaged across the nine selected climate projections and compared as a percent change from the simulated historical period are presented in Figure 3-6. For the majority of the nine projections, all of which are included in the overall averages, the median discharges decreased in both the near and far future periods, with the exception of projections 5 and 51 that simulate high precipitation, which translates into higher discharges. The median discharges decreased for all sites but the Au Sable site from the near to far future climate scenarios. The median discharges are predicted to decrease by as much as $70 \%$ in the Maumee watershed in projection 25 that predicts below average precipitation and temperature. However, median discharges increase by as much as $34 \%$ in the Cuyahoga in scenario 39 that predicts a wet-cool average climate.

The simulated $90^{\text {th }}$ percentile peak discharges also decrease in most of the future projections, except for projections 5 and 39 that both predict higher than average precipitation (Figure 3-7). The Au Sable site experiences increasing flows, 
while the other sites experience a decrease in peak flows (Figure 3-7). The Au Sable watershed is a highly forested watershed in the northern part of the study area with little human disturbance while the Maumee is a southern watershed that has great anthropogenic disturbance. The Au Sable watershed is predicted to have overall greater precipitation in the future as opposed to the Maumee watershed. Additionally, the increase in air temperatures is predicted to be greater in the southern part of the basin like the Maumee watershed; therefore the results indicate that the simulated evapotranspiration from a temperature increase of $1.5-3.5^{\circ} \mathrm{C}$ will offset up to a $10 \%$ increase in precipitation ultimately decreasing the discharges especially in the summer months of the CMIP3 projections. In addition as seen in Figure 3-6 and Figure 3-7, the Maumee watershed has the highest ET with the lowest runoff that becomes much greater in the future using the LBRM's temperature-proxy precipitation-ET approach. Part of the reason this basin has the highest ET is that it exhibits low baseflow and in the LBRM model much of the water is stored in the upper and lower soil layers making it readily available for ET. 


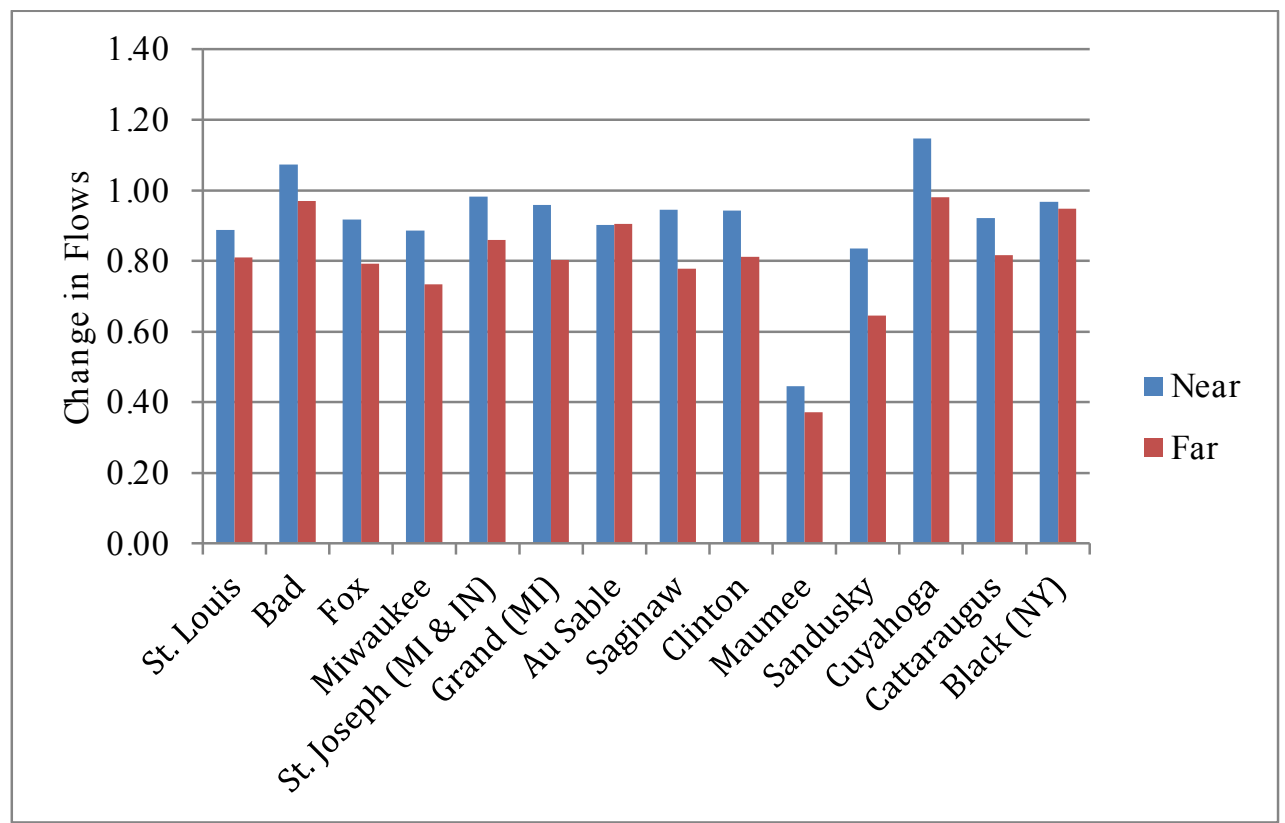

Figure 3-6: Normalized median discharges averaged over the 9 climate projections for the near and far future prediction intervals for the 14 selected watersheds. Discharges are normalized against median flows for the simulated historical period.

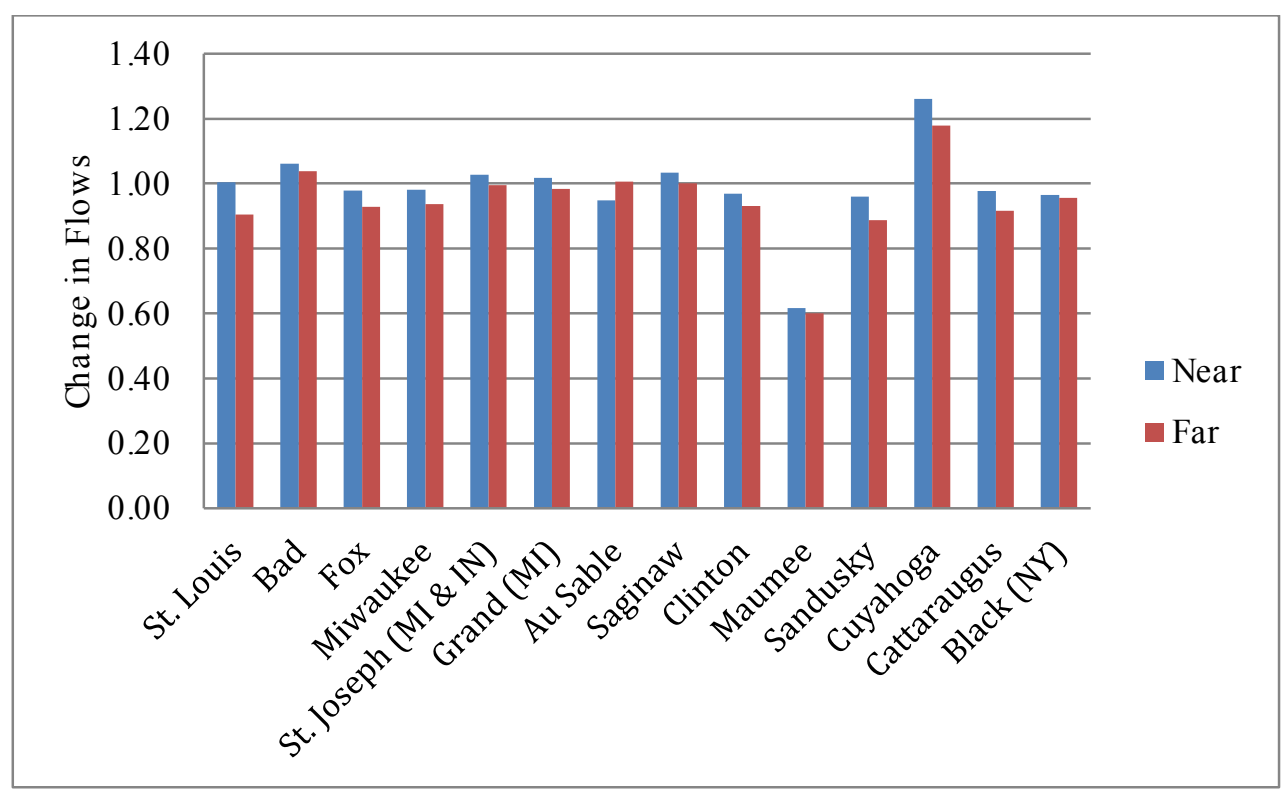

Figure 3-7: Normalized average $90^{\text {th }}$ percentile discharges over the 9 climate projections for the near and far future prediction intervals for the 14 selected watersheds. Discharges are normalized against $90^{\text {th }}$ percentile flows for the simulated historical period. 


\section{Changes in Loading}

The overall total loading for each of the simulated periods decreased for all sites for the 5 average-to-low dry precipitation projections (s10, s20, s25, s27, s33) and increased with the 4 wet precipitation projections (s5, s39, s41, s51) except the Cuyahoga, Bad, and Maumee sites (Table 3-6). Increases in total loading occurred in projection s10 for Cuyahoga and projection s33 for the Bad. These projections are the wet-cool outlier and wet-warm outlier. However, in the Maumee watershed the total loading is predicted to decrease across all nine projections. The increases in total loading for the wet precipitation projections (s5, s33, s41, s51) vary from 2 to $29 \%$ from the observed historical period. The greatest increases in total loads are in the Cuyahoga, Bad, St. Joseph, and Sandusky sites. The greatest decreases in total loading occurred in the Maumee watershed across all projections ranging from 16 to $68 \%$. The trends are similar for both the near and far future, therefore only the far future results are presented. The changes in total loading are important for future downstream eutrophication. In sites with increasing total loading, future eutrophication may be a continual ecosystem problem.

The same patterns are illustrated in changes in P loading occurring during the top $10 \%$ high flow events in the future, indicating increases in high flow loads during wet precipitation projections (s5, s39, s41, and s51) and decreasing frequency in the dry precipitation projections (Table 3-7). The sites experiencing decreases in high flow event loading for the high precipitation futures are the Cattaraugus, Black, and Maumee. These watersheds are experiencing decreases across all of the projections in the far future, ranging from 4 to $60 \%$ decrease. The Cuyahoga site has the greatest increases in storm flow loading ranging from 3 to $56 \%$ increases for all the projections. The St. Louis sites exhibits increases in storm flow loading for s5, s10, $\mathrm{s} 39$, s41, and s51, ranging from 4 to $50 \%$. This site is similar to the other modeled sites that are experiencing increases in high flow loading during the high precipitation futures. This illustrates that future climate changes could greatly alter P loading, most importantly during high flow regimes. 
Table 3-6: Changes in total load for far future simulation periods for the nine climate projections, normalized by the historical total loads. (Red indicating largest increases and blue illustrating largest decreases, with the temperatureprecipitation changes listed above each projection)

\begin{tabular}{|c|c|c|c|c|c|c|c|c|c|}
\hline \multirow[b]{2}{*}{ Site } & \multicolumn{2}{|c|}{ Warm-Dry } & \multicolumn{2}{|c|}{ Warm-Wet } & \multicolumn{3}{|c|}{ Cool-Wet } & \multicolumn{2}{|c|}{ Cool-Dry } \\
\hline & $s 20$ & $s 25$ & s5 & s33 & s39 & s10 & s51 & $s 41$ & s27 \\
\hline \multicolumn{10}{|l|}{ St. Louis } \\
\hline \multicolumn{10}{|l|}{ Bad } \\
\hline \multicolumn{10}{|l|}{ Fox } \\
\hline \multicolumn{10}{|l|}{ Miwaukee } \\
\hline \multicolumn{10}{|c|}{ St. Joseph (MI \& IN) } \\
\hline \multicolumn{10}{|l|}{ Grand (MI) } \\
\hline \multicolumn{10}{|l|}{ Au Sable } \\
\hline \multicolumn{10}{|l|}{ Saginaw } \\
\hline \multicolumn{10}{|l|}{ Clinton } \\
\hline \multicolumn{10}{|l|}{ Maumee } \\
\hline \multicolumn{10}{|l|}{ Sandusky } \\
\hline \multicolumn{10}{|l|}{ Cuyahoga } \\
\hline \multicolumn{10}{|l|}{ Cattaraugus } \\
\hline Black (NY) & & & & & & & & & \\
\hline
\end{tabular}

Table 3-7: Changes in high flow load (loads occurring during the highest $10 \%$ of flows) for far future simulation periods for the nine climate projections, normalized by the historical storm total loads. (Red indicating largest increases and blue illustrating largest decreases, with the temperature-precipitation changes listed above each projection)

\begin{tabular}{|c|c|c|c|c|c|c|c|c|c|}
\hline \multirow[b]{2}{*}{ Site } & \multicolumn{2}{|c|}{ Warm-Dry } & \multicolumn{2}{|c|}{ Warm-Wet } & \multicolumn{3}{|c|}{ Cool-Wet } & \multicolumn{2}{|c|}{ Cool-Dry } \\
\hline & $s 20$ & $s 25$ & s5 & s33 & s39 & s10 & s51 & s41 & s27 \\
\hline \multicolumn{10}{|l|}{ St. Louis } \\
\hline \multicolumn{10}{|l|}{ Bad } \\
\hline \multicolumn{10}{|l|}{ Fox } \\
\hline \multicolumn{10}{|l|}{ Miwaukee } \\
\hline \multicolumn{10}{|c|}{ St. Joseph (MI \& IN) } \\
\hline \multicolumn{10}{|c|}{ Grand (MI) } \\
\hline \multicolumn{10}{|l|}{ Au Sable } \\
\hline \multicolumn{10}{|l|}{ Saginaw } \\
\hline \multicolumn{10}{|l|}{ Clinton } \\
\hline \multicolumn{10}{|l|}{ Maumee } \\
\hline \multicolumn{10}{|l|}{ Sandusky } \\
\hline \multicolumn{10}{|l|}{ Cuyahoga } \\
\hline \multicolumn{10}{|l|}{ Cattaraugus } \\
\hline Black (NY) & & & & & & & & & \\
\hline
\end{tabular}


Changes in $\mathrm{P}$ loading across the basin ranged from increases of $51 \%$ to decreases of $74 \%$. The $51 \%$ increase in loading occurred in the Cuyahoga site for projection 5 , a wet-warm prediction. The extreme decrease in loading occurred for the Maumee site for projection 25, a dry-warm extreme prediction. These estimates of future median of the 14 sites, normalized to the historical period of 1961-1999, are presented in Table 3-8 for the far future (2081-2100). The predicted changes in P loads for the near future scenarios varied spatially across the Great Lakes Basin; however, certain patterns in changes occurred. P loads for both the L50 (median of daily loads) increased for the Cuyahoga site for half of the far future projections. The Maumee, Fox, Au Sable, and Cattaraugus sites experienced decreases in the L50 for most projections. Many other sites experienced loading increases and decreases depending on the future climate projection. The far future period exacerbated the changes that are forecast in the near future for the loads that experienced decreases. For the watersheds experiencing increases in L50 in the near future, the far future slightly decreased these increases, because in most projections there is a decrease in daily runoff from the near future to the far future. In the far future projections, the loading changes from the historical period ranged from increases of $63 \%$ to decreases of $90 \%$. The largest increase occurred in Bad site for projection 5 and the largest decrease occurring in the Maumee site for projection 25. For the majority of the sites, the loads increased or decreased depending on the projection. Overall, the median P loads are decreasing into the near and far future. 
Table 3-8: Median loads (L50) for far future simulation periods for 14 selected sites and each of the nine projections normalized against the historical median loads. (Red indicating largest increases and blue illustrating largest decreases, with the temperature-precipitation changes listed above each projection)

\begin{tabular}{|c|c|c|c|c|c|c|c|c|c|}
\hline \multirow[b]{2}{*}{ Site } & \multicolumn{2}{|c|}{ Warm-Dry } & \multicolumn{2}{|c|}{ Warm-Wet } & \multicolumn{3}{|c|}{ Cool-Wet } & \multicolumn{2}{|c|}{ Cool-Dry } \\
\hline & s20 & s25 & s5 & s33 & s39 & s10 & s51 & $s 41$ & s27 \\
\hline \multicolumn{10}{|l|}{ St. Louis } \\
\hline \multicolumn{10}{|l|}{ Bad } \\
\hline \multicolumn{10}{|l|}{ Fox } \\
\hline \multicolumn{10}{|l|}{ Miwaukee } \\
\hline \multicolumn{10}{|c|}{ St. Joseph (MI \& IN) } \\
\hline \multicolumn{10}{|c|}{ Grand (MI) } \\
\hline \multicolumn{10}{|l|}{ Au Sable } \\
\hline \multicolumn{10}{|l|}{ Saginaw } \\
\hline \multicolumn{10}{|l|}{ Clinton } \\
\hline \multicolumn{10}{|l|}{ Maumee } \\
\hline \multicolumn{10}{|l|}{ Sandusky } \\
\hline \multicolumn{10}{|l|}{ Cuyahoga } \\
\hline \multicolumn{10}{|l|}{ Cattaraugus } \\
\hline Black (NY) & & & & & & & & & \\
\hline
\end{tabular}




\section{Importance of High Flow Events}

The importance of event loading increased from 1 to $50 \%$ from the near to far futures as compared to the historical total loads. The largest increase in importance occurred for the Maumee site, where the overall loads decreased drastically, but had the storm loads accounted for a higher percentage of the total P loading (Table 3-9). This occurred even though the storm load total decreased into the future. The increase in relative storm loading was seen in all the sites except the Black and Bad. The Black site is forecasted to have a decrease in the relative importance of storm loads on the total loads for all of the projections except s10 and s25. Otherwise, these results indicate a shift in the relative importance of storm P loading into the future (Table 3-9) for many of the modeled. This information is critical for use in nutrient management and understanding loading trends.

Table 3-9: Changes in percentage of high flow load to total load for far future simulation periods for the nine climate projections, normalized by the historical total loads. (Red indicating largest increases and blue illustrating largest decreases, with the temperature-precipitation changes listed above each projection)

\begin{tabular}{|c|c|c|c|c|c|c|c|c|c|}
\hline \multirow[b]{2}{*}{ Site } & \multicolumn{2}{|c|}{ Warm-Dry } & \multicolumn{2}{|c|}{ Warm-Wet } & \multicolumn{3}{|c|}{ Cool-Wet } & \multicolumn{2}{|c|}{ Cool-Dry } \\
\hline & $s 20$ & s25 & s5 & s33 & $s 39$ & s10 & s51 & $s 41$ & s27 \\
\hline \multicolumn{10}{|l|}{ St. Louis } \\
\hline \multicolumn{10}{|l|}{ Bad } \\
\hline \multicolumn{10}{|l|}{ Fox } \\
\hline \multicolumn{10}{|l|}{ Miwaukee } \\
\hline \multicolumn{10}{|c|}{ St. Joseph (MI \& IN) } \\
\hline \multicolumn{10}{|c|}{ Grand (MI) } \\
\hline \multicolumn{10}{|l|}{ Au Sable } \\
\hline \multicolumn{10}{|l|}{ Saginaw } \\
\hline \multicolumn{10}{|l|}{ Clinton } \\
\hline \multicolumn{10}{|l|}{ Maumee } \\
\hline \multicolumn{10}{|l|}{ Sandusky } \\
\hline \multicolumn{10}{|l|}{ Cuyahoga } \\
\hline \multicolumn{10}{|l|}{ Cattaraugus } \\
\hline Black (NY) & & & & & & & & & \\
\hline
\end{tabular}

To further examine how climate change may impact P loads especially during high loading events, three sites that exhibited prototypical changes are further examined: Cuyahoga, Maumee, and St. Louis sites. Each of these sites experienced 
different types of changes in loadings for both the near and far future and exhibit different dominant land uses.

The median and high-flow loadings for the Cuyahoga site increased for all the projections except projections of 20 and 15, with the lowest predicted discharges. In the near future, the Cuyahoga will experience increases in loading ranging from 28 to $52 \%$ for peak loads and -9 to $+30 \%$ for median loads (Table $3-8$ ). The Cuyahoga site will not only have an increase in total loading, but the percentage of loading from the highest $10 \%$ of events will also increase from 7 to $30 \%$ (Table 3-9). Thus, this watershed will exhibit greater extreme $\mathrm{P}$ loading events in the future regardless of the future climate projection. These results provide evidence that these extreme flows will alter the $\mathrm{P}$ dynamics in an already human-altered watershed. The Cuyahoga is the only site of the 14 selected that experienced total loading increases in the future for all climate projections.

The Maumee site is predicted to experience the opposite effects in the future as the Cuyahoga site. The Maumee site should experience a decrease in total loading ranging from 36 to $90 \%$ for the near and far future in both peak and median loads (Table 3-8) The percentage of the total load contributed by the high flow P loading events will increase the greatest of the modeled sites, from 16-50\% (Table 3-9) with the overall storm flow loading decreasing from 6 to $55 \%$. The extreme event flows dominated the P loading for the Maumee site historically with 50\% of the total loading occurring in the top $10 \%$ of the high flow events. The Maumee site will experience decreases in loads, but will have a greater percentage of $\mathrm{P}$ delivery coming from the storm events. This is important in understanding $\mathrm{P}$ and eutrophication dynamics in a significantly human-altered watershed with very high loads. Potential changes in climate, based on any projection, will alter extreme P loading events that could hinder nutrient management.

Most of the other sites experienced increasing and decreasing loads depending on the simulated projections. These changes are demonstrated for the St. Louis site. The St. Louis site generally experienced increases in peak loads and decreases in 
median loads. For example, this site experienced an increase of $29 \%$ in peak loads and a $2 \%$ decrease in median loads in projection 5 . The overall total loading also decreased for most of the climate projections from many other sites including the Bad, Milwaukee, St. Joseph, Grand, Clinton, Saginaw, and Sandusky sites. All of these sites, except the Black site, exhibited increasing relative importance of high flow loading events on the total P load in the far future (Table 3-9), while the overall total load decreases except for the Cuyahoga site.

The potential increases from four of the climate projections in the extreme $\mathrm{P}$ loading events will only exacerbate the nutrient dynamics problems within the Great Lakes, especially in the sites experiencing increases in storm loading totals such as the Cuyahoga, St. Louis and Bad. Understanding the importance of high flows events is useful for designing management actions to manage nutrient dynamics. The increase in percentage of $\mathrm{P}$ loading during high flow events may have significant impacts on future water quality. This increase may cause greater cultural eutrophication in the already vulnerable sites including the Cuyahoga, Maumee, Saginaw, Sandusky, St. Joseph and Clinton. Most of these selected sites will experience an overall decrease in total loadings but an increase in the relative importance of high flow loads in the future. These high flow events generally occur during specific seasons, which can be seen through this seasonal regression analysis.

\subsection{Discussion and Summary}

Limited work has been done trying to determine how climate change may affect nutrient loading, especially in the Great Lakes Basin. This study presents a unique combination of climate model output, runoff models, and load-discharge regression models to simulate future P loads for 14 sites in the Great Lakes Basin for 1961-1999, 2046-2065 and 2081-2100. Simulating the effects of nine climatic projections predicting, including wet-warm or wet-cool future conditions altered discharges and loading. Discharges and loads were found to generally decrease in the future under the warm-dry scenarios, whereas high flow discharges and loads were found to increase in wet-cool and wet-warm scenarios. . The use of seasonal 
regression models allowed us to isolate different load-discharge relationships during the year. The seasonality of the models provided evidence of how changes in high flow events will affect overall loading in watershed ranging from predominantly forested to highly human-altered.

The effects of future simulations of how climate-induced changes in discharge on loading in the 14 selected sites in the Great Lakes Basin indicate that climate change will have consequences on P loading, especially an increase during high flow loading events. Sites, such as the Cuyahoga and St. Louis may experience increases in high flow loading events for the high precipitation projections. However the Maumee site will experience decreases in total and storm loading for most of the simulated projections. Mitigation policies may be useful to focus on reducing the impacts of climate change through changes on the structure of the watershed, including land use management through the creation of buffer systems on agriculture land to pervious pavement in urban land to increase the retention of $\mathrm{P}$, ultimately increasing the resilience of the system. The relative importance of storm loading to total loading is expected to increase for all of the sites. This increase in relative importance of storm events suggests that many watersheds may be vulnerable to extreme flushing events, which is important for developing mitigation actions for the Great Lakes.

This analyses used in this study are subject to limitations that may affect future loading dynamics. Some of the regression models underestimated loading during high flow events. This limitation would then suggest that the results presented here may under-predict the importance of $\mathrm{P}$ loads during future high loading events. While the regression models reflect the dynamics of load-discharge interactions for individual sites, these interactions may not remain static as the climate changes. For example, longer dry periods, where $\mathrm{P}$ may accumulate after fertilizer or manure applications, followed by intense rainfall events may result in increased P loads. The reverse situation could also occur when there are shorter periods of dry weather followed by intense rainfall, which will wash away soil and fertilizers also resulting in increasing $\mathrm{P}$ loads. 
The LBRM runoff model used in this work may overestimate the effects of increasing temperatures on evapotranspiration, leading to underestimation of discharges, especially for climate scenarios that predict larger temperature increase. The LBRM model uses temperature as a proxy for evapotranspiration. Using temperature as a proxy may have overestimated the evapotranspiration causing a decreased flow, especially during the warmer months. Improved runoff models may predict higher discharges, likely resulting in predictions of future increases in P loads in more areas rather than for the small number of areas predicted here. The approach used here ignores the potential for land use change in the basin. According to LaBeau et al. (in review) urbanization and expansion of biofuel crop cultivation are likely to cause increased $\mathrm{P}$ loads in many of the watersheds simulated in this work, due to increased $\mathrm{P}$ inputs. These changes are also likely to change the load-discharge relationships.

While there are limitations to the modeling approach used in this study and climate predictions must be viewed as uncertain; however, this work points to watersheds that may be the most vulnerable to the most likely trajectories of climate change in the Great Lakes Basin. This work reports on expected impacts of climate change on P loads for 14 out of roughly 200 similarly sized watersheds in the Great Lakes Basin. However, similarities can be drawn between the watersheds simulated here and other watersheds in the basin, to allow for at least qualitative predictions elsewhere.

\subsection{Acknowledgments}

This work was supported by award CBET- 0725636 from the National Science Foundation. The authors would like to thank David Saad from the USGS Wisconsin Science Center for data and discussions regarding P loading. 


\section{Phosphorus Monitoring in the U. S. Portion of the Laurentian Great Lake Basin: Drivers and Challenges ${ }^{3}$}

\subsection{Introduction}

The Laurentian Great Lakes Basin is home to a vast human population and ecosystem with competing demands for land and water, giving rise to concerns associated with resource health and sustainability. One major ecosystem health issue is the eutrophication of the Great Lakes, which is caused largely by increased loadings of nutrients, most notably phosphorus. $\mathrm{P}$ is delivered to the streams that drain the surrounding watersheds, which are home to urban centers, agricultural lands, and extensive forests. According to the International Joint Commission (IJC), these watersheds are being subjected to numerous stressors, including land use and climate change (54), potentially resulting in greater quantities of phosphorus entering the lakes because of increased stream flow flashiness, decreased soil infiltration rates, and greater soil erosion (55).

Currently, researchers characterize and predict phosphorus tributary loadings to the Great Lakes in regions across the U.S. by using statistical estimators including the Beale's ratio estimator (117) and deterministic models such as SPARROW (Spatially Referenced Regressions on Watershed Attributes) (15)(78)(118) and ECOFORE (Ecological Forecasting in Lake Erie) with uses a deterministic tributary model SWAT (Soil Water and Assessment Tool) and the Distributed Large Basin Runoff Model (119)(120). In general, these deterministic watershed models use attributes (such as nutrient application rates, land use patterns and precipitation rates) to predict the phosphorous loading of streams, whereas the statistical models estimate loads using the raw tributary monitoring data. However, for reliable estimates, deterministic models must be calibrated using actual measurements of phosphorous concentrations.

In the process of calibrating the deterministic Upper Midwest SPARROW watershed model Robertson and Saad (2011) assembled P concentration data and

\footnotetext{
${ }^{3}$ Most of the material contained in this chapter has been submitted to the Journal of Great Lakes Research.
} 
streamflow data for all sites with available information from 1970 to 2006 . In addition, Dolan and Chapra (2012) utilized P concentrations data and streamflow data from similar sources as SPARROW utilizing government databases and data retrieved directly from the monitoring agencies from 1967 to 2008 . Both of these models use similar raw data to develop tributary P loading estimates. For the SPARROW model, the final dataset for sites with sufficient data to compute P loads had 128 sites throughout the Great Lakes Basin (Figure 4-1), which was utilized in this study to develop potential monitoring stakeholders for interviews. The current Upper Midwest SPARROW model does not cover the Canadian portion of the Great Lakes basin but is currently integrating the data in an updated model.

This analysis utilizes the major 128 tributary water quality monitoring stations, employed by SPARROW and the loading analysis of Dolan and Chapra. These stations generate data for the majority of the Great Lakes Basin that represent a crucial piece of infrastructure for environmental managers and researchers interested in the effects of phosphorus loading on the ecology of the Great Lakes. Indeed, the value of statistical and deterministic models depends, in part, on the quality of data generated by this tributary water quality monitoring network. Given the importance of this network to current and future researchers, this paper examines the factors associated with the establishment and maintenance of phosphorus monitoring programs and the challenges that agencies face in operating and maintaining these programs for use in estimating loads and predicting P loading effects. 


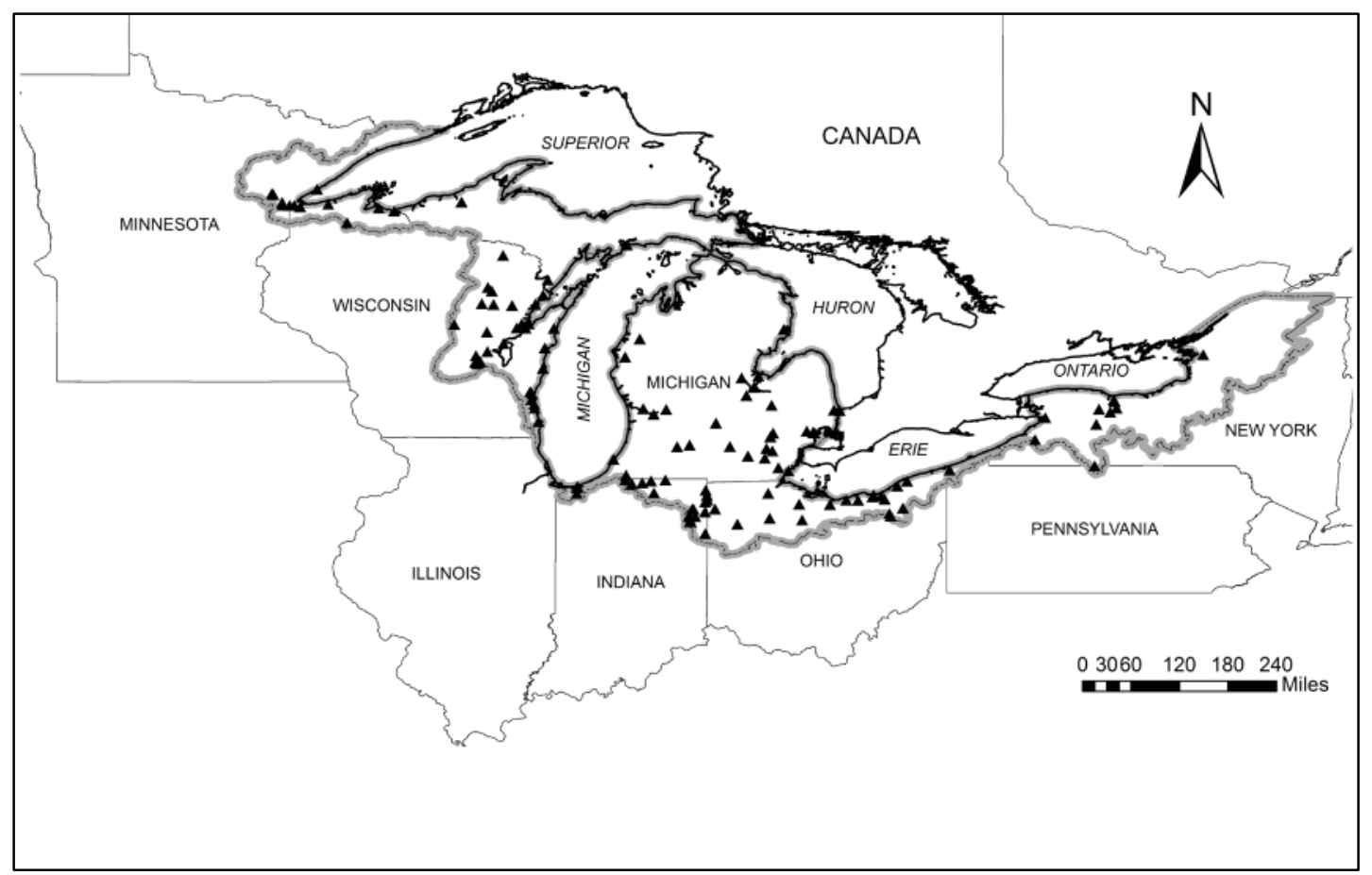

Figure 4-1: The Great Lakes States and Long-Term Water Quality Monitoring Sites used in SPARROW with the Great Lakes Basin outlined in grey (Figure created by author using data from (7)(62)).

\subsection{Background}

The regulation of water resources in the Laurentian Great Lakes began in 1909 with the Boundary Waters Treaty between the U.S. and Canada (122), which regulated water levels and flows for generation of electricity. This treaty established the International Joint Commission (IJC), an agency that represents both U.S. and Canadian interests on the policy, science and management of international waters, including the Great Lakes.

Interest in phosphorus first emerged in the mid-1960s because of concerns associated with the corresponding anoxic conditions and eutrophication of the rivers and lakes, especially Lake Erie. At that time, detergents in the U.S. contained about $10 \%$ phosphorus (123) and researchers identified that as a significant concern.

According to (124), one kilogram of phosphorus can facilitate the growth of 700 kilograms of algae, and around 9,000 kg of phosphorus per day was entering Lake Erie 
in the late 1960s. This flux of detergent-based phosphorus had many detrimental, linked effects on the Great Lakes ecosystem, including excessive algal growth, anoxic water conditions, deterioration of fisheries, and drinking water taste and odor problems $(15)(31)(125)(126)(127)(128)(129)(130)(131)$.

Driven by the effects of the P-based eutrophication in Lake Erie and the growth in competing demands for water resources, the U.S. and Canada signed the Great Lakes Water Quality Agreement (GLWQA) in 1972 (122). Among other things, the GLWQA initiated a coordinated effort to reduce phosphorus inputs into the Great Lakes. This agreement established guidance on the regulation of water quality called for the creation of a detailed management plan for the Great Lakes and began the process of estimating acceptable loadings of $\mathrm{P}$ and other pollutants and tracking the fate of the P released in the Great Lakes Basin.

A 1978 amendment to the GLWQA established target phosphorus loadings for the Great Lakes (28) (132), shown in Table 4-1 (133). The target loading rates for each Great Lake were based on current and historical phosphorus concentrations in the lakes and their desired trophic state designations and were developed as a guide to the U.S. and Canadian governments for enacting phosphate detergent limits and municipal wastewater effluent limits while managing diffuse phosphorus sources. 
Table 4-1: 1976 and Target Phosphorus Loads for the Great Lakes (133).

\begin{tabular}{ccc}
\hline Lake Basin & $\begin{array}{c}\text { 1976 P Load } \\
\text { (metric tons/yr) }\end{array}$ & $\begin{array}{c}\text { Target P Load } \\
\text { (metric tons/yr) }\end{array}$ \\
\hline Lake Superior & 3,600 & 3,400 \\
Lake Michigan & 6,700 & 5,600 \\
Main Lake Huron & 3,000 & 2,800 \\
Georgian Bay & 630 & 600 \\
North Channel & 550 & 520 \\
Saginaw Bay & 870 & 440 \\
Lake Erie & 20,000 & 11,000 \\
Lake Ontario & 11,000 & 7,000 \\
\hline
\end{tabular}

The target phosphorus loading estimates were derived using a mass balance model, not deterministic models like SPARROW, in which the lake-wide phosphorus concentrations were calculated by computing the differences between the inputs and outputs of phosphorus to and from the lakes (117) (134) (135). Inputs corresponded to phosphorus loads entering the lakes from the basin's tributaries, atmosphere, and point sources (136). Researchers estimated these loads from P concentrations and stream discharge data collected by monitoring programs sampling key tributaries in the late 1970s and throughout the 1980s and atmospheric deposition of phosphorus and phosphorus point sources contribution.

Conditions in Lake Erie improved in the 1970s because of limitations on phosphorus content in detergents, best management practices on agricultural land and improved wastewater treatment. The GLWQA and the 1972 Clean Water Act (CWA) developed actions to improve $\mathrm{P}$ export that drove nutrient loading changes including monitoring, point source pollution reduction and improving agricultural practices. Through these actions, the reduction in phosphorus load was rapid, resulting in a $60 \%$ 
reduction in phosphorus loading to Lake Erie by the early 1980s reducing eutrophication and algal blooms (137).

In the early 1990s, researchers ceased making loading estimates for the lakes, with the exception of a few estimates on Lake Erie and Lake Michigan because the U.S. and Canadian governments decreased their support for monitoring tributaries and reporting results on a lake-wide basin was no longer a priority. Much of this data is needed for continued load estimates were still being collected but at many sites at a reduced frequency. The streamflow data was not affected by this decrease, only the $\mathrm{P}$ concentration data, making it difficult to accurately estimate phosphorus loads from Great Lakes tributaries (15)(138). Therefore, it was difficult to estimate lake loadings and disturbances to the ecosystem. One of the remaining continuous data collection programs in the tributaries of the western basin of Lake Erie, National Center for Water Quality at Heidelberg College, suggested that in the late 1990s, the phosphorus loadings, particularly dissolved phosphorus, were increasing (56)(139)(140) and the summer blooms of algae returned to western Lake Erie with increases of harmful algae in the 2000s (141).

Given the increased incidence of algal blooms in Lake Erie and the other lakes and concerns associated with future land use and climate change, the $12^{\text {th }}$ Biennial Report on the Great Lakes Water Quality (IJC) calls for improved phosphorus monitoring from point and non-point sources to determine the contributions of external loads (132). Several researchers have commented on the need for increased spatial and temporal resolution in phosphorus monitoring and collecting samples over a range of streamflows, especially during high-flow events $(56)(57)(58)(59)(60)(61)(62)$ to increase the accuracy of trend and load analyses. Water quality monitoring is vital for most models for determination of current loads and trends, and the development of future predictions based on expected changes in the landscape and climate within the Great Lakes Basin. According to (62), if the current trends in monitoring funding continue, available data for the development of regional loading models will decrease. 
Here, we examine the challenges associated with maintaining a network of tributary phosphorus monitoring sites in the Laurentian Great Lakes. To understand the historical, current, and future status and trends in water quality monitoring within the Great Lakes Basin, we investigated why and how agency stakeholders develop, manage, and fund tributary water quality monitoring programs. Our primary objective was to better understand the practice of phosphorus monitoring in the Great Lakes Basin and to identify potential ways to improve the ability of the existing tributary network to generate data useful for researchers interested in lake-wide flows of phosphorous.

\subsection{Materials and Methods}

To examine the factors and challenges associated with maintaining a tributary monitoring network, we conducted stakeholder interviews with representatives of monitoring agencies in the Great Lakes Basin operated by state, federal, university or private organizations in February through April of 2012. Several of the sites have been sampled by multiple agencies; in those cases, we identified the site with the agency that collected the most water quality samples. We focused on identifying and assessing the primary factors that influence management of monitoring in the basin. There are other monitoring agencies in the U.S. Great Lakes Basin that were not included in this research including Green Bay, Milwaukee and Chicago Metropolitan Sewage Districts', as they were not included this analysis due to limited data collection with high detection limits. At each site, the sampling agency and type of collection record (continuous, intermittent, or ceased) were documented for further analysis. Many of the sites within the Great Lakes Basin ceased collecting in the late 90s to early 2000s. The categorical sites were then used to develop and identify the interviewed institutions in Table 4-2, which also includes the number of active sites in each tributary monitoring network. 
Table 4-2: Interviewed Organizations

\begin{tabular}{|c|c|c|c|c|c|}
\hline State & $\begin{array}{c}\text { Miles of } \\
\text { Great Lakes } \\
\text { Shoreline }^{\mathrm{a}}\end{array}$ & Organization & $\begin{array}{l}\text { Number of } \\
\text { Sites } \\
\text { Operating } \\
\text { 1975-2002 }\end{array}$ & $\begin{array}{l}\text { Number of } \\
\text { Sites } \\
\text { Continuing } \\
\text { after } 2005\end{array}$ & $\begin{array}{c}\text { Number of } \\
\text { Average } \\
\text { Observations } \\
\text { per Site }\end{array}$ \\
\hline \multirow[t]{2}{*}{ Ohio } & 312 & $\begin{array}{c}\text { Heidelberg } \\
\text { College Center for } \\
\text { Water Quality } \\
\text { Research } \\
\text { (Heidelberg) }\end{array}$ & 8 & 7 & 9000 \\
\hline & & $\begin{array}{c}\text { Ohio } \\
\text { Environmental } \\
\text { Protection } \\
\text { Agency (OHEPA) }\end{array}$ & 11 & 1 & 180 \\
\hline Indiana & 45 & $\begin{array}{c}\text { Indiana } \\
\text { Department of } \\
\text { Environmental } \\
\text { Management } \\
\text { (INDEM) }\end{array}$ & 24 & 19 & 220 \\
\hline Michigan & 3,052 & $\begin{array}{c}\text { Michigan } \\
\text { Department of } \\
\text { Environmental } \\
\text { Quality (MIDEQ) }\end{array}$ & 32 & 7 & 210 \\
\hline Minnesota & 189 & $\begin{array}{c}\text { Minnesota } \\
\text { Pollution Control } \\
\text { Agency and } \\
\text { Western Lake } \\
\text { Superior Sanitary } \\
\text { District } \\
\text { (MNPCA) }\end{array}$ & 8 & 7 & 270 \\
\hline New York & 408 & $\begin{array}{l}\text { New York State } \\
\text { Department of } \\
\text { Environmental } \\
\text { Conservation } \\
\text { (NYDEC) }\end{array}$ & 9 & 6 & 350 \\
\hline Wisconsin & 820 & $\begin{array}{c}\text { USGS }^{c} \\
\text { Wisconsin Water } \\
\text { Science Center } \\
\text { and Wisconsin } \\
\text { Department of } \\
\text { Natural Resources } \\
\text { (WIUSGS \& } \\
\text { WDNR) }\end{array}$ & 34 & 24 & 330 \\
\hline
\end{tabular}




\begin{tabular}{|c|c|c|c|c|c|}
\hline \multirow[t]{2}{*}{ Pennsylvania } & 51 & $\begin{array}{c}\text { Pennsylvania } \\
\text { Department of } \\
\text { Environmental } \\
\text { Quality }\end{array}$ & 2 & 0 & 150 \\
\hline & & $\begin{array}{l}\text { Total Long Term } \\
\text { Sites }\end{array}$ & 128 & 53 & \\
\hline $\begin{array}{l}\text { US Great } \\
\text { Lakes }\end{array}$ & 4,940 & $\begin{array}{l}\text { USGS (United } \\
\text { States Geological } \\
\text { Survey): Great } \\
\text { Lakes Restoration } \\
\text { Initiative (GLRI) } \\
\text { Monitoring } \\
\text { Program }\end{array}$ & $30^{\mathrm{b}}$ & 30 & \\
\hline
\end{tabular}

\footnotetext{
${ }^{a}$ Shorelines of the Great Lakes (www.michigan.gov/deq)

${ }^{\mathrm{b}}$ In the past managed by USGS via state, may overlap with state-by-state counts

${ }^{\mathrm{c}}$ United States Geological Survey
}

The interviews, which were recorded and transcribed, consisted of ten multi-part, open-ended questions designed for programs that had continuous, intermittent, and ceased monitoring sites (questions are listed in the Appendix). The interviews were conducted with program managers, coordinators or directors of the tributary monitoring programs who had intimate knowledge of the monitored sites, program goals, and program needs.

With the exception of Heidelberg College Center for National Water Quality program (HCC) all of the interviewed agencies were government agencies. HCC is a private non-governmental program that relies on a combination of non-governmental and governmental funds to maintain their monitoring network. The state and federal programs, with the exception of the Great Lakes Restoration Initiative (GLRI) Monitoring Program (GRLI) network and the Wisconsin Department of Natural Resources' (WDNR) Lake Michigan Monitoring program, were geared toward state selection of sites, not specific Great Lakes sites or programs. The GLRI is a federal investment, with funding from 2010-2014, in the Great Lakes that addresses urgent issues including protecting nearshore health and wetlands from pollution, cleaning up toxic areas and coordinates with strategic partners (142). The interviews were based on 
the general tributary water quality monitoring program of the agencies that included a suite of measured parameter including phosphorus. Therefore, the interviews focused mainly on programmatic tributary monitoring issues at the agency level instead of the Great Lakes level, suggesting that the tributary monitoring networks do not emphasize Great Lakes water quality but meeting the demands of the Clean Water Act.

\subsection{Results}

The results of the interviews are presented in four sections. First we describe the reasons for the original establishment of the tributary water quality monitoring programs. We then examine and summarize the challenges and concerns of the water quality monitoring programs throughout the basin. Next, we explore the future outlook of monitoring programs in the basin. Finally, we address the main organizational components of phosphorus monitoring in the Great Lakes region. These components focus on the core requirements for developing and maintaining a long-term program without data gaps.

\section{Rationales for Establishing Water Quality Monitoring Programs}

Six out of the nine stakeholders interviewed stated that their program's original impetus for developing monitoring programs was a combination of the passage of the Clean Water Act, with many of the states tributary monitoring program beginning in 1960s. The Clean Water Act requires states to characterize their waterbodies of the state, many of which had phosphorus pollution problems. In addition, the GLWQA added importance to tributary monitoring by setting specific water quality goals to restore and maintain the waters of the Great Lakes Basin. The CWA set standards for water quality objectives used by the state programs. For many programs, phosphorus tributary monitoring started because of the need to quantify point source impacts (MIDEQ, OHEPA, INDEM (Table 4-2)), primarily associated with detergents from wastewater effluent for reporting to the U.S. EPA. 
The state agency programs are required to characterize the status of their rivers and streams twice a year by the CWA. The characterization involves measuring a suite of water quality constituents in order to monitor, assess, and facilitate the protection and restoration of the designated uses (CWA) of all waters of the state. Most of the programs (five of the nine) selected their sites to "provide a broad spatial coverage over a range of land coverage and ecotypes for the purpose of assessing conditions and trends... and also sites were selected in conjunction with a USGS flow gaging station" (WIUSGS) so loads could be determined. Additionally, the programs chose sites that were major contributors of flow "to document the water quality for a certain percent of surface water...thereby picking them for size" (WDNR). However, many programs (four out of nine) have seen the number of sites diminish through the past four decades. Most of these changes were due to funding issues (MIDEQ, OHEPA, WIUSGS, NYDEC). Over the years, these programs developed their own state monitoring goals, as funding decreased. With the decrease in funding, many of the state programs devolved into state policy objectives driven by the needs of the CWA, which was to assess the conditions of their state waters, not the Great Lakes. These new policy objectives drove tributary monitoring programs to decrease collection frequency and develop new rotation monitoring programs to characterize their rivers not the Great Lakes. This change in objectives into the late $80 \mathrm{~s}$ and $90 \mathrm{~s}$ really altered the amount of tributary monitored data collected.

Unlike the state programs, the USGS tributary monitoring program, starting the 1970s, completed sampling on Great Lakes rivers as a part of the National Surface Water Quality Assessment Program, which was not driven the by Clean Water Act. This program was a nationally funded project to sample a number of key tributaries that were major contributors of flow to the Great Lakes for the assessment of trends and loads (WIUSGS). The constituent monitoring at these sites decreased in the mid90s and then many were completely discontinued due to changes in the funding priority of the USGS. 
Then, the USGS-GLRI tributary monitoring program was developed to begin to monitor these rivers again, but not in response to a major policy act for water quality; instead part of the Great Lakes Research Initiative (GLRI) funds were directed to document the status of the water quality of the tributaries to the Great Lakes and quantify changes as a result of actions taken in the basin. GLRI monitoring is directed by the USGS in cooperation with several state agencies. The GLRI funding "gave us the opportunity to implement a tributary monitoring program as a part of the National Monitoring Network ... and give a real world example of how to operate these multistate sites around the Great Lakes." The National Monitoring Network developed a framework for potential monitoring sites, which includes a list of constituents to measure, and recommendations on the frequency of sample collection. USGS-GLRI note that "monitoring is essential to figure out the processes and changes that are happening at these sites in the Great Lakes Basin" (USGS-GLRI) which drives the goals of this monitoring program.

Heidelberg College's program began in 1969 as an educational project, with the early program goal being to "conduct and develop accurate mass balance calculations for P sources going into Lake Erie.... and see what benefits came from point source removal." In 1981, the mission of the monitoring program shifted to include a broader assessment of the contributions of both point and non-point sources in the watersheds of western Lake Erie. The current purpose of the monitoring program "is to minimize the adverse impacts of agriculture on water resources in our area; streams and rivers into Lake Erie...recognizing the importance of food production and agriculture as a major industry in this area, but also monitoring the large economic consequences from the nutrients entering the lake Erie ecosystem" (Heidelberg). The Heidelberg program has been able to continue to monitor throughout the 90 s to the present when many programs monitoring sites began to reduce sampling frequency and sites. This program continues because of their ability to find funding from multiple funding sources including federal, state and private sources including the fertilizer and agricultural industry. Additionally, this program is 
one of the remaining continuous tributary data collection programs in the western basin of Lake Erie.

\section{Concerns and Challenges}

All interviewees stated that tributary monitoring programs must have many different actors to effectively characterize and sample rivers and streams; these include sample collectors, site managers, laboratory specialists, quality control specialists, computer database supporters and scientists who can analyze data trends and impacts of water quality on beneficial use impairments. One challenge for these programs is the need to develop and manage this organizational structure. Here, we use the term organizational structure to describe the staff, staff capabilities, and infrastructure required to maintain a sampling program at the monitoring site, the services of an analytical laboratory, and a process for analyzing and disseminating the data that is generated. A tributary water-monitoring program requires a complex structure to complete all phases of monitoring, data integration and dissemination, and assessment. First, staff and equipment are required to collect the chemical samples and measure or obtain streamflows. The sample must go through laboratory analysis to quantify the phosphorus concentrations, which requires a certified laboratory and chemists. The quantified sample is either recorded in an internal database and/or submitted to a central federal or state database for dispersal to the data customers. Once the samples are analyzed, some programs utilize scientific techniques to determine trends and nutrient loading.

The Heidelberg program illustrates the challenges faced by organizations in collecting and processing data. At each monitoring site three samples are collected per day. These samples must be retrieved by a technician and brought to the organization's laboratory for processing. The equipment also has to be maintained on a regular basis. The two technicians and one lab manager who perform these tasks also are responsible for moving "the data from the analytical equipment into the computers." Each step in the monitoring process, especially at Heidelberg, which collects daily samples, 
requires experienced staff personnel to effectively collect, analyze, and handle the phosphorus data.

Many agencies lack a sufficient number of personnel to maximize the value of the collected information. Five out of the 9 state agencies stated that difficulties in calculating loads and trends were the largest challenge associated with monitoring programs. According to MIDEQ, the major challenge is "really maximizing the value of information collected... it has been a challenge to really integrate across the media to get a comprehensive picture of what monitoring is telling us." To effectively meet this demand, more staff time is required to summarize data, develop cross-links and maximize the utility of this wealth of data. In addition, the Indiana interviewee also stated that we "currently lack the staff resources to fully utilize these data and to explore different methods for determining trends." All of these responses suggest that adequate funding and large organizational structures are required to maximize the utility of the data.

There are also challenges with making the data available and accessible to external researchers. Phosphorus water quality data are stored in and made accessible through the USGS centralized water database National Water Inventory System (NWIS) and EPA's water quality database housing state data, (STORET), and through specialized state level and private agencies' web services systems. Most of the states "load our chemistry data to the EPA national data warehouse" (NYDEC) or to the USGS NWIS database (WIUSGS \& USGS-GLRI). The federal databases enable site, state, and watershed specific analysis, but not all programs upload their data into these databases. Most of the state's load their chemistry data into STORET, but the data are not available for many years after it is was collected, therefore making STORET only useful for retrospective analyses. According to MIDEQ, making data accessible is "always a challenge... but we have a state system in place where people can actually access the data...that are more user friendly than STORET." The Heidelberg program makes "all the data available on the website and (they) have an analytical template that you can download and do exploratory analysis." Each of these programs 
store phosphorus data for the Great Lakes region in different databases. Therefore data users, such as researchers, spend an inordinate amount of time collecting data from various state, federal and private databases. Although there is a new data portal is operating to provide a common access site for integrated water - quality analysis (Water Quality Exchange (WQX))), that should ease in the collection of data from federal, state, tribes and other organizations (142). This tool was not discussed by any of the monitoring organizations.

Interviewees suggest that there is minimal organizational connection between state tributary monitoring programs. Most programs collect data required to fulfill its particular missions, which are not all the same. There have been other efforts within agencies to collect data throughout the basin for estimating background loads and concentrations (14)(15), but not to develop a regional monitoring network. Currently though, the USGS-GLRI program is coordinating a multi-state effort to link the tributary monitoring stations within various states together for a holistic look at the Great Lakes Basin. The USGS-GLRI program illustrates the need within this complex network to "convince cooperators (partners, other agencies) of the value of the multistate monitoring program" (USGS-GLRI) and connect the various tributary monitoring sites into a long-term network for the Great Lakes Basin. With an intertwined network of data providers, the data collection and costs can be shared through partnerships to "have a shared use of data for greater coverage on the same site" (NYDEC). Although this infrastructure is currently not in place in most sampling programs, it may be a necessary component for future longevity of these complex organizational structures.

Many interviewees were also concerned about their ability to secure funds. Continuous funding of tributary water quality monitoring programs is difficult and comes from a combination of state, federal, private and industry sources. Most of the interviewees (six out of eight) stated that their organization has to gather money together from a variety of different pools, such as federal EPA funds, point-source discharge fees, tipping fees (fees that are charged for solid waste disposal), and shortterm grants. The interviewees also stated that tributary monitoring is a low priority 
when compared to water related-permitting and compliance efforts. Heidelberg stated that the "funding [source] has constantly shifted and we have had to spend an inordinate amount of time chasing funding to keep the stations going." All of the programs have had funding sources end or staffing issues develop, causing them to shut down monitoring sites and reprioritize their efforts. As the Minnesota Pollution Control Agency states, "a lot of it gets back to project-based monitoring that is funded by some short term source, that kind of funding does not lend itself to long-term tributary monitoring."

A few states have combated these funding issues with state legislation for longterm funding. In 2008, Minnesota passed an amendment to the state's constitution that increases state sales tax by $0.375 \%$ and sets aside some of those funds for "water monitoring, protection, and restoration.” The Legacy Amendment, as it's called, will secure funds for water quality monitoring for the next 25 years. It has allowed the Minnesota Pollution Control Agency to jump-start its "event-based water quality monitoring including phosphorus on all 86 major watersheds in the state of Minnesota." Michigan also has funds secured by passed legislation. In 1998, the state passed the Clean Michigan Act, which set aside approximately $\$ 45$ million for water quality monitoring. The MIDEQ network has spread these funds out over at least 15 years. For the last, " 8 years MI government programs has been getting cut pretty much every year," but through this act, they forecast that secure funding for monitoring efforts will persist for many years.

For most programs (six out of eight), it has been difficult to secure funding for long-term tributary monitoring. The funding of a tributary monitoring program in the Great Lakes varies from the $\$ 15,000$ to $\$ 40,000$ per site/year depending on the temporal sampling design and parameters tested for phosphorus stations at the interviewed monitoring sites (this does include metals and polychlorinated biphenyls (PCB) testing). The annual costs of collecting water quality data and maintaining the sampling program range from $\$ 400,000$ to $\$ 1.2$ million (Table 4-3) for the programs that reported estimated expense of monitoring design. 
Table 4-3: Monitoring Program Costs in Great Lakes

\begin{tabular}{|c|c|c|}
\hline Monitoring Program & Cost per Site & $\begin{array}{c}\text { Annual Cost } \\
\text { (not including staff } \\
\text { salaries) }\end{array}$ \\
\hline Heidelberg College & $\$ 40,000$ & $\$ 400,000$ \\
\hline $\begin{array}{l}\text { New York Department of } \\
\text { Conservation }\end{array}$ & NA & $\$ 400,000$ \\
\hline $\begin{array}{l}\text { Michigan Department of } \\
\text { Environmental Quality }\end{array}$ & NA & $\begin{array}{l}\$ 400,000 \text { : fixed station } \\
\text { sampling }\end{array}$ \\
\hline \multirow{4}{*}{$\begin{array}{l}\text { USGS GRLI monitoring } \\
\text { program }\end{array}$} & & $\begin{array}{c}\$ 200,000: \text { probabilistic } \\
\text { program }\end{array}$ \\
\hline & $\$ 25,000 /$ basic site & $\$ 1$ to 1.2 million \\
\hline & $\begin{array}{c}\$ 30,000 / \text { additional wastewater } \\
\text { sampling }\end{array}$ & \\
\hline & $\begin{array}{l}\$ 40,000 / \text { additional virus } \\
\text { sampling }\end{array}$ & \\
\hline $\begin{array}{c}\text { Indiana Department of } \\
\text { Environmental Management }\end{array}$ & NA & $\$ 755,000$ \\
\hline $\begin{array}{c}\text { Wisconsin DNR Lake } \\
\text { Michigan Phosphorus Load } \\
\text { Monitoring }\end{array}$ & $\$ 15,000-\$ 20,000$ & $\$ 75,000$ to $\$ 100,000$ \\
\hline
\end{tabular}

Often, different groups within an agency are competing for the same pool of funds, which may be insufficient to meet all program needs. As a result, when funds are limited, monitoring may be the first aspect of a water quality program to be cut, since most states seem inclined to hold on to their higher priority programs, such as their permitting programs. As one stakeholder summarized,

"It is very short-sighted, because how do you know if things are effective or you are spending money in the right place if you are not out there doing the monitoring to figure out where the problems are? ... Compare monitoring to going to get a physical every year. How much longer do you need to keep getting a physical? You need to keep doing it. It is not like you get to the end of a process and you are all done. That is the problem. Funding is a problem, [and] monitoring is the first to cut when budgets get tight." 


\section{Differences in Sampling Regimes}

States in the Great Lakes Basin have a 30-year history of ambient tributary water quality monitoring. Despite this history, many of the programs have altered their monitoring program design to reflect state needs, funding, and management choices. Historically, a number of the state programs had monthly ambient tributary monitoring (NYDEC, OHEPA, WDNR, INDEM, MIDEQ). Eventually many of these monitoring programs scaled back their sampling frequency and number of sites because of funding constraints and changes in program objectives (Table 4-4). As stated in Table 4-2, the average numbers of observation per site vary by state, federal and private tributary monitoring programs. The program at Heidelberg College collects a vastly greater amount of data then another of agency in the tributary monitoring network with an average of 9000 collections compared to 150-350. This large disproportion in monitoring data collection is based on the there sampling regimes.

The sampling regime across the Great Lakes Basin varies both spatially and temporally. Programs in Ohio, Indiana, Michigan and New York utilize a dual monitoring program consisting of a fixed station program and a probabilistic/rotating program (Table 4-4). The fixed station programs target "specified tributaries, basically the major tributaries...near the mouths prior to discharging to the lake"(MIDEQ). The fixed stations are sampled either monthly or quarterly depending on the state program goals and objectives. The probabilistic/rotating monitoring program rotates among river basins within the states to intensively sample more sites. This rotating program runs on a 5-10 year basis depending on the sampling regime. The probability-based approach allows the program to characterize a greater range of the state's waters for less money, but the data are difficult to interpret for trends and inter-annual variability is hard to quantify. The suite of approaches allows states "to extrapolate results to understand the nutrient levels in a large majority of state's streams in a given two-year period" (MIDEQ) as defined by the CWA." In comparison, the interviewed programs in Minnesota, Heidelberg and USGS-GLRI incorporate approaches based on trying to 
sample during high-flow events. The program in Minnesota operates a major watershed loading program that samples their sites 30 times per year based on both high-flow runoff events and base-flow background concentrations. Heidelberg, conducts daily samples that capture the entire range of a site's flow regime. This program is unique to the Great Lakes Basin and the U.S. in that it collects daily samples at all of their sampling sites in the basin. Whereas, the USGS-GLRI multistate program conducts monthly sampling with the addition of up to six storm events per year at each of their 31 sites. The sampling regime is spatially and temporally distinct across each of these monitoring programs, providing evidence that funding and objectives are different along with little coordination between programs. 


\section{Table 4-4: Interview Responses of Sampling Design and Frequency}

\begin{tabular}{|c|c|c|}
\hline $\begin{array}{l}\text { Organization } \\
\text { Code }\end{array}$ & Program & $\begin{array}{l}\text { Current Sampling } \\
\text { Frequency }\end{array}$ \\
\hline \multirow[t]{2}{*}{ WDNR } & Long-Term Trends Monitoring Program & Monthly to Quarterly \\
\hline & $\begin{array}{c}\text { Lake Michigan Phosphorus Monitoring } \\
\text { Program }\end{array}$ & $\begin{array}{l}\text { Monthly (flow } \\
\text { proportional) }\end{array}$ \\
\hline WIUSGS & $\begin{array}{c}\text { National Surface Water Quality Assessment } \\
\text { Program }\end{array}$ & $\begin{array}{l}\text { One active site: } \\
\text { Monthly }\end{array}$ \\
\hline MNPCA & $\begin{array}{c}\text { Major Watersheds Load Monitoring } \\
\text { Program }\end{array}$ & $\begin{array}{l}30 / \text { year (most in } \\
\text { response to runoff } \\
\text { events) }\end{array}$ \\
\hline Heidelberg & National Center for Water Quality Research & Daily \\
\hline \multirow[t]{2}{*}{ OHEPA } & Fixed Monitoring Program & Quarterly \\
\hline & Rotating Basin Program & $\begin{array}{l}5-6 \text { samples/ half year } \\
\text { every ten years }\end{array}$ \\
\hline \multirow[t]{2}{*}{ INDEM } & Fixed-station Monitoring Program & $\begin{array}{l}\text { Monthly (potential } \\
\text { shift to Quarterly) }\end{array}$ \\
\hline & Probabilistic Monitoring Program & $\begin{array}{l}\text { Nine-year basin } \\
\text { rotation with } \\
\text { intensive sampling }\end{array}$ \\
\hline \multirow[t]{2}{*}{ MIDEQ } & Targeted Monitoring Program & $\begin{array}{l}\text { Monthly for } 6 \\
\text { sites (flow- } \\
\text { proportional) } \\
\text { 2uarterly for } \\
25 \text { sites, but } \\
\text { once every } \\
\text { five years } \\
\text { monthly }\end{array}$ \\
\hline & Probabilistic Monitoring Program & $\begin{array}{l}\text { Quarterly } 50 \text { sites } \\
\text { rotating every year }\end{array}$ \\
\hline \multirow[t]{2}{*}{ NYDEC } & Permanent Routine Monitoring Program & $6 /$ year \\
\hline & Intensive Monitoring Program & $\begin{array}{l}5 \text { year basin rotation: } \\
10 / \text { year }\end{array}$ \\
\hline USGS-GLRI & $\begin{array}{c}\text { Great Lakes Restoration Monitoring } \\
\text { Network }\end{array}$ & $\begin{array}{l}\text { Monthly + up to } 6 \\
\text { storm events }\end{array}$ \\
\hline
\end{tabular}


Additionally, Wisconsin and Ohio are the only states not entirely within the Great Lakes Basin that performs a Great Lakes specific monitoring program, not associated with state-wide assessments, to " specifically assess the waters of the Great Lakes Basin area in Wisconsin"(WDNR) through five water quality sampling sites. This program assesses rivers within the Lake Michigan watershed monthly with a flow-stratified protocol, similar to the MIDEQ targeted monitoring program. The HCC Lake Erie tributary monitoring program in Ohio assesses the waters of the western Lake Basin to understand the impact of agriculture on water quality.

The sampling protocols are important to effectively characterize water quality, analyze for trends and forecast future problems. The type of protocols can significantly alter the reliability of estimates of nutrient loads and trends in these loads. According to Heidelberg, "in a typical time-based (date sampling program) you are not going to characterize the high flow end, which is where all the action is in terms of loading," unless high-flow samples are collected in addition to a time-based program. The importance of continuous monitoring networks and sampling regimes, that include long-term sampling, for water quality concerns across the Great Lakes is seen in the following case study of the Western Lake Erie Basin. Major eutrophication problems have occurred in the Western basin of Lake Erie from increased algal blooms driven by increases in phosphorus loads (40). The International Joint Commission (IJC) issued a letter stating the lack of understanding of the deterioration of the nearshore waters of Lake Erie is "a consequence of decisions to curtail nutrient monitoring and control (state and federal) programs" except for the HCC program. Over the past fifteen years, dissolved reactive phosphorus concentrations, a constituent of total phosphorus, have increased, indicated successful best management farm practices but possibly altering the phosphorus dynamics in Lake Erie. This trend was discovered through the National Center for Water Quality Research at Heidelberg College's daily monitoring program, which has been operating since 1975. Without the continuous data set from Heidelberg College, researchers and managers would have been ill informed to the status of Lake Erie phosphorus loads since 1995. The Heidelberg 
program was not curtailed in the Western Lake Erie basin because their funding is from several sources and collaborations. The IJC states that "dedicated funding for long-term monitoring of phosphorus export from major tributaries should be secure and permanently funded so that progress or lack of progress under the Great Lakes Water Quality Agreement can easily be discerned" (144). In the Great Lakes, there is a need for more consistent funding programs for water quality monitoring.

The success of tributary water quality monitoring in the future requires an adequate organizational structure, sufficient funding and effective sampling protocols for understanding in changes in phosphorus concentrations and loads. Despite being aware of the requirements for effective monitoring, many program managers indicated doubts at being able to achieve them in years to come, at least without strong interagency collaboration. The MIDEQ hopes they will be able to secure funding for staff and monitoring by getting support for another bond initiative but this, "can be very political and it can polarize who supports it and who does not... If we are not successful, then there is no way to avoid that fact that the amount of monitoring we do is going to drop." Funding challenges could also lead combining monitoring programs with increased inter-agency collaboration, greater organizational structure to support and continue monitoring efforts.

\subsection{Discussions and Conclusions}

In order to assess current phosphorous loadings and to make accurate predictions of phosphorous loads, researchers depend on having continued access to tributary phosphorous concentration data generated by water quality monitoring programs. In this paper, we investigated the concerns and challenges associated with maintaining effective tributary water quality monitoring programs through interviews with managers responsible for some aspect of the existing programs.

Results from these open-ended interviews suggest three issues that policy makers interested in maintaining an effective phosphorus tributary monitoring network in the Great Lakes basin should consider. First, the objectives driving the 
development and operation of tributary monitoring programs vary across the basin. The requirements of the CWA motivate many of the state-based agency programs including the MIDEQ, INDEM and the OHEPA, with most of the state programs selecting a monitoring design to provide broad spatial coverages of their state waters and quantify point source impacts in their rivers, not the Great Lakes. The goal of the USGS-GLRI program, a nationally-administered and funded effort; however, is to document the status of water quality across the entire Great Lakes Basin to support future Great Lakes management plans and the development of watershed models. Finally, the goal of Heidelberg College program is to better understand the relationship between agricultural practices and $\mathrm{P}$ sources flowing into Lake Erie. Thus, this program is driven by a science question, rather than a policy initiative.

These varied goals and objectives result in spatial and temporal differences in sampling frequency and design. Minnesota's program, for example, involves the collection of 30 phosphorus samples per year, incorporating both ambient and storm nutrient sampling. This sampling design is meant to meet the Minnesota agencies' goals and objectives of characterizing seasonal and annual phosphorus loads. The Heidelberg program involves collection of daily phosphorus data. The daily sampling design is meant to generate sufficient data to provide reliable estimates of $\mathrm{P}$ loads which will inform strategies for minimizing the impacts of agriculture on water resources in western Lake Erie. The collection of flow-stratified data through storm event sampling by the USGS-GRLI, WDNR and MIDEQ enables the data to be used in models and trend analysis by reducing the amount of error in estimations. However, other state programs including OHEPA, INDEM, and NYDEC collect only ambient phosphorus data, on a monthly to quarterly basis, to characterize their state waters as specified by the CWA. These protocols do not include flow-stratified or storm event sampling.

Second, these differences in frequency and design limit the ability of the various programs across the Great Lakes to coordinate efforts for collaboration and data sharing. Under current policies, programs have relatively few incentives to 
engage in cross-basin tributary monitoring for an integrated water quality assessment at the Great Lakes Basin scale. As might be expected, most state programs are concerned only with their state's waters, as opposed to the waters of the Great Lakes Basin. The new USGS-GLRI program is implementing a cross-basin monitoring effort to assess the waters of the Great Lakes. However, this effort may be confounded if there is little incentive for state-level programs to participate in basin-wide efforts. The success of the basin-wide program depends on collaboration across the region from federal, state, and local agencies to fund and develop monitoring sites that fit into the goals of the USGS-GLRI program, which suggests that greater consistency of statelevel policies and sampling regimes would be desirable.

Finally, the consistency of funding for tributary water monitoring programs varies by program, complicating long-term efforts to collect sufficient water-quality data for use in understanding phosphorous trends and loads. Funding structures differ across the state programs. Most programs are contending with significant reduction of funding except in Minnesota and Michigan. Minnesota's long-term data collection program is funded through state taxes. Michigan's program has funding through the Clean Michigan Initiative Act, which allocates bonds for environmental and natural resources protection. For most other programs, securing consistent funding is a difficult task, since monitoring is commonly a lesser priority relative to activities such as permitting in some states' environmental programs. Many of these programs face challenges securing funds sufficient for sustaining a long-term monitoring network, which include costs associated with personnel, supplies and equipment. Funding levels often determines the number of sample locations and sample frequency.

To establish a consensus among state, federal and private tributary monitoring programs, there needs to be more discussion on what the required minimum necessary level of monitoring for each Great Lake to continue the assessment of loading trends at a level of certainty necessary for use in statistical models and load control programs. Given these issues, we recommend the following actions for improving monitoring networks for assessing phosphorus loads into the Great Lakes: 
1. Develop state-level policies with consistent goals, which will help program managers develop an integrated plan of characterizing the phosphorus loads in the Great Lakes Basin by establishing similar sampling frequencies and site selections criteria and by engaging in inter-agency collaborations to secure funding for long-term monitoring.

2. Develop funding mechanisms consistent with the policy goals. If the policy goal is to generate data for the long-term monitoring of phosphorus loads, the funding mechanism must be sufficient to meet those goals without agencies, as is now the case with the MI and MN models.

3. Develop monitoring protocols that include sufficient samples to identify trends, quantify loads and develop ecosystem models. This sampling design should include data from a range of flows and seasons.

Incorporating these recommendations into monitoring programs will provide a bettercoordinated system for providing adequate data for researchers who are investigating science questions and for natural resource managers attempting to prioritize ecosystem restoration efforts.

\subsection{Acknowledgements}

This work was supported by award CBET- 0725636 from the National Science Foundation. Thanks are due to USGS Wisconsin Science Center for support in data availability in the Great Lakes Region. Thanks also for the water quality managers across the basin for donating their valuable time for the interviews described in this work. 


\section{Synthesis}

Clearly the intertwined topics of land use, climate change, and policy effects on nutrient loading and eutrophication offer enormous opportunities for research and management implications. With the Great Lakes, being the world's largest body of freshwater, impacts to the lakes are long lasting and ever changing. In addition, the phosphorus supply has been significantly altered by human activities and climate changes. Therefore, this dissertation examines three related areas of phosphorus knowledge and management: anthropogenic alteration, climate change, and policy.

A greater understanding of these various impacts is required to manage the terrestrial-aquatic ecosystem in the future, which is a major scientific challenge for the Great Lakes and the world. In the future, the ecosystems will have to mitigate the projected land use and hydrologic changes due in large part to a changing climate. To understand and model these future changes, researchers need long-term monitoring data that provides flow-load measurements throughout the entire hydrologic cycle (low to high flow) to accurately categorize the effects of climate and land use.

Each paper in this dissertation has significant management implications for the future of the Laurentian Great Lakes and its watersheds. Chapter 2, the Land Use paper, provides evidence for targeting vulnerable watersheds with significant changes in P loading for future scenarios. This paper offers information on land use changes will affect $\mathrm{P}$ loading to each of the Great Lakes. In addition, it also provides evidence of where to reduce land-based P inputs onto the watersheds with significant land use changes or lack of $\mathrm{P}$ retention.

Chapter 3, the Climate Change and extreme events research, indicates certain watersheds where the change in the distribution of $\mathrm{P}$ loading events will change the most in the future. Utilizing different climate scenarios, the results suggest that many watersheds will have an increase in high-loading events, which is of significance for managers to reduce $\mathrm{P}$ loading to the Great Lakes and the eutrophication potential. 
Land use changes may exacerbate these climate changes; therefore this manuscript provides evidence of where future management is needed.

Finally, in chapter 4, the analysis of monitoring networks in the Great Lakes, suggests that more data are required to understand and model the changes resulting from land use and climate change. This analysis shows that monitoring efforts are decreasing around much of the basin. This decrease in monitoring may alter modeled P loading estimates, thereby complicating estimates and management efforts as shown in chapter 2 and 3 . The seasonal regressions in chapter 3 vary in their ability to capture the variability of $\mathrm{P}$ loading because the data sets do not contain $\mathrm{P}$ loads over the entire flow range. The need for greater data sets as seen in chapter 2 and 3 further substantiates the importance of having good $\mathrm{P}$ data sets. Therefore, this manuscript greatly compliments the entire dissertation.

By combining results from each of these chapters, we can focus on areas where the effects of land use change and climate change will greatly alter the ecosystem, thereby changing the magnitude and distribution of $\mathrm{P}$ loads, potentially in areas with very little monitoring. Watersheds including the Saginaw, Clinton, Sandusky, Cuyahoga, St. Louis, and Grand should experience an increase in the magnitude of annual P loading due to increases in urban expansion and potential need for biofuels. These are also the same watersheds that are expected to have increase in high-loading events due to climate change (chapter 3), which contribute to most of the P loading. Therefore, combining the results of these two chapters together suggest that these watersheds are both vulnerable in terms of climate change and could be exacerbated by increases in loadings from land use change and sites where there is a need for increased monitoring. Some of these watersheds including the Grand and Clinton River Basins have decreasing P monitoring. The decrease in effective monitoring at these sites will only continue to perpetuate a lack of knowledge of potentially devastating impacts from both climate and land use change. Utilizing results from all of the chapters enables managers to focus on areas that will be significantly vulnerable to anthropogenic and climate forces in the future decades. 
To combat the future changes in $\mathrm{P}$ transport, greater nutrient and watershed management is needed in the Great Lakes Basin. To estimate the amount of P loading into the lakes, an effective monitoring design and policy are critical to illustrate the future changes both annually and seasonally. With monitoring data, there is a potential to enact policies to mitigate climate change through land use management in especially vulnerable watersheds of the Great Lakes. The success of management measures can only be quantified with effective monitoring throughout the Great Lakes Basin.

Further research following this dissertation, should focus on combining these climate induced hydrological changes with the impacts of land use change to study their impacts on future water resources of this complex system. Currently the work is divided into two different models, but the next step would be to integrate the future hydrological simulations and flows into HydroSPARROW to do a holistic analysis on combined effects of climate and land use change. This model should then incorporate the P loading from the Canadian side of the Great Lakes Basin. In addition, these results should be used to develop the best management plan for these future conditions. Additional work is needed to develop future monitoring plans to accurately quantify the effects of climate and land use changes, and to utilize these results to develop long-term monitoring designs for watersheds of the Great Lakes. Development of a systems model that incorporates results of these three chapters would provide a novel next step to understand the vulnerability of watersheds in the Great Lakes for future decades. Each of the chapters link together to provide a unique scientific contribution on the understanding of the role of human, climate, and policy on future phosphorus dynamics in the Great Lakes Basin for use in watershed management. 


\section{Works Gited}

(1) Suess, Dr. Lorax. Random House: New York, N.Y., 1971.

(2) USEPA: United States Environmental Protection Agency's National Water Quality Inventory: 2004 Report to Congress. U.S. Environmental Protection Agency. Office of Water, EPA 841-R-08-001, Washington D.C., 2009.

(3) Austin, J. C.; Anderson, S.; Courant, P. N.; Litan, R. E. Healthy waters, strong economy: the benefits of restoring the Great Lakes ecosystem. The Brookings Institution. 2007.

(4) Government of Canada, and U. S. Environmental Protection Agency. The Great Lakes: an environmental atlas and resource book, $3^{\text {rd }}$ ed.; EPA 905-B95-001. Illinois, 1995.

(5) Grunwald, S.; Qi, C. GIS-based water quality modeling in the Sandusky Watershed. Journal of American Water Resources Association 2006, 42(4): 957-973.

(6) National Oceanic and Atmospheric Administration: Great Lakes Environmental Research Laboratory (NOAA-GLERL) Website: http://www.glerl.noaa.gov/pr/ourlakes/facts.html

(7) GLIN: Great Lakes Information Network. Website; http://gis.glin.net/ogc/services.php?by=topic

(8) PRISM Climate Group. Gridded climate: United States Annual Precipitation, 1971-2000. Oregon State University, 2006.

(9) Sprague, L. A.; Lorenz, D. L. Regional Nutrient Trends in Streams and Rivers of the United States, 1993-2003 Environmental Science and Technology 2009 43(10): 3430-3435.

(10) Morrice, J. A.; Danz, N. P.; Regal, R. R.; Kelly, J. R.; Niemi, G. J.; Reavie, E. D.; Hollenhorst, T.; Axler, R. R.; Trebitz, A. S.; Cotter, A. M.; Peterson, G. S. Human Influences on Water Quality in Great Lakes Coastal Wetlands. Environmental Management 2008 41: 347-357. 
(11) Danz, N. P.; Niemi, G. J.; Regal, R. R.; Hollenhorst, T.; Johnson, L. B.; Hanowski, J. M.; Axler, R. P.; Ciborowski, J. J. H.; Hrabik, T.; Brady, V. J.; Kelly, J. R.; Morrice, J. A.; Brazner, J.C.; Howe, R. W.; Johnston, C.A.; Host G. E. Integrated Measures of Anthropogenic Stress in the U.S. Great Lakes Basin. Environmental Management 2007 39: 631-647.

(12) The Nature Conservancy. The Conservation of Biological Diversity in the Great Lakes Ecosystem: Issues and Opportunities, The Nature Conservancy Great Lakes Program. Illinois, 1994.

(13) Crosbie, B.; Chow-Fraser, P. Percent land use in the watershed determines the water- and sediment-quality of 21 wetlands in the Great Lakes basin. Canadian Journal of Fisheries and Aquatic Science 1999 56: 1781-1791.

(14) Robertson, D. M. Regionalized loads of sediment and phosphorus to Lakes Michigan and Superior-High flow and long term average. Journal of Great Lakes Research 1997 23: 416-439.

(15) Robertson, D. M.; Saad, D. A. Landscape-derived nutrient inputs to the Laurentian Great Lakes by Source and Watershed. Journal of the American Water Resources Association 2011, 47(5), 1011-1033.

(16) Rathke, D. E., McRae, G. Eds. Great Lakes Water Quality Board, Report to the International Joint Commission. 1987 Report on Great Lakes Water Quality Great Lakes Surveillance Vol. III. 1989.

(17) Fry, J.; Xian, G.; Jin, S.; Dewitz, J.; Homer, C.; Yang, L.; Barnes, C.; Herold, N.; Wickham, J. Completion of the 2006 National Land Cover Database for the Conterminous United States, Photogrammetric Engineering and Remote Sensing 2011 77(9): 858-864.

(18) Allan, D.; Johengen, T.; Rutherford, E. Nutrient Loading and its Relevance to the Great Lakes Basin. A White Paper prepared for a University of Michigan Initiative in Great Lakes Research. 2002.

(19) Jones, A. R.; Lee, G. F. Recent advances in assessing impact of phosphorus loads on eutrophication-related water quality. Water Research 1982, 16: 503515. 
(20) Carpenter, S.; Carcao, N. F.; Correll, D. L.; Howarth, R. W.; Sharpley, A. N.; Smith, V. H. Nonpoint pollution of surface waters with phosphorus and nitrogen. Ecological Applications 1998, 8:559-568.

(21) International Joint Commission. Pollution of Lake Erie, Lake Ontario, and the International Section of the St. Lawrence River. Ottawa, Ontario. 1970.

(22) Burns, N. M.; Ross, C. Project HYPO: An intensive study of the Lake Erie central basin hypolimnion and related surface water phenomena. Technical Report TS-05-71-208-24. U.S. EPA, Washington, D.C. 1972.

(23) D'Elia, C. F. Nutrient enrichment of the Chesapeake Bay - Too much of a good thing. Environment 1987, 29(6-11), 30-33.

(24) Schultze, S. Bradford is the dirtiest city beach. Milwaukee Journal Sentinel [Online], May 30, 2005.

http://www.jsonline.com/news/metro/may05/329987.asp (accessed March 5, 2012).

(25) Smith, V. H.; Schindler, D. W. Eutrophication science: where do we go from here? Trends in Ecology and Evolution 2009, 24(4): 201-207.

(26) Sonzogni, W. C.; Monteith, T. J.; Skimin, W. E.; Chapra, S. C. A summary, U.S. Task D, PLUARG. International Joint Commission, PLUARG Report Series: Windsor, ONT. 1979.

(27) Freedman, P. L.; Monson, B. A. The Great Lakes Water Quality Agreement. Water Environment and Technology 1989 1(2): 285-291.

(28) USGAO. GREAT LAKES: An overall strategy and indicators for measuring progress are needed to better achieve restoration. GAO-03-515; United States General Accounting Office: Washington DC, 2003.

(29) SOLEC. 1994 State of the Lakes Ecosystems Conference Background Paper, Nutrients: Trends and System Response. Environment Canada and US Environmental Protection Agency. EPA 905-R-95-015, 1995.

(30) DePinto, J. V.; Lam, D.; Auer, M. T.; Burns, N.; Chapra, S.; Charlton, D.; Dolan, D.; Kreis, R.; Howell, T.; Rockwell, D.; Scavia, D. Examination of the Status of the Goals of Annex 3 of the Great Lakes Water Quality 
Agreement. Report of the Annex 3 model review sub-group to the GLWQA Review Working Group D- Nutrients, 2007.

(31) Auer, M. T.; Tomlinsin, L. M.; Higgins, S. N.; Malkin, S. Y.; Howell, E. T.; Bootsma, H. A. Great Lakes Cladophora in the $21^{\text {st }}$ century: same algaedifferent ecosystem. Journal of Great Lakes Research 2010, 36: 248-255.

(32) Johnson, L.; Richards, C.; Host, G.; Arthur, J. Landscape influences on water chemistry in Midwestern stream ecosystems. Freshwater Biology 1997 37(1): 193-208.

(33) Arnold, J. G.; Muttiah, R. S.; Williams, J. R. Large Area Hydrologic Modeling and Assessment Part I: Model Development. Journal of the American Water Resources Assocoiation 1998 34(1): 73-89.

(34) International Panel on Climate Change, I. P. O. C. C. Climate Change 2007: The Physical Science Basis, Summary for Policy Makers. Contribution of Working Group I to the Fourth Assessment Report of the IPCC. Fourth Assessment Report of the IPCC. Intergovernmental Panel on Climate Change. 2007.

(35) Southworth, J.; Randolph, J. C.; Habeck, M.; Doering, O. C.; Pfeifer, R. A.; Rao, D. G.; Johnston, J. J. Consequences of future climate change and changing climate variability on maize yields in the Midwestern United States. Agriculture, Ecosystems and Environment 2000, 82 (1-3): 139-158.

(36) Tayyebi, A.; Pekin, B. K.; Pijanowski, B. C.; Plourde, J. D.; Doucette, J. S.; Braun D. Hierarchical modeling of urban growth across the conterminous USA: developing meso-scale quantity drivers for the Land Transformation Model. Journal of Land Use Science 2012, DOI 10.1080/1747423X.2012.675364.

(37) Pijanowski, B. C.; Shellito, B. Pithadia, S. Using artificial neural networks, geographic information systems and remote sensing to model urban sprawl in coastal watersheds along eastern Lake Michigan. Lakes Reservoirs 2002, 7 : 271-285. 
(38) Plourde, J. D. Assessing changes and drivers of crop rotation patterns and their implications for nitrogen loading in the United States. MS Thesis, Purdue University, West Lafayette, IN, July 2012.

(39) United States Department of Agriculture (USDA). Agricultural Projections to 2020. USDA Office of the Chief Economist, World Agricultural Outlook, Long Term Projections Report, 2011.

(40) Great Lakes Commission (GLC). Priorities for Reducing Phosphorus Loadings and Abating Algal Blooms in the Great Lakes- St. Lawrence River Basin: Opportunities and Challenges for Improving Great Lakes Aquatic Ecosystems. A Report of the Phosphorus Reduction Task Force 2012.

(41) Hubbard, L.; Kolpin, D. W.; Kalkhoff, S. J.; Robertson, D. M. Nutrient and Sediment Concentrations and Corresponding Loads during the Historic June 2008 Flooding in Eastern Iowa. Journal of Environmental Quality 201140: 166-175.

(42) Whitehead, P. G.; Wilby, R. L.; Battarbee, R. W.; Kernan, M.; Wade, A. J. A review of the potential impacts of climate change on surface water quality. Hydrological Sciences Journal 2009 54: 101-123.

(43) Jeppesen, E.; Kronvang, B.; Meerhoff, M.; Sondergaard, M.; Hansen, K. M.; Andersen, H. E.; Lauridsen, T. L.; Liboriussen, L.; Beklioglu, M.; Ozen, A.; Olesen, J. E. Climate change effects on runoff, catchment phosphorus loading and lake ecological state, and potential adaptations. Journal of Environmental Quality 2009 38: 1930-1941.

(44) Melfi, D. A.; Yaksich, S. M.; Baker, D. B.; Kramer, J. W. Lake Erie Nutrient loads, 1970-1980. Journal of Great Lakes Research 1985 11: 117-131.

(45) Dove, A. Long-term trends in major ions and nutrients in Lake Ontario. Aquatic. Ecosyste, Health and Management 2009 12: 281-295.

(46) Mida, J. L.; Scavia, D.; Fahnenstiel, G.L.; Pothoven, S. A.; Vanderploeg, H. A.; Dolan, D. M. Long-term and recent changes in southern Lake Michigan water quality with implications for present trophic status. Journal of Great Lakes Research 2010 36: 42-49. 
(47) Urban, N. R. Nutrient cycling in Lake Superior: retrospective and update. In State of Lake Superior Ecovision World Monograph Series, Aquatic Ecosystem Health and Management Society; Munawar, M.; Munawar, I. F., Eds.; 2009; p. 83-115.

(48) Trefry, C. M.; Watkins, D. W.; Johnson, D. L. Regional rainfall frequency analysis for the state of Michigan. Journal of Hydrological Engineering 2005, 10: 437-449.

(49) Kunkel, E. K.; Andsager, K.; Easterling, D. R. Long-term trends in extreme precipitation events over the conterminous United States and Canada. Journal of Climate 1999, 12: 2515.

(50) Cherkauer, K. A.; Sinha, T. Hydrologic impacts of projected future climate change in the Lake Michigan region. Journal of Great Lakes Research 2010 36: $33-50$.

(51) Griffs, V. W.; Stedinger, J. R. The use of GLS Regression in Regional Hydrologic Analyses. Journal of Hydrology 2007 344: 82-95.

(52) Meehl, G. A.; Covey, C.; Delworth, T.; Latif, M.; McAvaney, B.; Mitchell, J. F. B.; Stouffer, R. J.; Taylor, K. E. The WCRP CMIP3 multi-model dataset: A new era in climate change research. Bulletin of American Meteorological Society 2007 88: 1383-1394.

(53) Croley, T. E. Large Basin Runoff Model. In Mathematical Models of Large Watershed Hydrology, Water Resources Publications, Littleton, Colorado; Singh, V.; Frevert, D.; Meyer, S., Eds.; 2002; 717-770.

(54) International Joint Commission (IJC). Climate Change and Water Quality in the Great Lakes Region: Risks, Opportunities and Responses. Report for the Great Lakes Water Quality Board, 2003; www.ijc.org/rel/pdf/climate change 2003 part3.pdf.

(55) Murdoch, P. S.; Baron, J. S.; Miller, T. L.; Potential effects of climate change on surface-water quality in North America. Journal of the American Water Resources Association 200036 (2): 347-366. 
(56) Cha, Y. K.; Stow, C. A.; Reckhow, K. H.; DeMarchi, C.; Johengen, T. H. Phosphorus load estimation in the Saginaw River, MI using Bayesian hierarchical/multilevel model. Water Research 2010 44: 3270-3282.

(57) Johnson, A. H. Estimating solute transport in streams from grab samples. Water Resources Research 1979 15(5): 1224-1228.

(58) Dolan, D.; Yui, A. K.; Geist, R. D. Evaluation of river load estimation methods for total phosphorus. Journal of Great Lakes Research 1981 7: 207214.

(59) Phillips, J. M.; Webb, B. W.; Walling, D. E.; Leeks, G. J. L. Estimating the suspended sediments loads of rivers in the LOIS study area using infrequent samples. Hydrological Processes 199913 (7): 1035-1050.

(60) Johnes, P. J. Uncertainties in annual riverine phosphorus load estimation: impact of load estimation methodology, sampling frequency, baseflow index and catchment population density. Journal of Hydrology 200732 (1-2): 241258.

(61) Moatar, F.; Maybeck, M. Riverine fluxes of pollutants: towards predictions of uncertainties by flux duration indicators. Comptes Rendus Geoscience 2007339 (6): 367-382.

(62) Saad, D.A., Schwarz, G. E., Robertson, D. M., Booth, N. L. A Multi-Agency Nutrient Dataset Used to Estimate Loads, Improve Monitoring Design, and Calibrate Regional Nutrient SPARROW Models. Journal of the American Water Resources Association 2011 47: 933-949.

(63) Krantzberg, G.; de Boer, C. A Valuation of Ecological Services in the Great Lakes Basin Ecosystem to Sustain Healthy Communities and a Dynamic Economy. Paper prepared for Ontario Ministry of Natural Resources by Dofasco Centre for Engineering and Public Policy, McMaster University. 2006.

(64) Pijanowski, B. C.; Robinson, K. D. Rates and patterns of land use change in the Great Lakes States, USA: A framework for spatial temporal analysis. Landscape Urban Planning 2011, 102: 102-116. 
(65) Nechyba, T. J.; Walsh R. P. Urban Sprawl. Journal of Economic Perspectives 2004, 18: 177-200.

(66) Greene, R. P. The farmland conversion process in a polynucleated metropolis. Landscape and Urban Planning 1997, 36: 291-300.

(67) Ouyang, D.; Kang, Y. T.; Bartolic, J. Agricultural phosphorus assessment in the Great Lakes Basin: A Case Study. Great Lakes Agricultural Summit, 1996 East Lansing, MI.

(68) Ewert, F.; Rounsevell, M. D. A.; Reginster, I. R.; Metzge, M. J.; Leemans, R. Future scenarios of European agricultural land use. I. Estimating changes in crop productivity. Agriculture, Ecosystems and Environments 2005, 107, $101-116$.

(69) Rounsevell, M. D. A.; Reginster, I.; Arau'jo, M. B.; Carter, T. R.;

Dendoncker, N.; Ewert, F.; House, J. L.; Kankaanpa“a”, S.; Leemans, R.; Metzger, M. J.; Schmit, C.; Smith, P.; Tuck, G. A coherent set of future land use change scenarios for Europe. Agriculture, Ecosystems and Environments. 2006, 114: 57-68.

(70) Great Lakes Water Quality Protocol of 2012. Ammending the agreement between the United States of American and Canada on Great Lakes Water Quality, 1978. September 7, 2012. www.epa.gov/glnpo/glwqa/20120907Canada-USA_GLWQA_FINAL.pdf

(71) Seaber, P.R., Kapinos, F. P., Knapp, G. L. Hydrologic Unit maps: U.S. Geol. Surv. Water-Supply Paper 2294. 1987, 63 p. http://water.usgs.gov/GIS/huc.html.

(72) Johnes, P. J. Evaluation and management of the impact of land use change on the nitrogen and phosphorus load delivered to surface waters: the export coefficient modeling approach. Journal of Hydrology 1996, 183(3-4): 323349.

(73) Daly, K.; Mills, P.; Coulter, B.; McGarrigle, M. Modeling phosphorus concentrations in Irish rivers using land use, soil type, and soil phosphorus data. Journal of Environmental Quality 2002, 31: 590-599. 
(74) Young, W. J.; Marston, F. M.; Davis, R. J. Nutrient Exports and Land Use in Australian Catchments. Journal of Environmental Management 1996, 47(2): 165-183.

(75) Johnes, P. J.; Heathwaite, A. L. Modeling impact of land use change on water quality in agricultural catchments. Hydrological Processes 1997, 11 : 269-286.

(76) McGuckin, S. O.; Jordan, C.; Smith,R. V. Deriving phosphorus export coefficients for CORINE land cover types. Water Science and Technology 1999, 39:47-53.

(77) Ouyang, D.; Bartolic, J.; Selegean, J. Assessing sediment loading from agricultural croplands in the Great Lakes Basin. Journal of American Science 2005, 1(2): 14-21.

(78) Smith, R. A.; Schwarz, G. E.; Alexander, R. B. Regional interpretation of water-quality monitoring data, Water Resources Research 1997 (33) 12: 2781-2798.

(79) Jones, K. B. An Ecological Assessment of the United States Mid-Atlantic Region: A Landscape Atlas. Office of Research and Development, Washington, D.C. 1997; 20460 EPA-600-R.-97-130.

(80) Tang, Z.; Engel, B. A.; Pijanowski, B. C.; Lim, K. J. Forecasting Land Use Change and Its Environmental Impact at a Watershed Scale. Journal of Environmental Management 2005, 76: 35-45.

(81) Wiley, M.; Hyndman, D.; Pijanowski, B.; Kendall, A.; Riseng, C.; Rutherford, E.; Cheng, S.; Carlson, M.; Richards, R.; Seelbach, R.; Koches, J. A multi-modeling approach to evaluate the impacts of global change on river ecosystems. Hydrobiologia 2010, 657:243-262.

(82) Ruddy, B. C.; Lorenz, D. L.; Mueller, D. K. County-level estimates of nutrient inputs to the land surface of the conterminous United States, 19822001. U. S. Geological Survey Scientific Investigations Report 2006-5012, Reston, Virginia 2006. 
(83) Pijanowski, B.; Pithadia, S.; Alexandridis, K.; Shellito, B. Forecasting largescale land use change with GIS and neural networks. International Journal of Geographic Information Science 2005, 19(2): 197-215.

(84) U.S. Census State Data Center Network Website; http:// www.census.gov/sdc/network.html.

(85) Tyner, W. E. Cellulosic Biofuels Market Uncertainties and Government Policy. Biofuels 2010, 1: 389-91.

(86) Wetzel, R. Clean water: a fading resource. Hydrobiologia 1992 243/244: 21 30.

(87) Berndtsson, R.; Larson, M.; Lindh, G.; Malm, J.; Niemczynowicz, J.; Tielin, Zhang. Climate induced effects on the water balance. In Climate and Water International Conference Helsinki, Finland, Sept. 11-15: 437-449. 1989.

(88) Meyer, J. L.; Pulliam, W. M. Modifications of Terrestrial-aquatic interactions by a changing climate. In Global Climate Change and Freshwater Ecosystems; Firth, P. Fisher, S. G., Eds.; Springer Verlag: New York 1992; pp. 177-191.

(89) Stottlemyer, R. Processes regulating watershed chemical export during snowmelt, fraser experimental forest, Colorado. Journal of Hydrology 2001 245: 177-195.

(90) Sterner, R. W.; Anagnostou, E.; Brovold, S.; Bullerjahn, G. S.; Finlay, J. C.; Kumar, S.; McKay, R. M. L.; Sherrell, R. M. Increasing stoichiometric imbalance in North America's largest lake: Nitrification in Lake Superior, Geophysical Research Letters 2007, 34, L10406.

(91) Angel, J. R.; Huff, F. A. Changes in heavy rainfall in Midwestern United States. Journal of Water Resources Planning Management 1997, 123: 246249.

(92) Lenters, J. D. Trends in the Lake Superior Water Budget since 1948: A Weakening Seasonal Cycle. Journal of Great Lakes Research 2004, 30: 2040. 
(93) Stuntebeck, T.D.; Bannerman, R. T. Effectiveness of barnyard best management practices in Wisconsin. U.S. Geological Survey Fact Sheet 05198, 1998; 4 p.

(94) Corsi, S. R.; Walker, J. F.; Wang, L.; Horwatich, J. A.; Bannerman, R.T. Effects of best management practices in Otter Creek in the Sheboygan River Priority Watershed, Wisconsin, 1990-2002. U.S. Geological Survey Scientific Investigations Report 2005-5009, 2005; 26 p.

(95) Danz, M. E.; Corsi, S. R.; Graczyk, D. J. Characterization of Suspended Solids and Total Phosphorus Loadings from Small Watersheds in Wisconsin. U.S. Geological Survey Scientific Investigations Report 2010-5039, 2010; 16 p.

(96) Littlewood, I. G.; Watts, C. D.; Custance, J. M. Systematic application of United Kingdom river flow and quality databases for estimating annual river mass loads (1975-1994). Sci. Total Environ. 1998 210: 21-40.

(97) Quilbé, R.; Rousseau, A. N.; Duchemin, M.; Poulin, A.; Gangbazo, G.; Villeneuve, J. P. Selecting a calculation method to estimate sediment and nutrient loads in streams: Application to the Beaurivage River (Québec, Canada). Journal of Hydrology 2006 326(1-4): 295-310.

(98) Borah, D. K.; Yagow, G.; Saleh, A.; Barnes, P. L.; Rosenthal, W.; Krug, E. C.; Hauck, L. M. Sediment and nutrient modeling for TMDL development and implementation. Transactions of ASABE 2006, 49(4): 967-986.

(99) Haith, D. A.; Shoemaker, L. L. Generalized watershed loading functions for stream flow nutrients. Water Resources Bulletin 1987, 23(3): 471-478.

(100)Schwarz, G. E.; Hoos, A. B.; Alexander, R. B.; Smith, R. A. SPARROWMOD: user documentation for the SPARROW surface water-quality model: U.S. Geological Survey Techniques and Methods, book 6, section B, Surface water, chapter 3 (6-B3); 2006.

(101)Agren, A.; Buffam, I.; Bishop, K.; Laudon, H. Modeling stream dissolved organic carbon concentrations during spring flood in the boreal forest: A 
simple empirical approach for regional predictions. Journal of Geophysical Research-Biogeochemistry 2010, 115.

(102)Bower, M. J.; Smith, J. T.; Jarvie, H. P.; Neal C. Modelling of phosphorus inputs to rivers from diffuse and point sources. Science of the Total Environment 2008, 395: 125-138.

(103)Royer, T. V.; David, M.B.; Gentry, L. E. Timing of riverine export of nitrate and phosphorus from agricultural watersheds in Illinois: Implications for reducing nutrient loading to the Mississippi River. Environmental Science and Technology 2006, 40: 4126-4131.

(104)Dorioz, J. M.; et al. Sediment impact on phosphorus transport in a river system. In: Proc. MAB/UNESCO, PIREN/CNRS Int. Symp. Lauga, J., Decamps, H., Holland, M. M., Eds.; Tolouse, France, 1986, pp. 25-34.

(105)House, W. A.; et al. Transport of phosphorus in rivers. In: Phosphorus Cycles in Terrestrial and Aquatic Ecosystems. Regional Workshop 1: Europe. SCOPE/UNEP Proceedings; Tiessen, H. Ed.; University of Saskatchewan: Saskatoon, Canada 1986; pp. 253-282.

(106)R Development Core Team. R: A Language and Environment for Statistical Computing. R Foundation for Statistical Computing, Vienna, Austria 2010.

(107)Duan, N. Smearing Estimate: A Nonparametric Retransformation Method. Journal of the American Statistical Association 1983 48: 605-610.

(108)Moriasi, D. N.; Arnold, J. G.; Van Liew, M. W.; Bingner, R. L.; Harmel, R. D.; Veith, T. L. Model evaluation guideline for systematic quantification of accuracy in watershed simulations. Transaction of ASABE 2007, 50: 885900.

(109)Towler, E.; Rajagopalan, B.; Gilleland, E.; Scott Summers, R.; Yates, D.; Katz, R. W.; Modeling hydrologic and water quality extremes in a changing climate: A statistical approach based on extreme value theory. Water Resources Research 2010, 46: W11504.

(110) Maurer, E. P.; Brekke, L. D.; Pruitt, T. Contrasting lumped and distributed hydrology models for estimating climate change impacts on California 
watersheds. Journal of American Water Resources Association 2010, 46: 1024-1035.

(111)Hidalgo, H.; Das, T.; Dettinger, M. D.; Cayan, D. R.; Pierce, D. W.; Barnett, T. P.; Bala, G.; Mirin, A.; Wood, A. W.; Bonfils, C.; Santer, B. D.; Nozawa, T. Detection and attribution of streamflow timing changes to climate change in the western United States. Journal of Climate 2009, 22: 3838-3855.

(112)Lofgren, B. M.; Hunter, T. S.; Wilbrager, J. Effects of using air temperature as a proxy for potential evapotranspiration in climate change scenarios of Great Lakes basin hydrology. Journal of Great Lakes Research 2011, 37: 744-752.

(113) Stenback, G. A.; Crumpton, W. G.; Schilling, K. E.; Helmers, M. J. Rating curve estimation of nutrient loads in Iowa rivers. Journal of Hydrology 2011, 396: 158-169.

(114)Sharpley, A. N.; McDowell, R. W.; Weld, J. L.; Kleinman, P. J. Assessing site vulnerability to phosphorus loss in an agricultural watershed. Journal of Environmental Quality 2001, 30(6): 2026-2036.

(115)Alexander, R. B.; Smith, R. A.; Schwarz, G. E. Estimates of diffuse phosphorus sources in surface waters of the United States using a spatially referenced watershed model. Water Science and Technology 2004, 49: 1-10.

(116)Heathwaite, A. L.; Quinn, P. F.; Hewett, C. J. M. Modelling and managing critical source areas of diffuse pollution from agricultural land using flow connectivity simulation. Journal of Hydrology 2005, 304: 446-461.

(117)Chapra, S. C.; Dolan, D. M. Great Lakes total phosphorus revisited: 2. Mass balance modeling. Journal of Great Lakes Research 2012, 38 (4), 741-754.

(118)Alexander, R. B.; Slack, J. R.; Ludtke, A.S.; Fitzgerald, K. K.; Schertz, T. L. Data from selected U.S. Geological Survey national stream water quality monitoring networks. Water Resources Research 1998 34:2401-2405.

(119)Bosch, N. S.; Allan, J. D.; Dolan, D.M.; Han, H.; Richards, R.P. Application of the Soil and Water Assessment Tool for six watersheds of Lake Erie: 
Model parameterization and calibration. Journal of Great Lakes Research 2011, 37: 263-271.

(120)DeMarchi, C.; Xing, F.; Croley, T. E.; He, C.; Wang, Y. Application of a Distributed Large Basin Runoff Model to Lake Erie: Model Calibration and Analysis of Parameter Spatial Variation. Journal of Hydrological Engineering 2011, 16(3): 193- 202.

(121)Dolan, D. M.; Chapra, S. C. Great Lakes total phosphorus revisited: 1. Loading analysis and update (1994-2008). Journal of Great Lakes Research 2012, 38: 730-740.

(122) International Joint Commission (IJC). A Guide to the Great Lakes Water Quality Agreement, Background for 2006 Governmental Review. ISBN 1984280-53-9, 2005.

(123)Turk, A.; Turk, J.; Wittes, J.T.; Ecology, Pollution, Environment. W.B. Saunders Co. Philadelphia, 1972.

(124)Beeton, A. M. Eutrophication of the St. Lawrence Great Lakes. In: Man's Impact on Environment, T. R. Detwyler (ed.), McGraw-Hill Book Co., New York 1971; pp. 233-245.

(125)Lee, F. G. Role of phosphorus in eutrophication and diffuse source control. Water Research 1973 7(1-2): 111-128.

(126)Boyce, F. M.; Charlton, M. N.; Rathke, D.; Mortimer, C. H.; Bennett, J. Lake Erie research: recent results, remaining gaps. Journal of Great Lakes Research 1987, 13: 826-840.

(127)El-Shaarawi, A.H. Water quality changes in Lake Erie, 1968-1980. Journal of Great Lakes Research 1987, 13:674-683.

(128)Rosa, F.; Burns, N.M. Lake Erie central basin oxygen depletion changes from 1929-1980. Journal of Great Lakes Research 1987, 13: 684-696.

(129) Watson, S. B.; Ridal, J.; Boyer, G. L. Taste and odour and cyanobacterial toxins: impairment, prediction, and management in the Great Lakes. Canadian Journal of Fisheries and Aquatic Science 2008, 65: 1779-1796. 
(130)Pothoven, S. A.; Vanderploeg, H. A.; Ludsin, S. A.; Hook, T. O.; Brandt, S. B. Feeding ecology of emerald shiners and rainbow smelt in central Lake Erie. Journal of Great Lakes Research 2009, 35 (2): 190-198.

(131)Qualls, T. M.; Harris, H. J.; Harris, V. A.; Medland, V. State of Green Bay. University of Wisconsin Sea Grant Institute 2009.

(132) McCone, M.; et al. From Role of international policy and science in addressing Great Lakes management and Lake Erie eutrophication. Hydrology and Water Law-Bridging the Gap. In Hydrological information in water law and policy: current practice and future potential, Wallace, J. S., Wouters, P., Pazvakavambwa, S., Eds.; The Hague: Kluwer 2006; pp 78 107.

(133)GLWQA. Revised Great Lakes Water Quality Agreement of 1978. International Joint Commission, Windsor, Ontario. As amended by protocol November 18th, 1987.

(134)Chapra, S. C. Total Phosphorus Model for the Great Lakes. Journal of Environmental Engineering Division 1997 103: 146-161.

(135) Vollenweider, R. A.; et al. The phosphorus loading concept and Great Lakes eutrophication. In Phosphorus Management Strategies for Lakes. Loehr, R. C., Martin, C. S., Rast, W., Eds.; Ann Arbor Science, Ann Arbor, MI 1980; pp 207-234.

(136)Dolan, D. M.; McGunagle, K. P. Lake Erie total phosphorus loading analysis and update: 1996-2002. Journal of Great Lakes Research 2005, 31 (Suppl. 2): 11-22.

(137)Hartig, J. H. Detroit's role in reversing cultural eutrophication of Lake Eire. In Honoring Our Detroit River, Caring for Our Home, Ed. Cranbrook Institute for Science, Michigan 2003.

(138)Rossman, R., Ed. Results of the Lake Michigan Mass Balance study: PCBs modeling report. U.S. Environmental Protection Agency, Office of Research and Development, National Health and Environmental Effects Research Laboratory, Mid-Continent Ecology Division, Large Lakes and Rivers 
Forecasting Research Branch, Large Lakes Research Station EPA/600/R04/167; Gross Ile, Michigan 2008; 579pp.

(139)Richards, R. P.; Baker, D. B.; Crumrine, J. P.; Stearns, A. M. Unusually large loads in 2007 from the Maumee and Sandusky Rivers, tributaries to Lake Erie. Journal of Soil and Water Conservation 2010, 65: 450-462.

(140)Millie, D. F.; Fahnenstiel, G. L.; Bressie, J. D.; Pigg, R. J.; Rediske, R. R; Klarer, D. M.; Tester, P. A.; Litaker, R. W. Late-summer phytoplankton in western Lake Erie (Laurentian Great Lakes): Bloom distributions, toxicity and environmental influences. Aquatic Ecology 2009 43: 915-934.

(141) Ouellette, A. J.; Handy, Wilhelm, S.W. Toxic Microcystis is widespread in Lake Erie: PCR detection of toxin genes and molecular characterization of associated cyanobacterial communities. Microbial Ecology 2006 51(2): 154165.

(142) Great Lakes Restoration Intiative (GLRI); www.glc.org/tributary/documents/meetings/.../GLC_May2012.pdf; (accessed July 2, 2012).

(143)Environmental Protection Agency (EPA): Water Quality Exchange; www.epa.gov/storet/wqx; (accessed September 3, 2012).

(144) International Joint Commission (IJC). Letter to the Governments: Dissolved Reactive Phosphorus. Washington D.C.; September 8, 2010. 


\section{Appendix A: Supporting Information for ES\&T Manuscript ${ }^{4}$}

\section{Description of SPARROW Input Data}

\section{Point Sources}

Point sources for HydroSPARROW are calculated from the effluent of sewage treatment, commercial and industrial operations. The forecasted HydroSPARROW predictions were made using these P sources from the 2002 SPARROW model (1) and assuming that flow remained static to the calibrated 2002 model. P inputs from urban point sources are related to population, under the assumptions that (a) per capita generation of $\mathrm{P}$ from these point sources remains constant and (b) locations of point sources remain fixed (1). Predicted urban point sources were calculated using county population projections for 2010-2040. The distribution of point sources for $\mathrm{P}$ was variable across the basin, but large inputs were found around major urban centers across the MRB3 (Figure 6-1). The point source input rates are shown in Figure 6-1(a\&b) for 2010 and 2040. The rates increase across much of the MRB3 from 2010 to 2040 .

\footnotetext{
${ }^{4}$ Most of this material has been submitted to Environmental Science and Technology as supplemental information to Chapter 2.
} 
A.

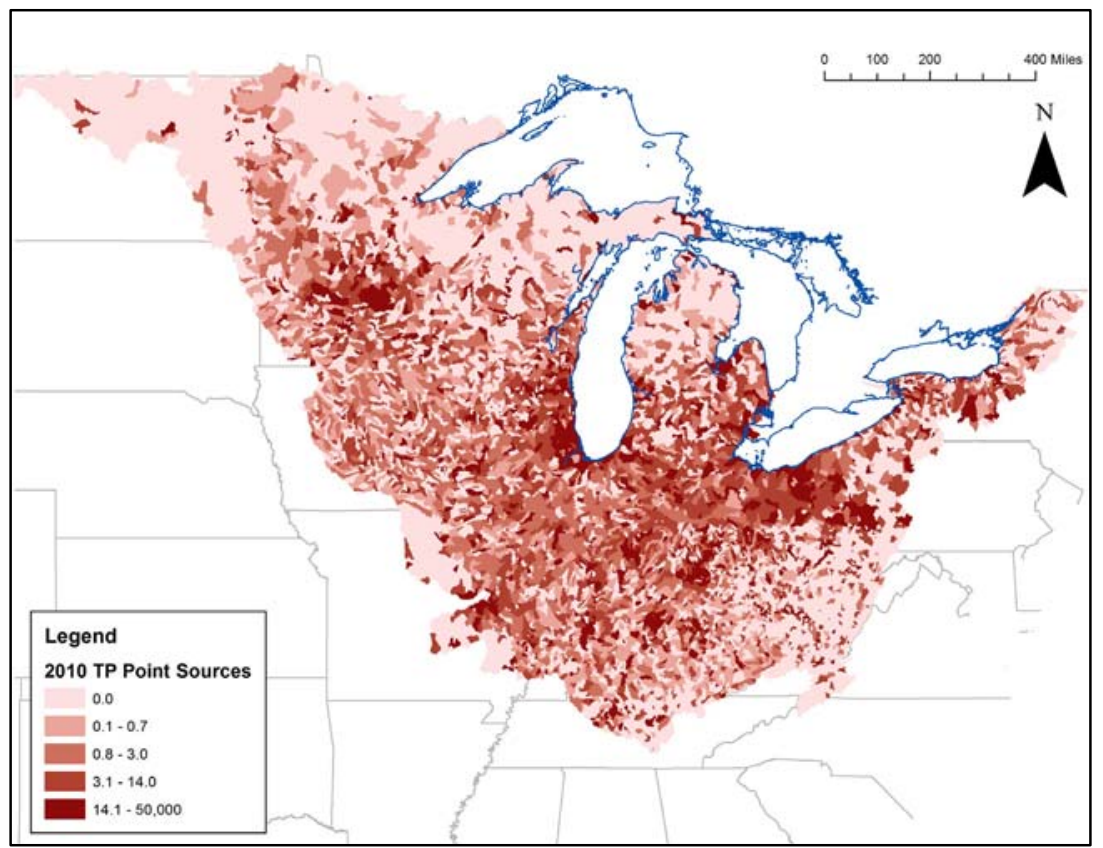

B.

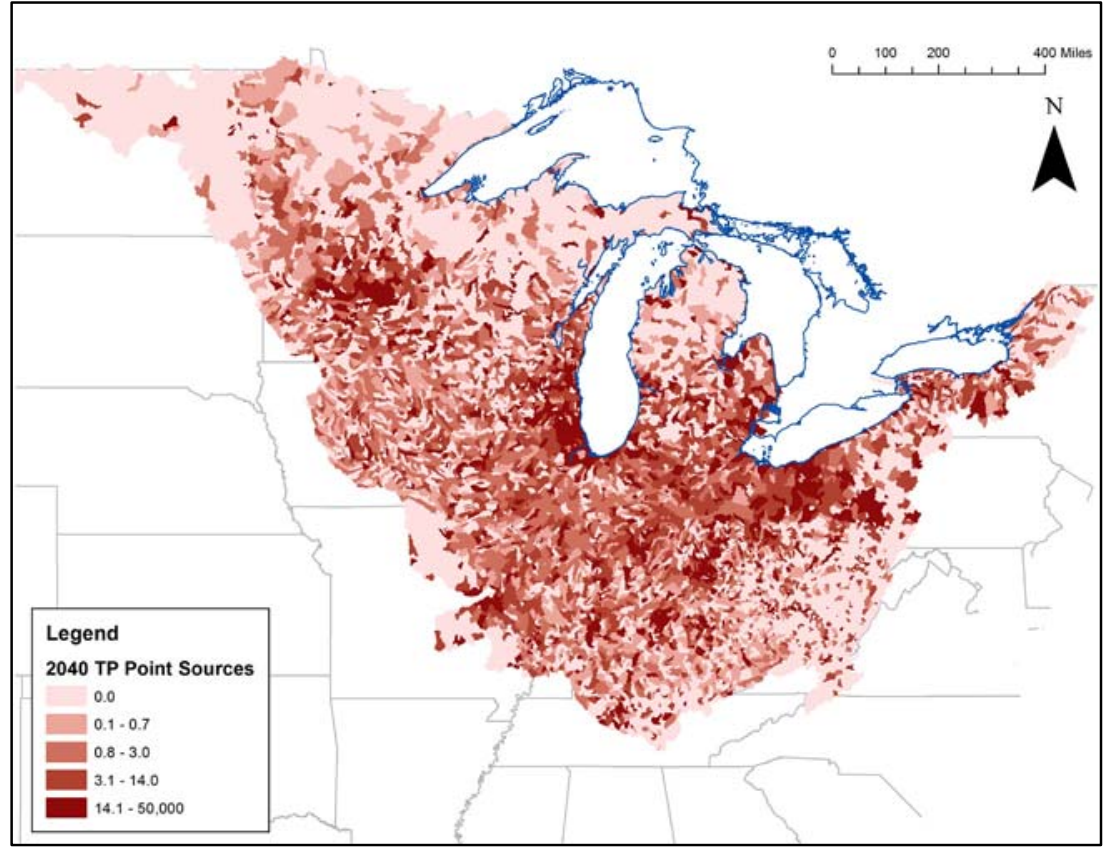

Figure 6-1: Point source input rates for TP in $\mathrm{kg} / \mathrm{km}^{2} / \mathrm{yr}$ for 2010 (A) and 2040 (B). Great Lakes outline from GLIN and US states outline from USGS. (Figure created by author using data from (2)) 
Fertilizer and Manure Inputs

Inputs from fertilizers and manure for model simulations were based on future agricultural land as a surrogate for agricultural source growth in each SPARROW catchment. Confined manure, unconfined manure, and farm fertilizer application rate catchment coefficients were developed from the 2002 SPARROW model (1) based on each catchment's fertilizer and manure use from 2002 county sales and livestock population data. This application rate coefficient was then applied to the forecasted agricultural land in each catchment for 2010 and 2040 (Figure 6-2(a,b,c,d,e,f)). The highest input rates of confined manure rates for $\mathrm{P}$ are found in southern Minnesota, Iowa, southern Wisconsin, northern Indiana, and northern Ohio, whereas the highest manure unconfined rates are located in Kentucky, Tennessee, eastern Iowa, and Missouri. Farm P fertilizer inputs are the highest in the western and central parts of the basin, with high inputs in eastern Lower Michigan.

A.

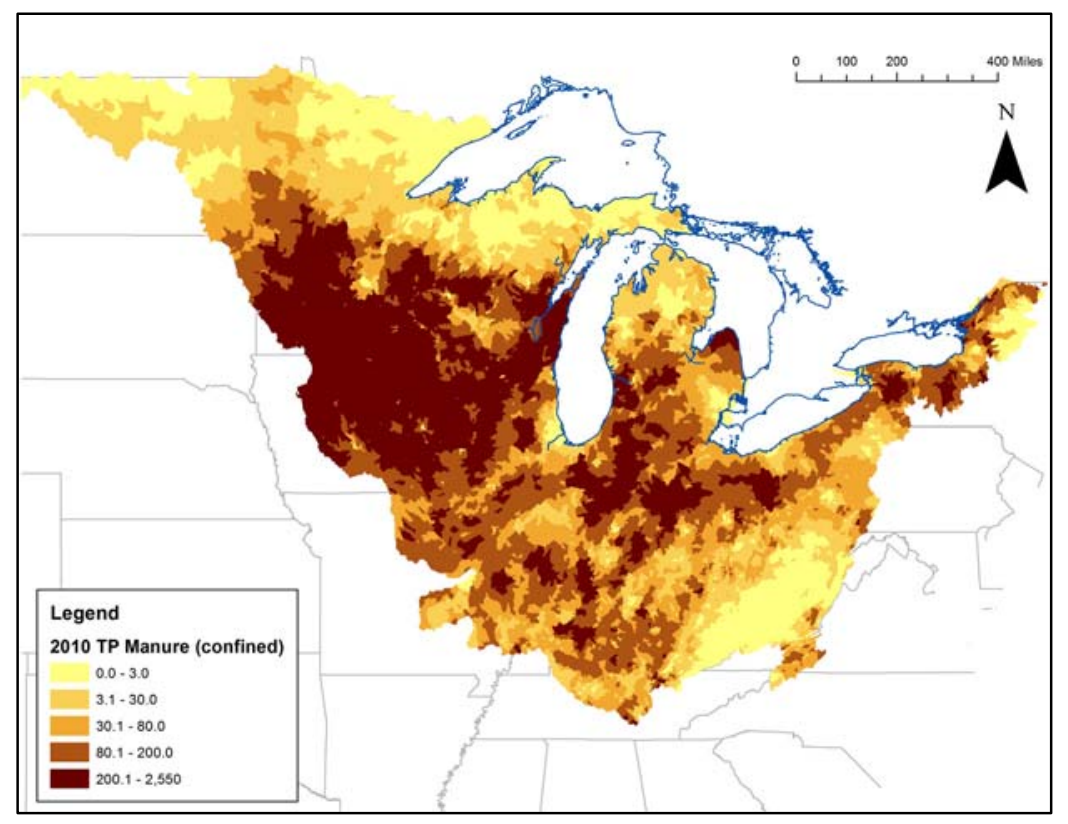


B.

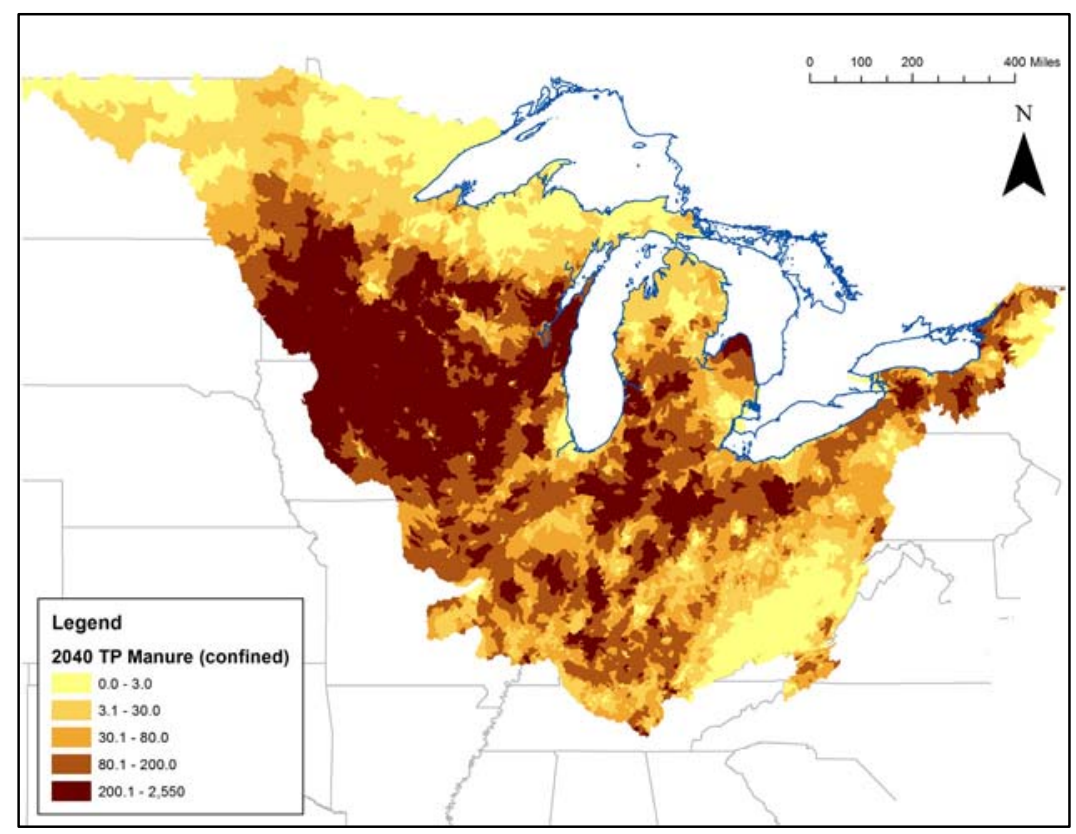

C.

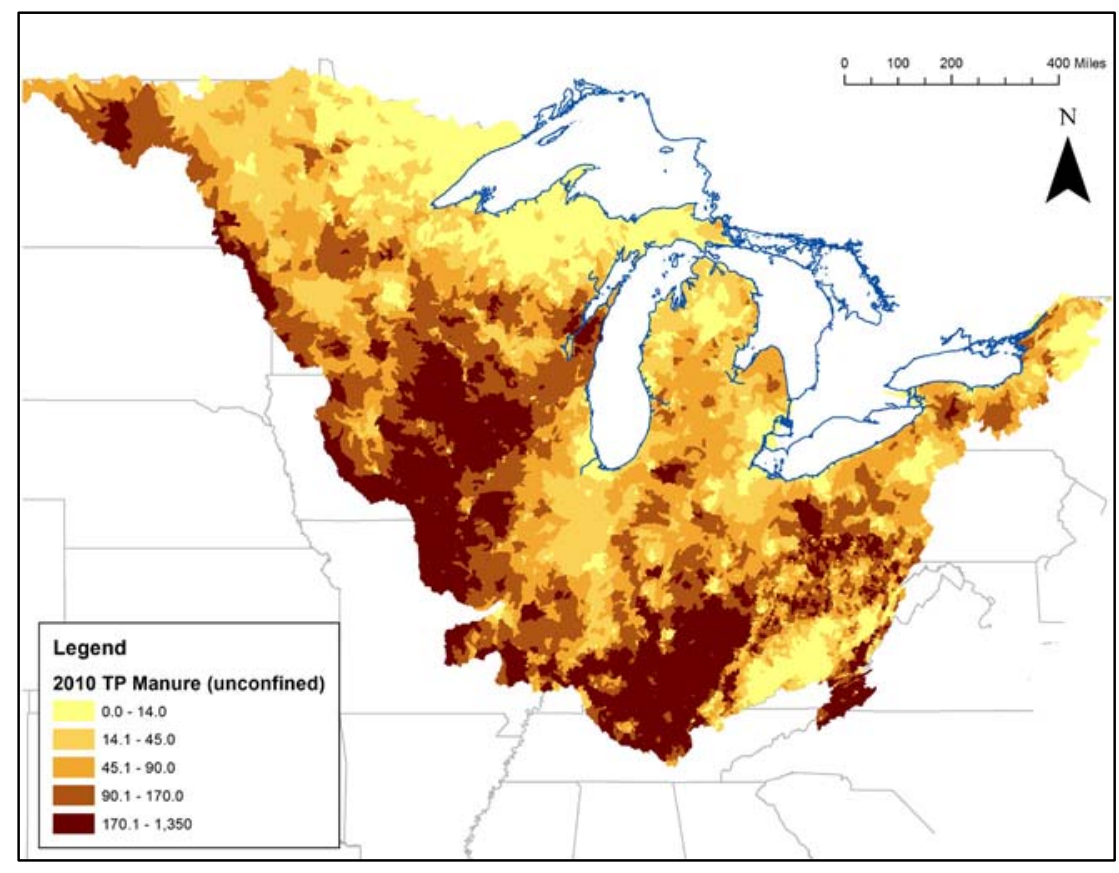


D.

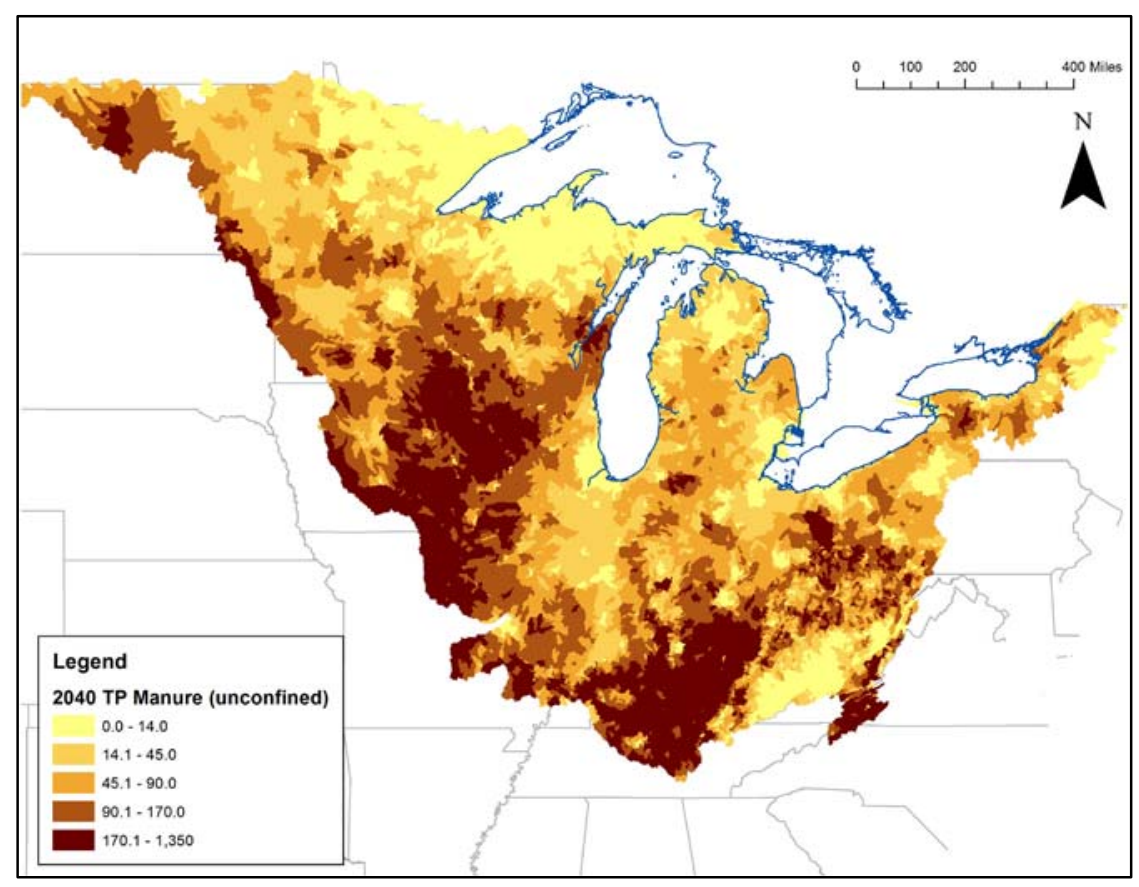

E.

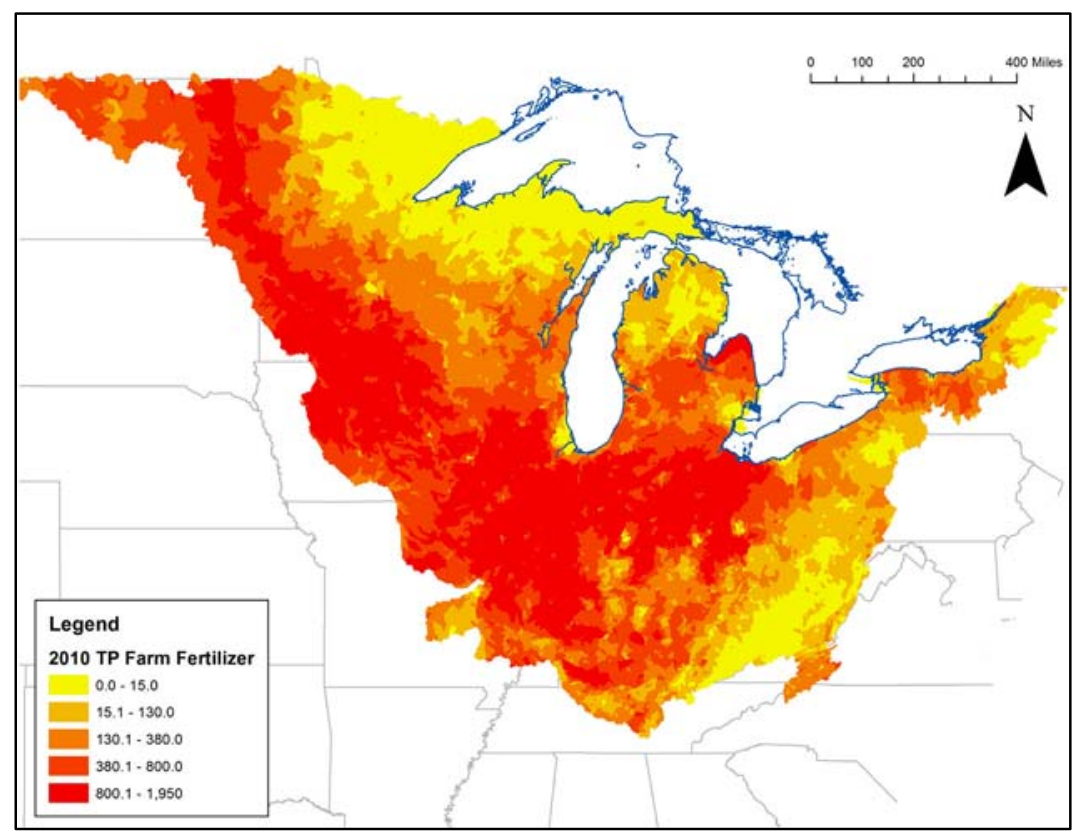


F.

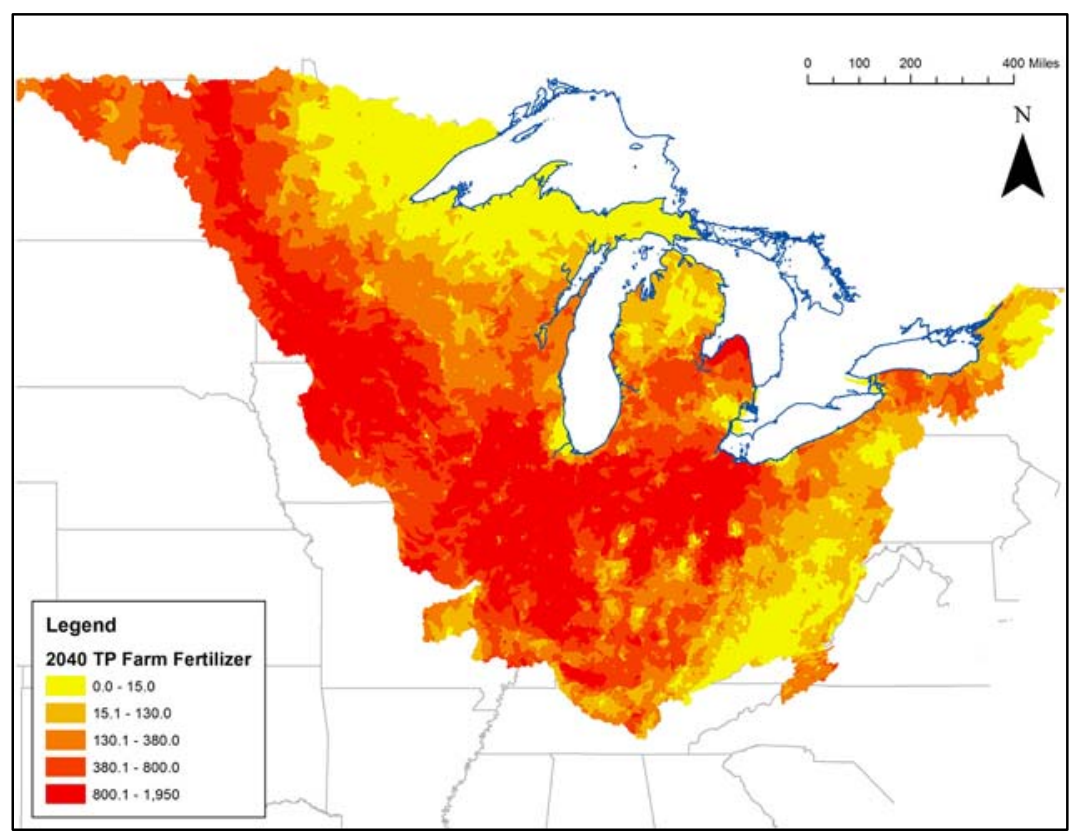

Figure 6-2: Manure Confined (A and B), Manure Unconfined (C and D), and Farm Fertilizer (E and F) input rates from TP in $\mathrm{kg} / \mathrm{km}^{2} / \mathrm{yr}$ for 2010 and 2040. (Figure created by author using data from (2))

Output from the MRB3 HydroSPARROW TP models for the MRB3, Great Lakes, each HUC8 and draining tributary basin greater than $150 \mathrm{~km}^{2}$

Incremental P Yields. To examine the predicted changes in P loadings from 2010 to 2040 at a smaller scale, incremental P yields from each SPARROW catchment were generated, where incremental load is the load generated within a specific catchment divided by the incremental catchment area, with transport losses occurring over half the stream length in each catchment). The 2010 MRB3 incremental P yields are shown in Figure 6-3(a) and the change from 2010 to 2040 in the urban expansion (UE) scenario is shown in Figure 6-3(b), and the change from 2010 to 2040 in the biofuels future $(\mathrm{BF})$ scenario is shown in Figure 6-3(c). 
A.

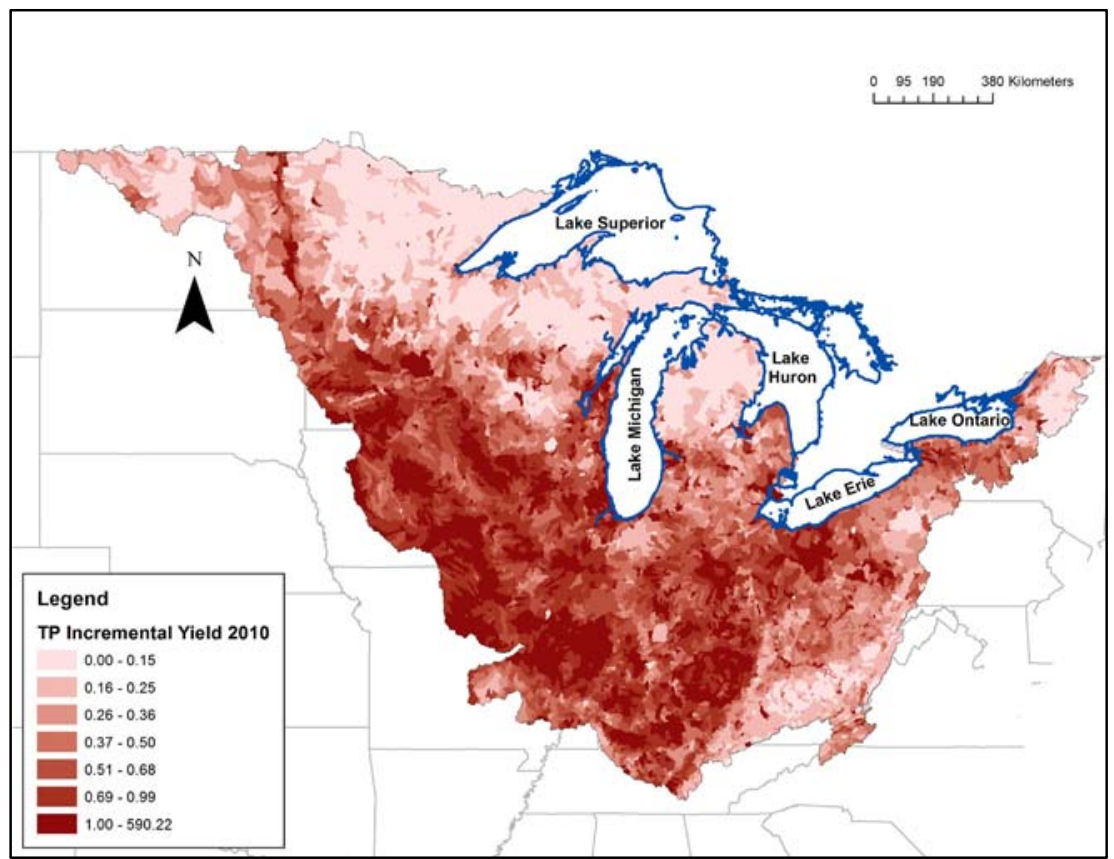

B.

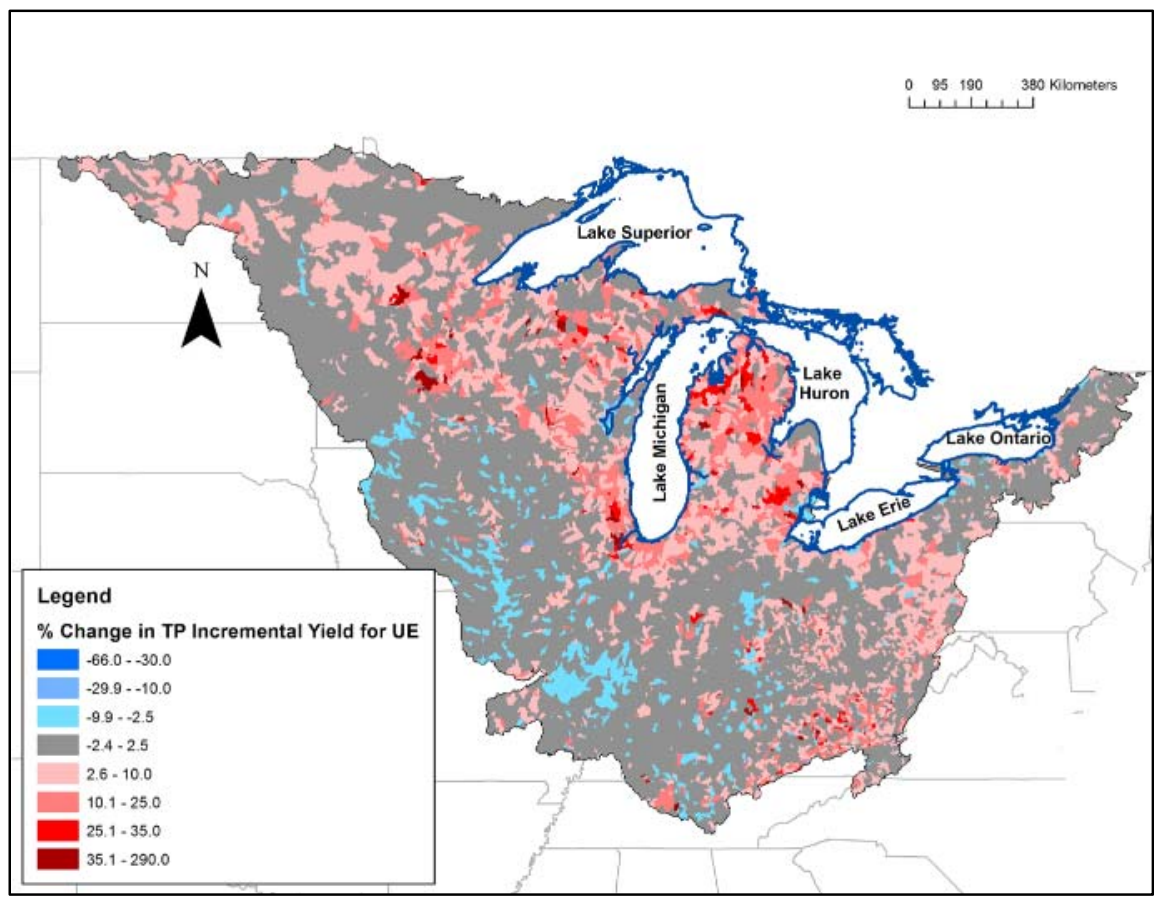


C.

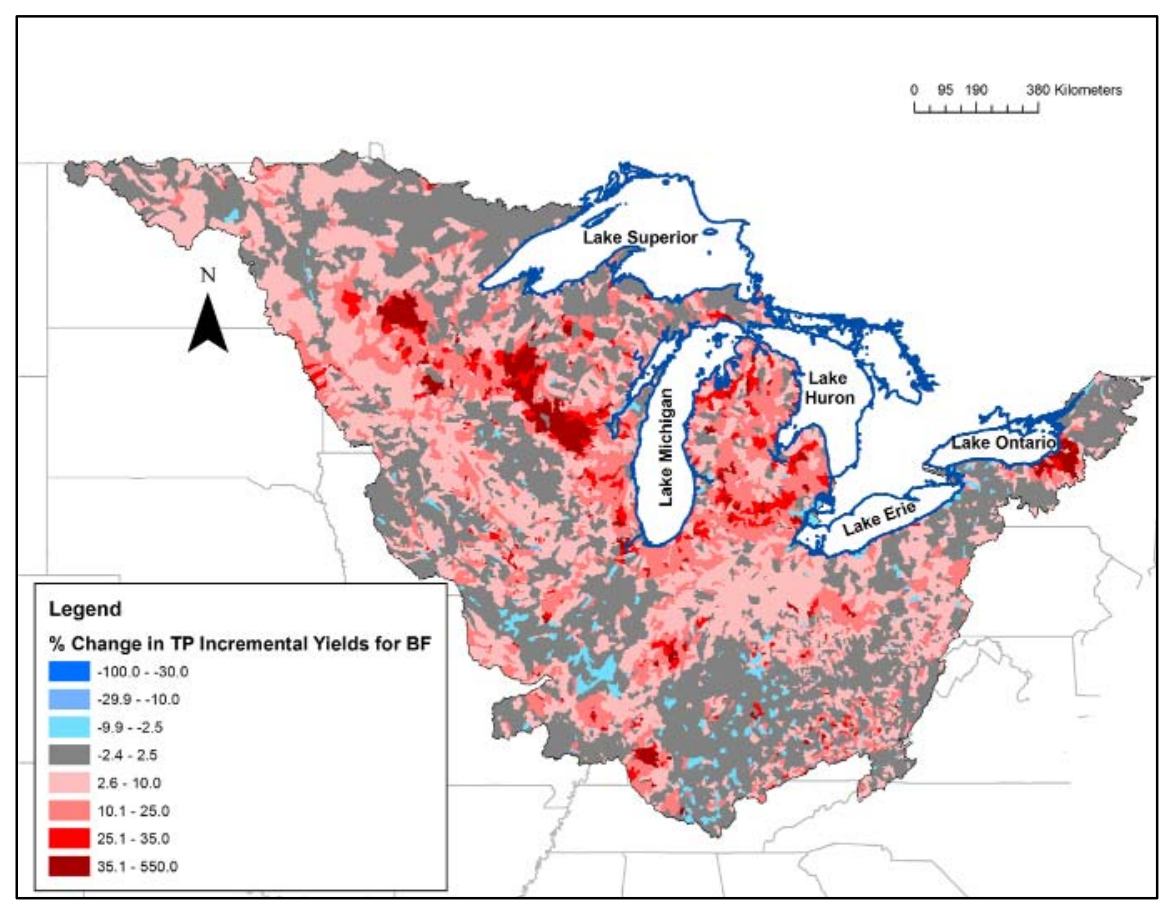

Figure 6-3: Incremental $P$ yields in $\mathrm{kg} / \mathrm{km}^{2}$ for MRB3 Basin (A) and the $\%$ changes from 2010 to 2040 for the UE scenario (B) and BF scenario (C). (Figure created by author using data from (2))

The overall mean incremental annual P yield in 2010 was $54.0 \mathrm{~kg} / \mathrm{km}^{2}$ and increased to $54.6 \mathrm{~kg} / \mathrm{km}^{2}$ in 2040 for the urban expansion scenario for the entire U.S. Great Lakes Basin. The mean incremental yield across the U.S. Great Lakes basin only increased in the "biofuels future" to $56.0 \mathrm{~kg} / \mathrm{km}^{2}$ in 2040 . High incremental P yields were found in northern Ohio, eastern Wisconsin, Iowa, Illinois, Indiana and central Michigan because of the incidence of high anthropogenic activities, either urban centers or agriculture. These high P yields only increase in the "biofuels future" because of the increase in agricultural lands and nutrients required for corn production.

\section{Lake Erie: Case Study}

The total TP loads for Lake Erie were calculated as a case study to understand potential loading rates into the future for an ecosystem that is already experiencing problems with major summer eutrophication problems driven by increases in 
phosphorus loads (3). Therefore, we present an illustrated look into the future changes to the Lake Erie HUC8s in both the UE and BF scenario from 2010 to 2040 (Figure 6-4 (a,b,c)). In the UE scenario, loads are not changing much from 2010 to 2040 except in the watersheds surrounding the Detroit River and upper reaches of the western Lake Erie Basin. It is important to note, that although many of the loads are not predicted to increase, they are also not decreasing, so this area should be a focus of future management objectives. The areas that are experiencing increases may potentially add to the major summer eutrophication problem. In the BF scenario, the western Lake Erie Basin watersheds are experiencing a greater increase in TP loading from 2010 to 2040, this may also add to future eutrophication problems.

A.

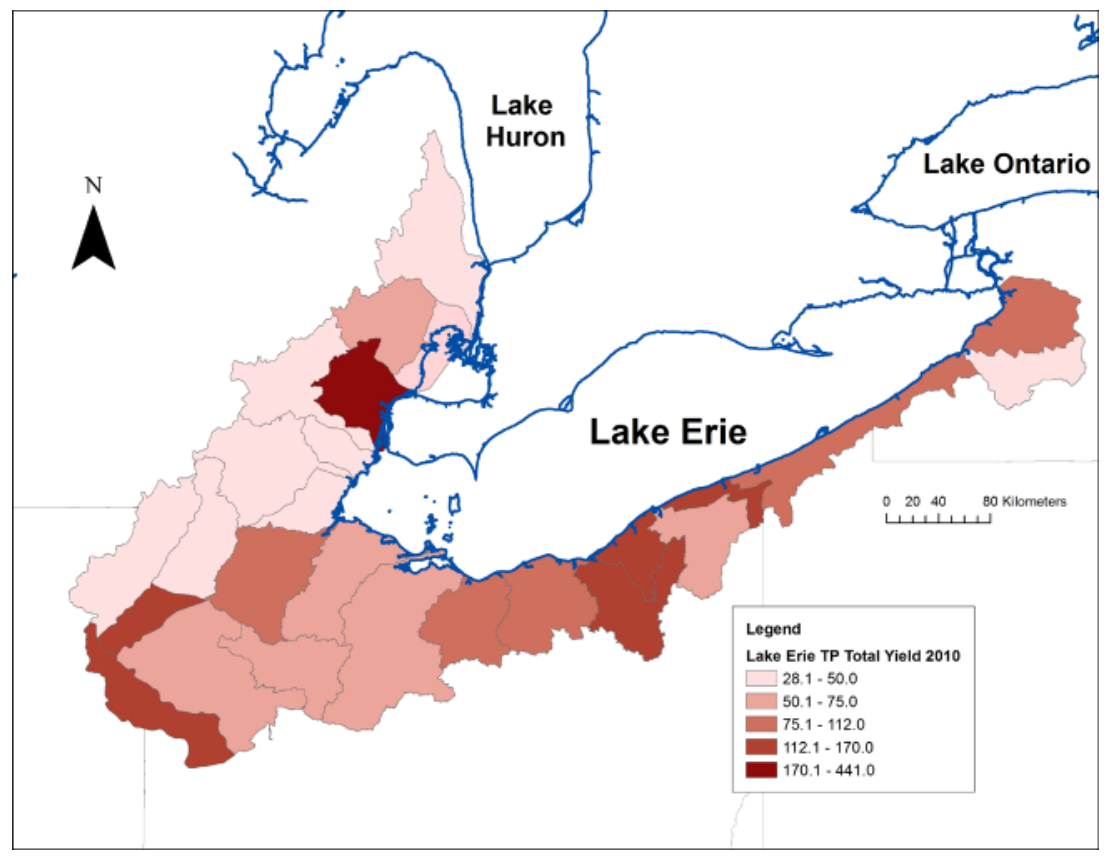


B.

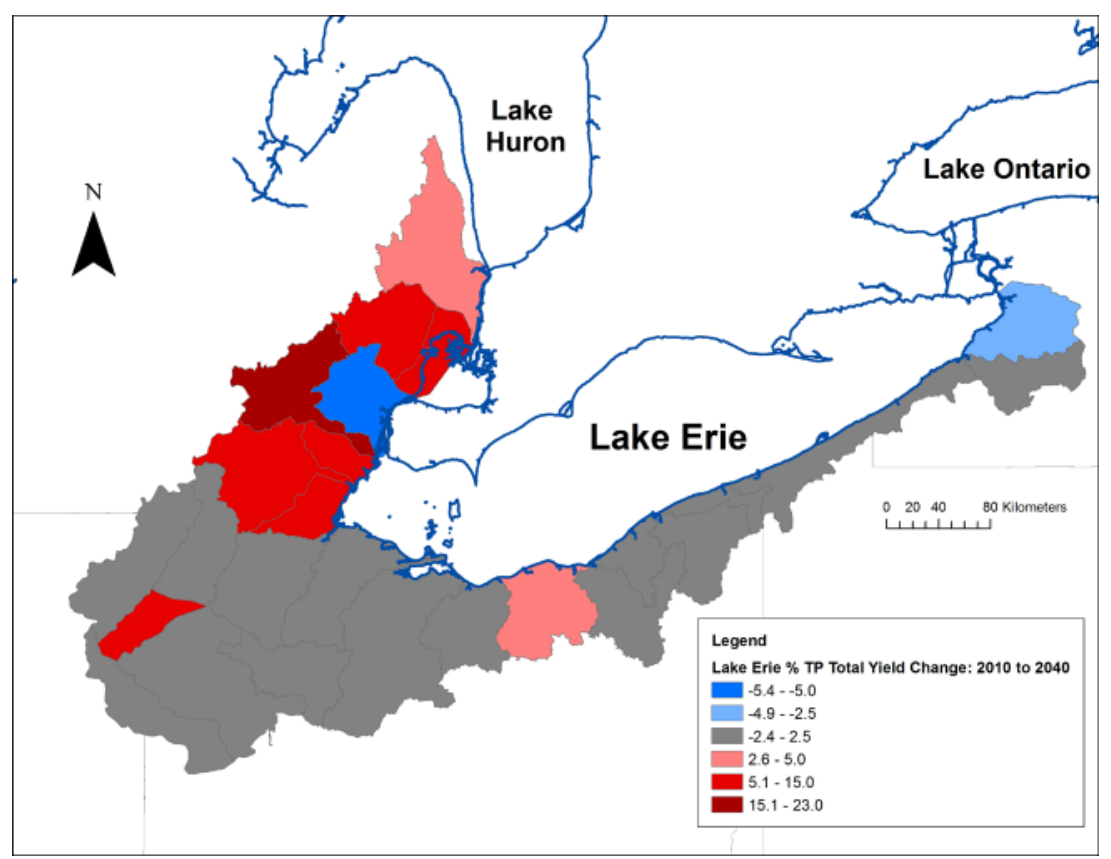

C.

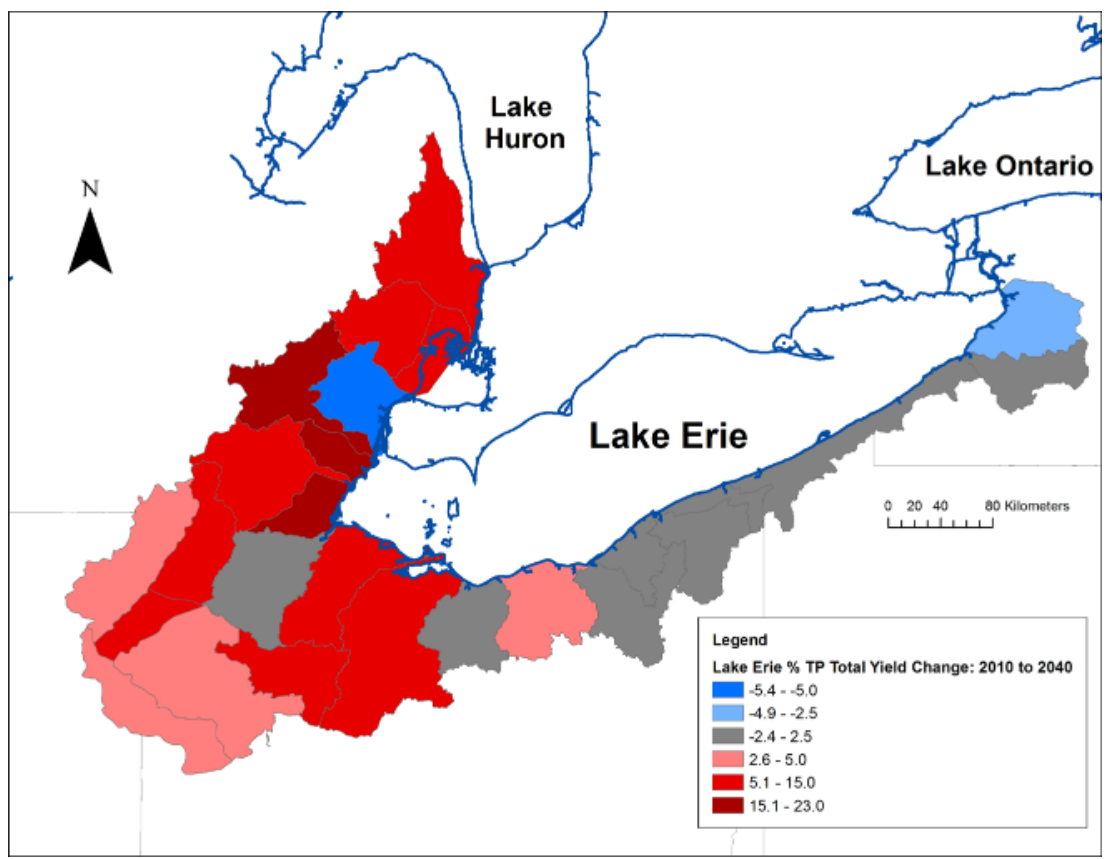

Figure 6-4: HUC8s of Lake Erie TP Yield in $\mathrm{kg} / \mathrm{km}^{2}$ for 2010 (A) and the changes to 2040 for UE (B) and BF (C). (Figure created by author using data from (2)). 


\section{P Retention and Delivery}

The ability for catchments to process $\mathrm{P}$ within the land and through delivery was analyzed through three factors contributing to P losses: amount of nutrient inputs, land-to-water delivery, and through in-stream and reservoir losses. These three factors determine a catchments ability to retain $\mathrm{P}$ or have it transported downstream to the Great Lakes. The land-to-water delivery is determined by soil permeability and the amount of tile drainage for the P model. Soil permeability was calculated for each catchment in the Great Lakes basin by using the average 2002 soil permeability compiled from STATSGO database and the 2002 SPARROW model (1). Soils with relatively poor permeability were found in the western Lake Erie basin, western Lake Ontario basin and near Green Bay, Wisconsin. Soil with relatively high permeability was found in the western Lake Superior and northern Lake Michigan basins (Figure 6-5).

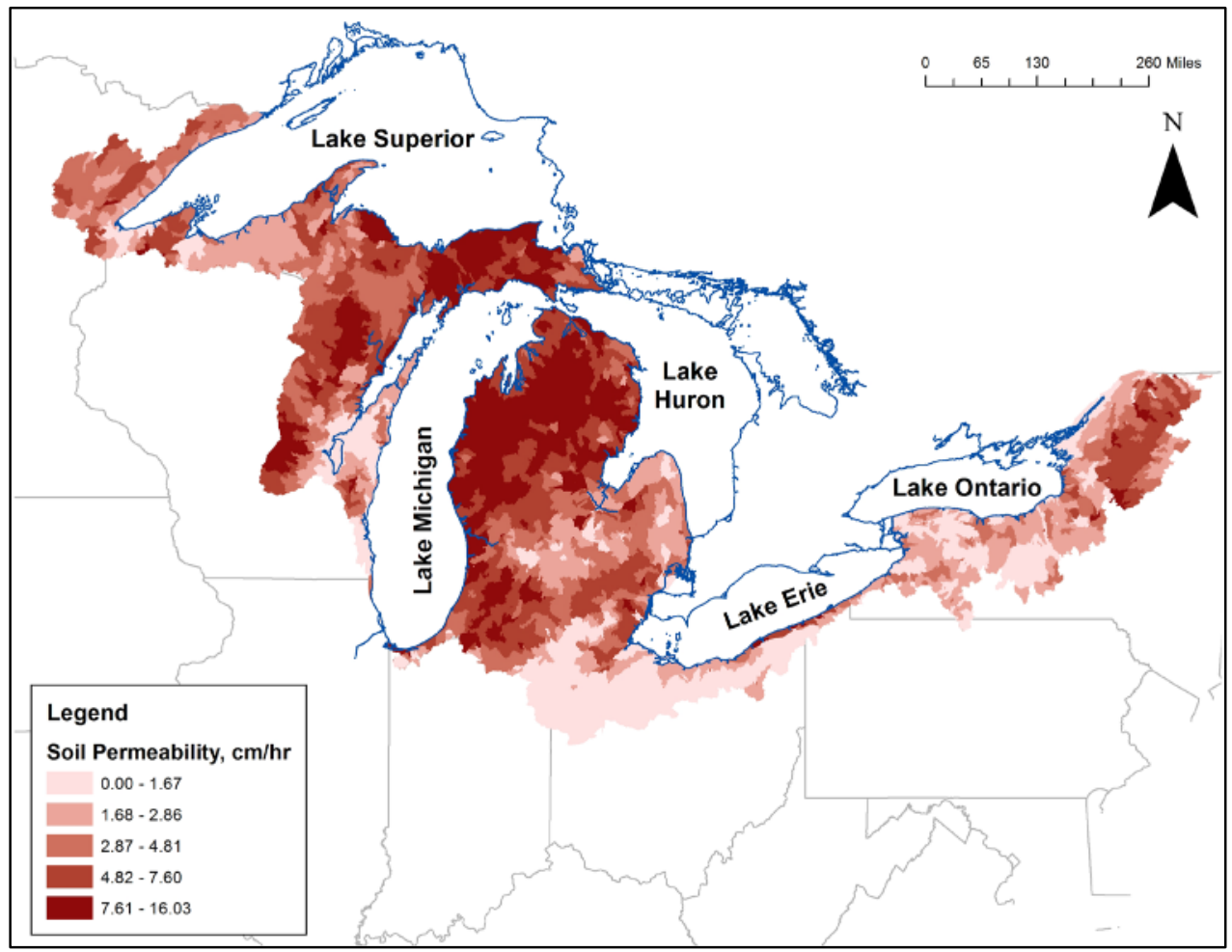

Figure 6-5: Average Soil Permeability for catchments in the Great Lakes basin. (Figure created by author using data from (2)). 
Tile drains also contribute to the catchments ability to process $\mathrm{P}$ from land-derived inputs. The average percent of tiles draining each catchment in the Great Lakes was calculated through values from the 2002 SPARROW model (1). The area with the greatest percentage of tile drainage was found in the western Lake Erie basin, southern Huron basin, and the Ontario Basin. The lowest percent of tile drains were found in the Lake Superior and northwestern Lake Michigan basins (Figure 6-6).

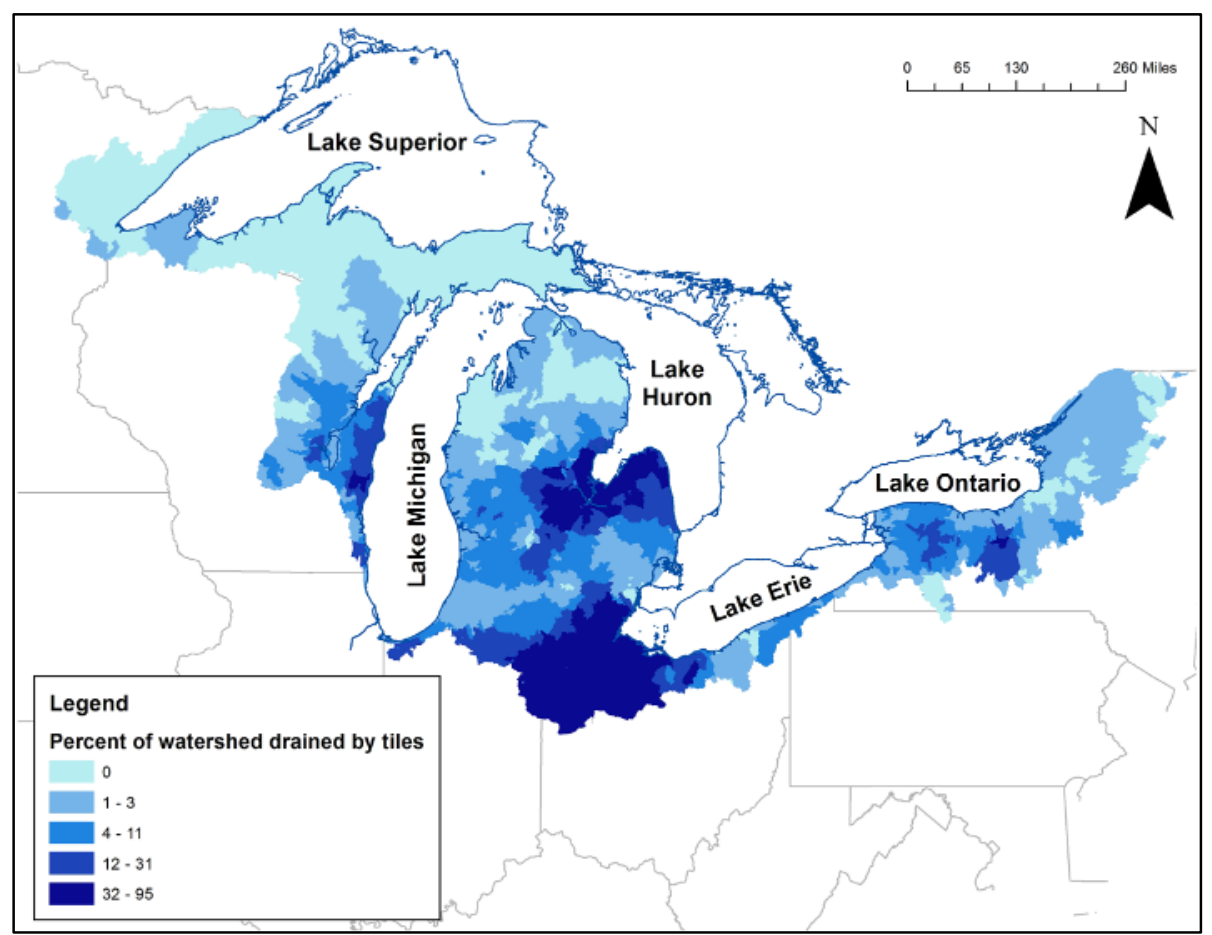

Figure 6-6: Percentage of area drained by tiles for catchments in the Great Lakes (Figure created by author using data from (2)).

Losses during downstream transport are based on in-stream processes and reservoir losses are represented through the delivery fraction computed within the SPARROW model based on first order removal rates. The delivery fraction of each catchment in the Great Lakes is presented in Figure 6-7. From Figure 6-7, areas upstream of lakes have a much lower delivery fraction than those without lakes (i.e. upstream on the Fox River as compared to upstream on the Grand River). Also areas with short travel paths, areas along Lake Erie, have larger delivery fractions 


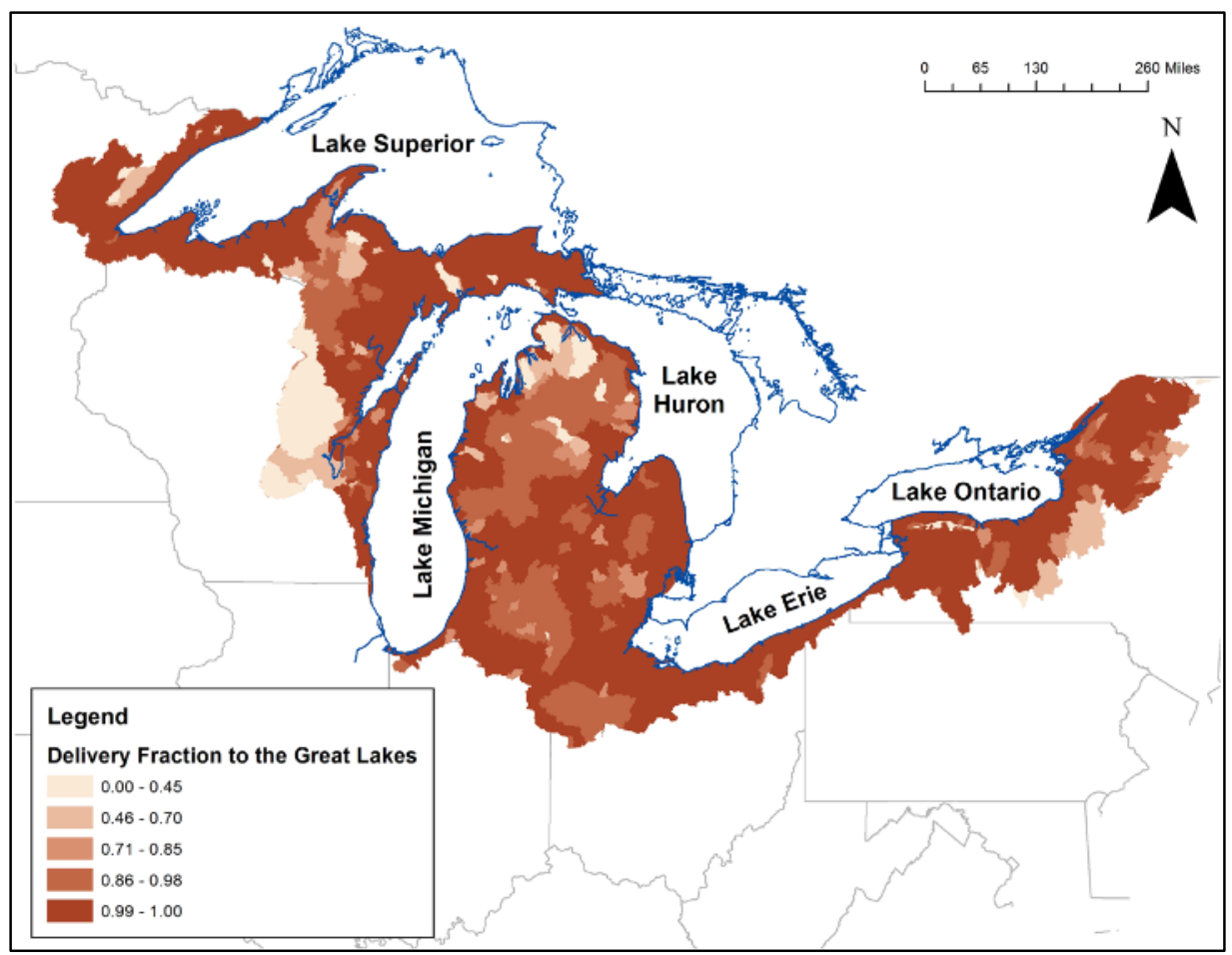

Figure 6-7: Delivery fraction of catchments in the Great Lakes (Figure created by author using data from (2)).

Finally, these areas with the combination of low soil permeability, low tile drainage and high delivery fractions will be especially vulnerable in the future if the application of nutrient inputs change. The 2010 input of fertilizer and manure is in Figure 6-8, but for future source inputs please refer to the figures earlier in this document (Figure 6-1; Figure 6-2). The areas in western Lake Erie Basin, mid-central Michigan and Wisconsin are experiencing significant amounts of $\mathrm{P}$ application from agricultural practices. 


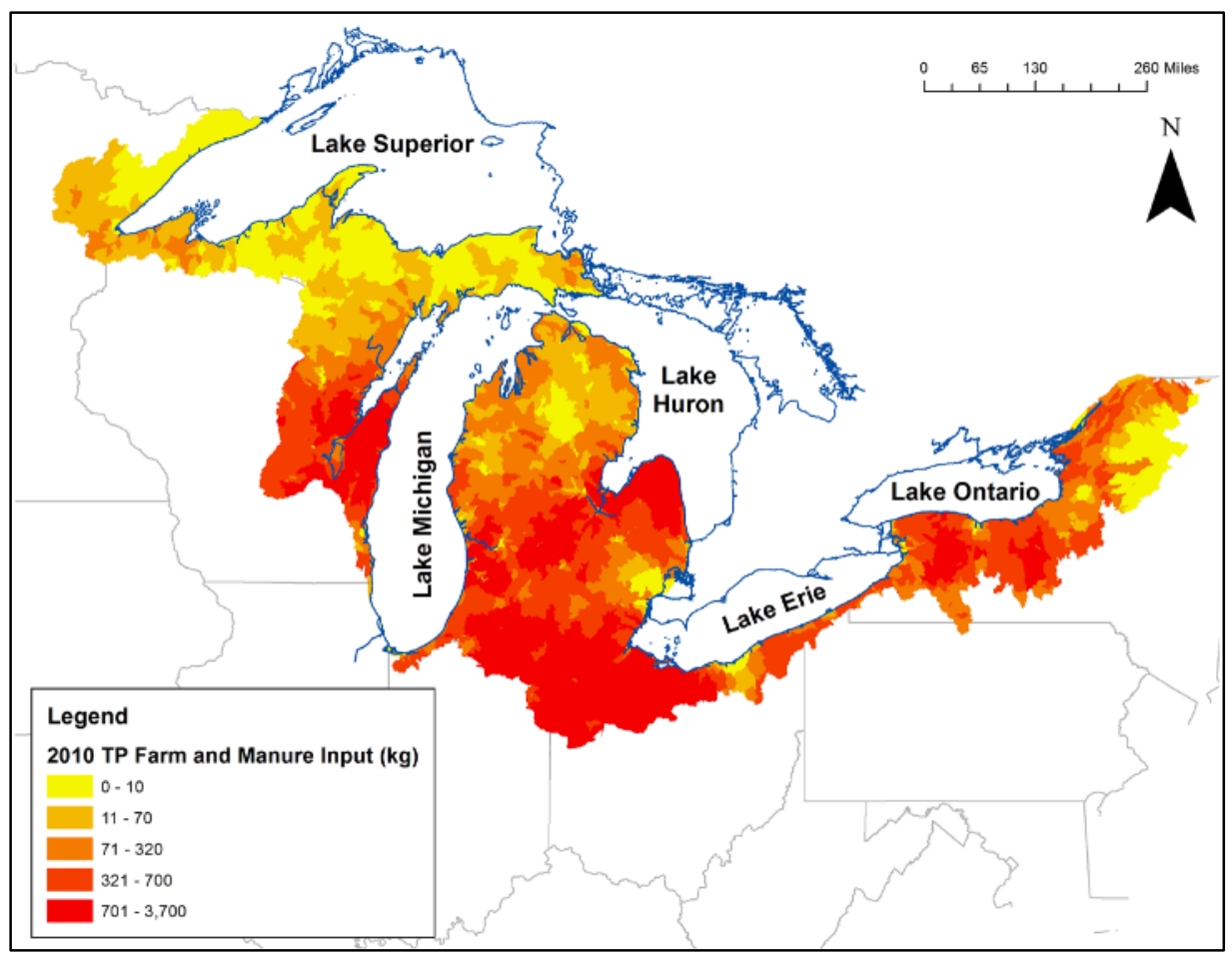

Figure 6-8: Fertilizer and Manure Inputs (kg) to catchments in the Great Lakes in 2010 model (Figure created by author using data from (2)).

Utilizing these four figures, we can locate areas of future vulnerability including the Grand River watershed in mid-central Michigan and south-western basin of Lake Ontario. This also provides a focus for determining future areas of remediation and management.

Output of HydroSPARROW TP models for each Great Lake

The total TP load and yield to each Great Lake is provided in Table 6-1; Table 6-2; Table 6-3 for 2010, 2040UE and 2040BF scenarios. The percent contribution by source of phosphorus is also included. In Table 6-4, the total TP load for 2020 and 2030 are presented. 
Table 6-1: Total Annual 2010 Load and Yields for each Great Lake and percent of $P$ source

\begin{tabular}{|c|c|c|c|c|c|c|c|c|c|c|}
\hline Great & U. S. & 2010 & 2010 & 2010 & & $\%$ Contrib & ion by $\mathrm{S}$ & & & \\
\hline \multirow{4}{*}{ Lake } & Drainage & Load & Yield & Delivery & & & & & & \\
\hline & Area & $(1,000$ & $\left(\mathrm{kg} / \mathrm{km}^{2}\right)$ & Ratio & Forested & Point & Urban & Fertilizers & Manure & Manure \\
\hline & $(1,000$ & MT) & & & Area & Sources & Areas & (farm) & (confined) & (unconfined) \\
\hline & $\mathrm{km}^{2}$ ) & & & & & & & & & \\
\hline Superior & 44 & 0.7 & 16.5 & 0.97 & 63.3 & 20.3 & 10.7 & 0.7 & 3.1 & 9.3 \\
\hline Michigan & 116 & 4.9 & 42.4 & 0.92 & 9.4 & 43.5 & 13.7 & 10.6 & 19.8 & 6.8 \\
\hline Erie & 55 & 5.0 & 89.6 & 0.99 & 3.8 & 48.6 & 13.4 & 20.6 & 12.1 & 3.2 \\
\hline Ontario & 36 & 3.4 & 96.3 & 0.96 & 7.4 & 66.2 & 4.5 & 7.2 & 12.3 & 3.6 \\
\hline
\end{tabular}

Table 6-2: Total Annual 2040 UE Load and Yields for each Great Lake and percent of $P$ source ("con" is confined and "uncon" is unconfined)

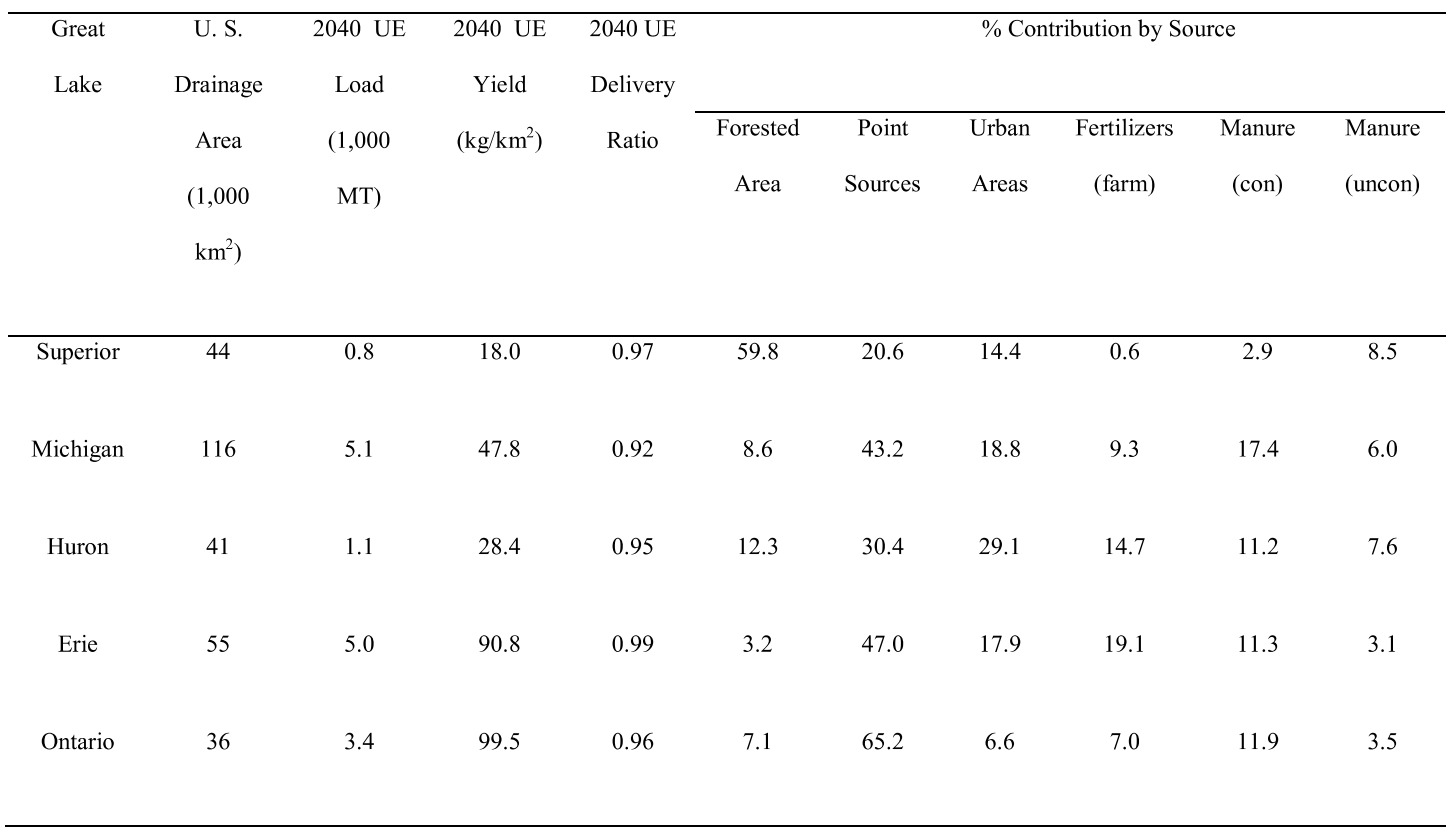


Table 6-3: Total Annual 2040 BF Load and Yields for each Great Lake and percent of $P$ source ("con" is confined and "uncon" is unconfined)

\begin{tabular}{|c|c|c|c|c|c|c|c|c|c|c|}
\hline Great & U.S. & $2040 \mathrm{BF}$ & $2040 \mathrm{BF}$ & $2040 \mathrm{BF}$ & \multicolumn{6}{|c|}{$\%$ Contribution by Source } \\
\hline \multirow{3}{*}{ Lake } & Drantage & & & Donivery & & & & & & \\
\hline & Area & $(1,000$ & $\left(\mathrm{kg} / \mathrm{km}^{2}\right)$ & Ratio & Forested & Point & Urban & Fertilizers & Manure & Manure \\
\hline & $(1,000$ & MT) & & & Area & Sources & Areas & (farm) & (con) & (uncon) \\
\hline Superior & 44 & 0.8 & 18.0 & 0.97 & 59.8 & 20.6 & 14.4 & 0.6 & 2.9 & 8.5 \\
\hline Michigan & 116 & 5.1 & 47.8 & 0.92 & 7.1 & 41.7 & 18.1 & 10.8 & 19.3 & 6.9 \\
\hline Erie & 55 & 5.0 & 90.8 & 0.99 & 2.5 & 46.0 & 17.6 & 20.4 & 12.0 & 3.3 \\
\hline Ontario & 36 & 3.4 & 99.5 & 0.96 & 6.0 & 63.7 & 6.4 & 7.8 & 13.5 & 4.1 \\
\hline
\end{tabular}

Table 6-4: Total TP loads for 2020 and 2030 for each Great Lake

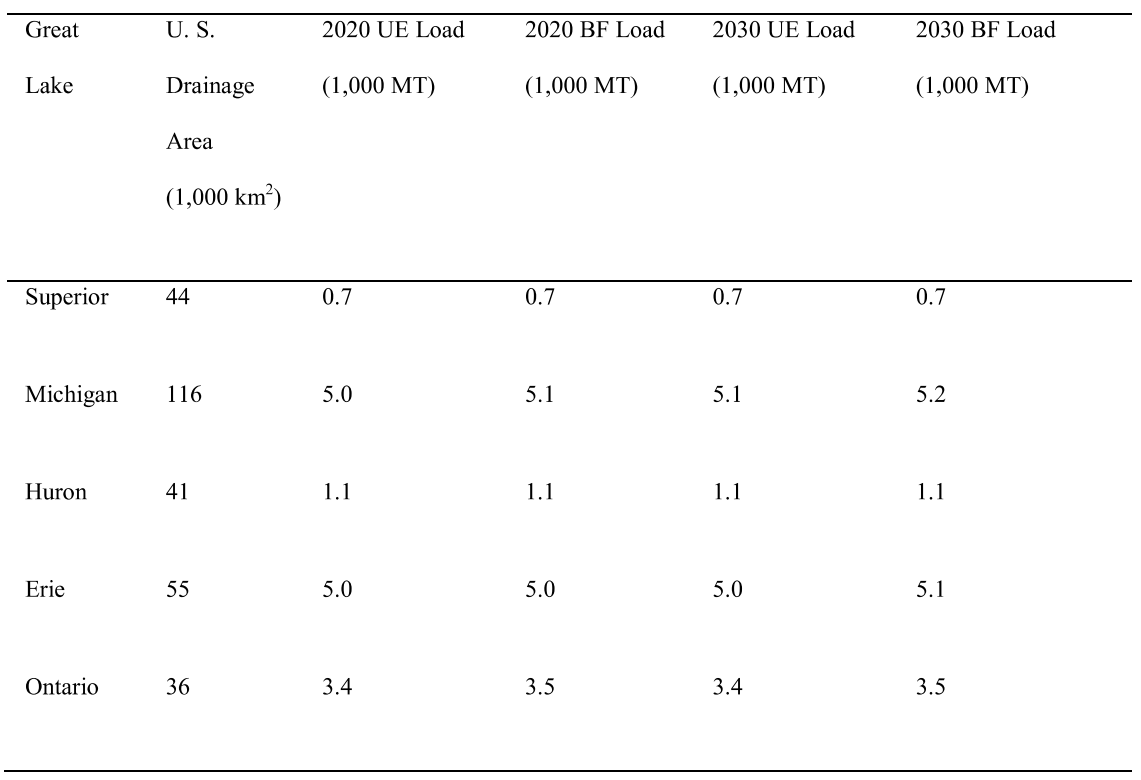


Total P load and yields at HUC8 in the MRB3 and Tributary $\left(>150 \mathrm{~km}^{2}\right)$ to each Great Lake

The total TP load and yields to each 8-digit Hydrologic Unit Code (4) is provided in Table 6-5;Table 6-6; Table 6-7; Table 6-8; Table 6-9; Table 6-10; Table 6-11 for 2010, 2020 UE, 2020 BF, 2030UE, 2030BF, 2040 UE and 2040 BF. For each Great Lake, the tributary loading in Table 6-12; Table 6-13; Table 6-14; Table 6-15; Table 6-16; Table 6-17; Table 6-18 are ranked by contribution to Great Lake (The MRB Identification Number in the tables corresponds to the outlet reach). (Table 6-5; Table 6-6; Table 6-7; Table 6-8; Table 6-9; Table 6-10; Table 6-11; Table 6-12; Table 6-13; Table 6-14; Table 6-15; Table 6-16; Table 6-17; Table 6-18 are attached via a cd)

Table 6-5: Total annual 2010 TP loads and yields with percent contribution by source for Major River Basin 3's HUC8. (kg, kilogram; km², square kilometer) (HUCs are based on 4)

Table 6-6: Total annual 2020 UE TP loads and yields with percent contribution by source for Major River Basin 3's HUC8. (kg, kilogram; km², square kilometer) (HUCs are based on 4)

Table 6-7: Total annual 2020 BF TP loads and yields with percent contribution by source for Major River Basin 3's HUC8. (kg, kilogram; km², square kilometer) (HUCs are based on 4)

Table 6-8: Total annual 2030 UE TP loads and yields with percent contribution by source for Major River Basin 3's HUC8. (kg, kilogram; km², square kilometer) (HUCs are based on 4)

Table 6-9: Total annual 2030 BF TP loads and yields with percent contribution by source for Major River Basin 3's HUC8. (kg, kilogram; km², square kilometer) (HUCs are based on 4)

Table 6-10: Total annual 2040 UE TP loads and yields with percent contribution by source for Major River Basin 3's HUC8. (kg, kilogram; km², square kilometer) (HUCs are based on 4)

Table 6-11: Total annual 2040 BF TP loads and yields with percent contribution by source for Major River Basin 3's HUC8. (kg, kilogram; km², square kilometer) (HUCs are based on 4) 
Table 6-12: Total 2010 annual phosphorus loads and yields for all tributaries into the U.S. Great Lakes greater than 150 square kilometers. The ranks are based on their relative loads and yields, with a value of 1 indicating it has the largest load or relatively largest yield. ( $\mathrm{kg}$, kilogram; $\mathbf{~ k m}^{2}$, square kilometer)

Table 6-13: Total $2020 \mathrm{UE}$ annual phosphorus loads and yields for all tributaries into the U.S. Great Lakes greater than 150 square kilometers. The ranks are based on their relative loads and yields, with a value of 1 indicating it has the largest load or relatively largest yield. (kg, kilogram; $\mathbf{~ k m}^{2}$, square kilometer)

Table 6-14: Total $2020 \mathrm{BF}$ annual phosphorus loads and yields for all tributaries into the U.S. Great Lakes greater than 150 square kilometers. The ranks are based on their relative loads and yields, with a value of 1 indicating it has the largest load or relatively largest yield. (kg, kilogram; $\mathbf{k m}^{2}$, square kilometer)

Table 6-15: Total $2030 \mathrm{UE}$ annual phosphorus loads and yields for all tributaries into the U.S. Great Lakes greater than 150 square kilometers. The ranks are based on their relative loads and yields, with a value of 1 indicating it has the largest load or relatively largest yield. (kg, kilogram; $\mathbf{k m}^{2}$, square kilometer)

Table 6-16: Total 2030 BF annual phosphorus loads and yields for all tributaries into the U.S. Great Lakes greater than 150 square kilometers. The ranks are based on their relative loads and yields, with a value of 1 indicating it has the largest load or relatively largest yield. (kg, kilogram; $\mathbf{k m}^{2}$, square kilometer)

Table 6-17: Total $2040 \mathrm{UE}$ annual phosphorus loads and yields for all tributaries into the U.S. Great Lakes greater than 150 square kilometers. The ranks are based on their relative loads and yields, with a value of 1 indicating it has the largest load or relatively largest yield. (kg, kilogram; $\mathbf{k m}^{2}$, square kilometer)

Table 6-18: Total $2040 \mathrm{BF}$ annual phosphorus loads and yields for all tributaries into the U.S. Great Lakes greater than 150 square kilometers. The ranks are based on their relative loads and yields, with a value of 1 indicating it has the largest load or relatively largest yield. (kg, kilogram; $\mathbf{k m}^{2}$, square kilometer) 
SI References:

(1) Robertson, D. M.; Saad, D. A. Landscape-derived nutrient inputs to the Laurentian Great Lakes by Source and Watershed. J. Am. Water Resour. Assoc. 2011, 47(5), 1011-1033.

(2) GLIN: Great Lakes Information Network. GIS spatial data. 2012. http://gis.glin.net/ogc/services.php?by=topic

(3) Great Lakes Commission (GLC), 2012. Priorities for Reducing Phosphorus Loadings and Abating Algal Blooms in the Great Lakes-St. Lawrence River Basin: Opportunities and Challenges for Improving Great Lakes Aquatic Ecosystems.

http://www.glc.org/announce/12/pdf/FINAL_PTaskForceReport_Sept2012.pd f. Last accessed September 13, 2012.

(4) Seaber, P.R., Kapinos, F. P., Knapp, G. L. Hydrologic Unit maps: U.S. Geol. Surv. Water-Supply Paper 2294. 1987, 63 p. Available online at:

http://water.usgs.gov/GIS/huc.html 


\section{Appendix B: Open-Ended Multipart Interview Questions For all programs:}

1. What was the original motivation for establishing the monitoring programs associated with the rivers that feed the Great Lakes?

a. What factors led to the selection of these specific sites?

b. What type of monitoring is currently performed?

c. Do you know if the type of monitoring and/ or methodology has changed over time?

2. How are the monitoring sites funded?

a. Has the source of that funding changed over time?

b. Is the funded tied to generating data for a specific purpose?

c. What is the approximate expense of maintaining these stations?

d. Has it been a challenge to secure sufficient funding?

3. What have been the largest challenges associated with managing the site, processing the data and making it accessible?

a. How much data is required for usability?

4. What are the goals or original goals of the monitoring program?

a. What is the frequency structure of the network and how is it determined?

5. Would you describe the monitoring program as being tied to the research program of specific individuals or linked to larger institutional goals?

\section{For monitoring programs that ceased operating:}

6. What were the reasons for ending the monitoring program?

\section{For monitoring programs that ceased operating and have been resumed:}

7. What led to the monitoring program being resumed?

a. Was a new source of funding involved?

b. Did the type of monitoring change?

c. Has the gap in data posed unexpected challenges?

\section{For monitoring programs that have been intermittent:}

8. What are the reasons for the monitoring program being intermittent?

a. Did the source of funding change?

b. Are there any special challenges associated with intermittent monitoring?

\section{Questions for All Sites:}

1. What is required to maintain effective monitoring?

2. What do you see as the future of this monitoring program? 